\title{
Microwave-Assisted Synthesis of Quinazolines and Quinazolinones: An Overview
}

\author{
Leyla Mohammadkhani ${ }^{\dagger}$ and Majid M. Heravi ${ }^{\star \dagger}$ \\ Department of Chemistry, School of Sciences, Alzahra University, Tehran, Iran
}

Microwave irradiation (MWI), as a unique, effective, sustainable, more economic, and greener source of energy compared to conventional heating, is applied in different organic transformations to result in the rapid formation of desired compounds due to thermal/kinetic effects. In this review, we try to underscore the applications of microwave irradiation (MWI) in the synthesis of quinazoline and quinazolinone derivatives that have been achieved and reported on in the last two decades.

Quaid-i-Azam University, Pakistan

Reviewed by:

Malose Jack Mphahlele,

University of South Africa, South Africa Albert Moyano,

University of Barcelona, Spain

*Correspondence:

Majid M. Herav mmh1331@yahoo.com; mmheravi@alzahra.ac.ir

TORCID:

Leyla Mohammadkhani orcid.org/0000-0001-8835-9058

Majid M. Heravi orcid.org/0000-0002-9259-0591

Keywords: quinazoline, quinazolinone, microwave irradiation, MWI, multicomponent reactions (MCRs), niementowski quinazoline synthesis

\section{INTRODUCTION}

In the past two decades, microwave irradiation (MWI) has become an effective, powerful, and green source of energy in the art of organic synthesis. As early as the 1950's, it was found that microwaves could heat water. The popular use of domestic microwave ovens happened during the1970 and 1980's as a result of actual and operative Japanese technology transfers and worldwide marketing. The use of MWI in chemical modification can, however, be traced back to the 1950's (Lidström et al., 2001; Bogdal et al., 2003; Kappe, 2004; de la Hoz et al., 2005). In 1986, Gedye et al. investigated four different types of organic reactions in a domestic microwave oven. They observed an increased rate of the formation of products compared to the rate of synthesis of the products under conventional reaction conditions (Gedye et al., 1986). Since then, the conduction of chemical reactions under MWI in the laboratory has started to gain wide recognition. However, MWI's role in organic synthesis has brought intense differences of opinion which resulted in diverse theories.

MW chemistry is the science of applying MWI to chemical reactions. When the rate of heat conduction is high between system areas, hot spots lacklong-term existence as the components reach thermal equilibrium rapidly. In a system where the heat transfer is slow, it would be possible to have the presence of a steady-state hot spot that may increase the rate of the chemical reaction within that hot spot. Based on this theory, specific molecules or certain functional groups within molecules should be excited when exposed to MWI. As a result, the time of distribution of thermal energy under MWI is much shorter than the period that thermal energy is distributed under ambient or conventional heating and laboratory conditions. The MW region of the electromagnetic spectrum lies between infra-red radiation and radio frequencies, relating to frequencies of $30 \mathrm{GHz}$ to $300 \mathrm{MHz}$ respectively. In order not to obstruct these uses, domestic MW ovens and industrial MW heaters are required to operate at either $2.45 \mathrm{GHz}$ or $900 \mathrm{MHz}$, unless the apparatus is protected in such a way that no loss of radiation happens. Commonly, domestic MW ovens are designed and made to operate at $2.45 \mathrm{GHz}$ (Mingos and Baghurst, 1991). Although synthetic chemists began to use domestic MW ovens in the mid-1980's, over the years, some problems have risen. The essential problem that one can have while using a commercial MW oven is caused by 
the nonhomogeneous distribution of energy. The other drawbacks involve the lack of temperature and pressure control, which does not allow for the use of flammable solvents and reproducibility (Bacher, 2016; Nain et al., 2019).

Consequently, special MW systems were designed for use in the laboratory, which demonstrates improved prospects for re-procreativity, fast synthesis, easy reaction optimization, and the potential exploration of new synthetic pathways. Dedicated microwave reactors allow fast heating of reaction mixtures to high pressures and temperatures-far above the boiling point of the used solvent. MWI can have certain advantages over conventional heating. Under MWI, reactions proceed to completion much faster, are performed under milder and greener reaction conditions, give higher chemical yields, require lower energy usage, and are selective or sometimes show different selectivity. Above all, its uses have become inevitable in cases when conventional approaches need constraining reaction conditions, when prolonged reaction times are required, or when certain selectivity is required. Thus, MW has been widely applied in the fields of organic and inorganic chemistry (Abramovitch, 1991; Loupy, 1993, 1994; Majetich and Hicks, 1994, 1995; Caddick, 1995; Strauss and Trainor, 1995).

Quinazoline and quinazolinone analogs are two important heterocyclic systems with diverse biological activities; thus, they have attracted much attention from synthetic organic chemists as desirable targets (Michael, 2004).

Quinazoline and quinazolinone derivatives constitute a noteworthy class of naturally occurring fused heterocycles (Wang et al., 1996; Sheu et al., 2000; Wu et al., 2001; Liu et al., 2018b), which were initially isolated from different natural sources such as plant families, microorganisms, and animals. Their structures were elucidated, showing diverse biological properties (Michael, 2003; Connolly et al., 2005; Mhaske and Argade, 2006; Khan et al., 2014, 2015; Kshirsagar, 2015). Several quinazoline and quinazolinone derivatives have passed clinical trials and are recognized as potential candidates for prescribed drugs (Inoue et al., 1976). Quinazoline and quinazolinone analogs possess a wide range of useful biological properties, including being antitumor (El-Azab et al., 2010; Sharma et al., 2013), anticancer (Wakeling et al., 2002; Vasdev et al., 2005; Chandregowda et al., 2009; Kabri et al., 2009; Pathania et al., 2014), anti-microbial (Gupta et al., 2008; Rohini et al., 2010; Rajasekaran et al., 2013), anti-bacterial (Mohammadi et al., 2014), anti-virus (Li et al., 1998), anti-inflammation, anti-tuberculosis (Nandy et al., 2006), and anti-obesity (Sasmal et al., 2012).

The first synthesis of the quinazoline nucleus was achieved and reported by Griess in 1869 through the reaction of anthranilic acid with cyanogen as a source of nitrogen (Griess, 1869). Von Niementowski optimized the reaction using amides instead of cyanogen (Von Niementowski, 1895). Owing to the diverse range of pharmacological activities, various synthetic routes for the synthesis of quinazolinone derivatives have been developed by employing 2-aminobenzoic acid, anthranilamide, anthranilonitrile, isatoic anhydride, 2carbomethoxyphenyl isocyanate, $\mathrm{N}$-arylnitrilium salts, and benzoxazines as starting materials (Michael, 2003; Connolly et al., 2005; Mhaske and Argade, 2006; Khan et al., 2014, 2015; Kshirsagar, 2015).

In 2007, a review on the synthesis of bioactive quinazolines and quinazolinones was published, focusing only on the synthesis of heterocyclic systems of specific biological activities or commercially important compounds (Besson and Chosson, 2007). In 2017, a review entitled "Green approaches toward [the] synthesis of substituted quinazolines" appeared in the chemical literature (Devi et al., 2017). Many researchers have used MWI as a green and sustainable source of energy in different organic transformations (Chatel and Varma, 2019). MWI has been frequently used in the synthesis of $N$-heterocyclic systems (Majumder et al., 2013). Applications of MWI as greener and more ecological trends emerge has also been extended to the synthesis of quinazoline and quinazolinone derivatives, particularly to those required for biological screening and in drug discovery studies, where rapid, high-yielding preparation of samples in highly pure forms are needed.

In the continuation of our interest in the chemistry of quinazolines and quinazilidinones (Heravi et al., 2008, 2009, 2010, 2011; Saeedi et al., 2011; Shiri et al., 2018) and our continuous attempts to conduct some of our reactions under MWI (Heravi et al., 1999, 2016; Valizadeh et al., 2010a,b, 2016; Fazeli et al., 2013; Heravi and Moghimi, 2013), in this review, we try to underscore all the successful strategies selected and progress made in the synthesis of quinazoline and quinazolinone derivatives, being conducted under MWI.

\section{SYNTHESIS OF QUINAZOLINE DERIVATIVES}

\section{Intramolecular Heterocyclization}

2-Benzimidazoylbenzamides have been employed as substrates for intramolecular heterocyclization to create quinazolines under MW conditions. For example, Pessoa-Mahana et al. reported the synthesis of 6-arylbenzimidazo[1,2-c]quinazolines 2 by intramolecular heterocyclization of 2-benzimidazoylbenzamides 1 under MWI in a solventless system (Pessoa-Mahana et al., 2004). Compounds 1 were efficiently and cleanly transformed into the corresponding tetracyclic compounds $\mathbf{2}$ in moderate yields under MWI in the presence of $\mathrm{SiO}_{2}-\mathrm{MnO}_{2}$ as a solid inorganic matrix in only $30-45 \mathrm{~min}$ (Scheme 1). The same reaction under conventional thermal conditions (anhydrous $m$ xylene, reflux) increased the reaction times. This novel and interesting strategy has shown the application of MWI in the heterocyclization for producing complex polycyclic systems.

\section{Intramolecular Friedel-Crafts-Type Cyclization}

Intramolecular Friedel-Crafts-type cyclization strategy has been applied in the synthesis of quinazolines. An original and efficient method based on the MW-assisted intramolecular Friedel-Crafts-type cyclization of guanidines 3 to access 4phenylquinazolines 4 in [OMIm] X ionic liquid in $10 \mathrm{~min}$ was reported by Debray et al. (2010). The reaction mechanism includes three steps as represented in Scheme 2. In the first 

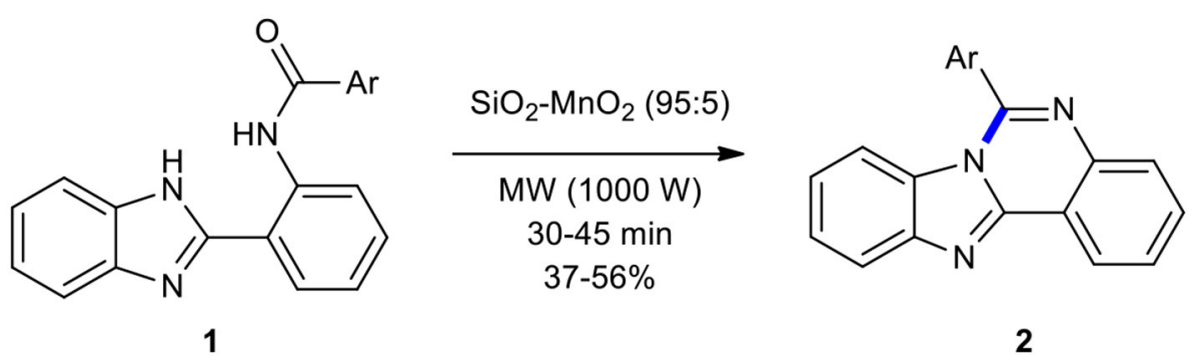

2

SCHEME 1 | MW-assisted synthesis of $\mathbf{2}$ through intramolecular heterocyclization of $\mathbf{1}$.<smiles>[R]N([R])/C(=N\C(=O)c1ccccc1)Nc1ccc2ncccc2c1</smiles>

$[\mathrm{OMIm}] \mathrm{Cl}$<smiles></smiles>

$\mathrm{MW}, 110^{\circ} \mathrm{C}, 10 \mathrm{~min}$<smiles>[R]N([R])c1cc2ncccc2c(-c2ccccc2)n1</smiles><smiles></smiles><smiles>CCON1C=CN(C)C1</smiles>

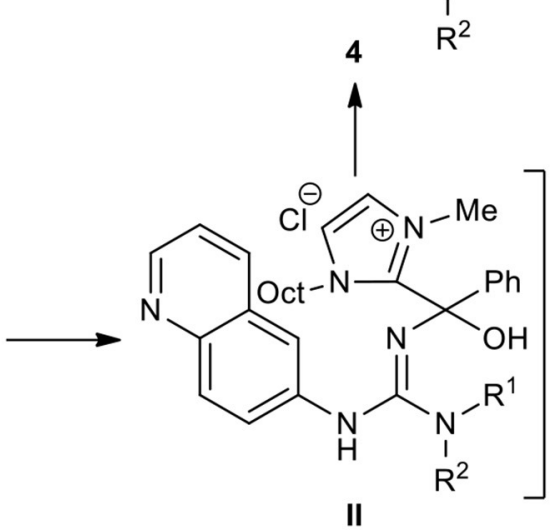

SCHEME 2 | Mechanism of formation of $\mathbf{4}$ using ionic liquid as solvent under MWI.

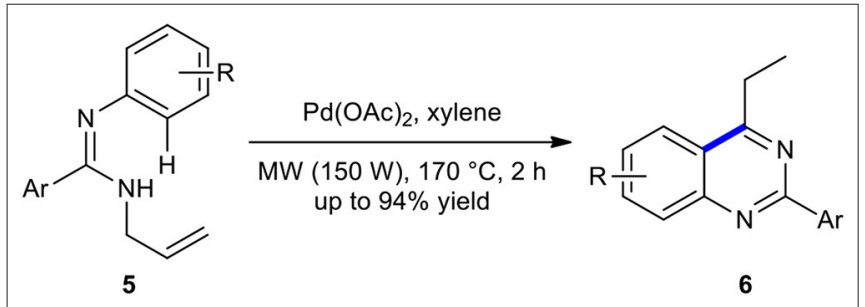

SCHEME 3 | Pd(OAC) ${ }_{2}$-catalyzed annulation of $\mathbf{5}$ to create $\mathbf{6}$ under MWI.

step, the basic arylguanidine abstracted the [OMIm] H-2 with the generation of the carbene and the acylguanidinium species (I). The second step involved the addition of the corresponding $\mathrm{N}$-heterocyclic carbene to the hydroxyimino tautomer (I), providing the highly electrophilic intermediate (II). In the next step, the intermediate (II) underwent Friedel-Crafts-type cyclization along with the elimination of imidazolium and water, completing the synthesis of the expected products 4 . The use of traditional heating $\left(110^{\circ} \mathrm{C}\right)$ instead of MWI required a longer time to achieve completion of this reaction ( $1 \mathrm{~h}$ instead of $10 \mathrm{~min}$ ).

\section{Palladium-Catalyzed Annulation of $\mathbf{N}$-Allylamidines}

$N$-Allylamidines have been used as substrates for palladiumcatalyzed annulation to produce the quinazolines. For example, $\mathrm{Pd}(\mathrm{OAc})_{2}$-catalyzed annulation strategy for the construction of multi-substituted quinazolines $\mathbf{6}$ from $N$-allylamidines $\mathbf{5}$ under MWI has been developed and reported (Xu et al., 2015). Quinazolines 6 were obtained as the major products through the isomerization of $\mathrm{Pd}$-alkene complex intermediate of $\mathrm{N}$-allylamidines 5 and $\mathrm{C}-\mathrm{H}$ activation in the presence of a catalytic amount of $\mathrm{Pd}(\mathrm{OAc})_{2}$ under $\mathrm{MWI}$ at $170^{\circ} \mathrm{C}$ in a sealed tube (Scheme 3). It was found that heating the reaction mixture conventionally improved the yield of the reaction. 


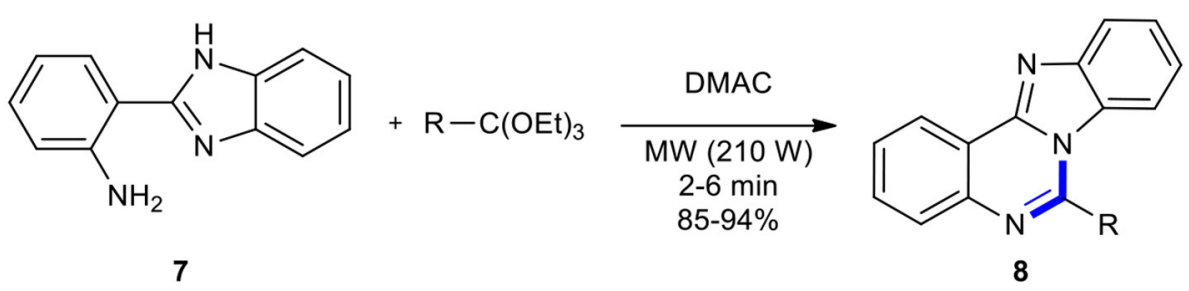

SCHEME 4 | MW-assisted synthesis of 8 from $\mathbf{7}$ and ortho-esters.<smiles>[R]C(CC)OCC</smiles>

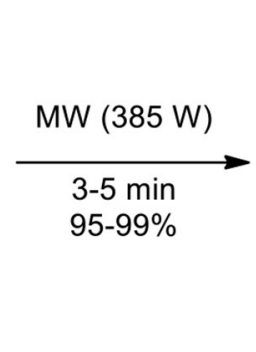<smiles>[R]c1nc2ccccc2c2nc3ccccc3c(=O)n12</smiles>

SCHEME $\mathbf{5}$ | MW-assisted synthesis of $\mathbf{1 0}$ form $\mathbf{9}$ and ortho-esters.<smiles></smiles>

SCHEME 6 | MW-promoted aza-Wittig synthesis of quinazolines 12.<smiles>[R]C=O</smiles>

14

$72-80 \%$<smiles>[R]c1nc(-c2ccccc2)nc2ccc(C)cc12</smiles><smiles>[R]CCCCCN([R])c1nc([R1])c2cc(C)ccc2n1</smiles>

15

$72-84 \%$

SCHEME 7 | MW-assisted synthesis of 12, 14, and $\mathbf{1 5}$.

Cyclocondensation Using Various Methods MWI has been used to promote cyclocondensation of various nitrogen-containing precursors with ortho-esters, benzaldehydes, alcohols, amines, ammonium formate, nitriles, HMTA, and thiourea, as described below. 
<smiles>[R]c1cc(C(F)(F)F)c(C#N)c(N)c1C#N</smiles>

16<smiles>[R]c1nc(-c2ccccc2)c2c([R])cc(C(F)(F)F)c([AlH2])c2n1</smiles>

$69-75 \%$<smiles></smiles>

$78-88 \%$<smiles>[R]c1cc(C(F)(F)F)c(C#N)c(N)c1C(=[NH2+])c1ccccc1</smiles>

18

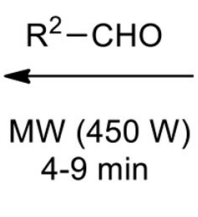

17

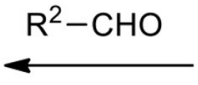

$\mathrm{MW}(450 \mathrm{~W})$ 4-9 min

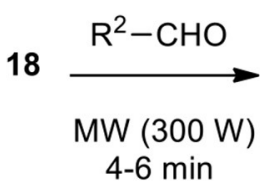

4-6 min<smiles>[R]c1cc(C(F)(F)F)c(C#[Y17])c2c1C(c1ccccc1)=NC([R])N2</smiles>

$55-63 \%$<smiles>[R]c1cc(C(F)(F)F)c2c(c1C#N)NC([R])N=C2c1ccccc1</smiles>

$58-65 \%$

SCHEME 8 | MW-assisted synthesis of quinazolines 19 and $\mathbf{2 0}$ from $\mathbf{1 7}$ and $\mathbf{1 8}$, respectively.<smiles></smiles>

23
$\mathrm{EmimPF}_{6}, \mathrm{ZnCl}_{2}$

PhMe, MW

$160{ }^{\circ} \mathrm{C}, 30 \mathrm{~min}$

$71-91 \%$<smiles>[R]c1nc(C)c2ccccc2n1</smiles>

24

SCHEME 9 | MW-assisted synthesis of $\mathbf{2 4}$ from $\mathbf{2 3}$ and aldehydes using emimPF 6 and $\mathrm{ZnCl}_{2}$.

\section{Ortho-esters}

Ortho-esters have been condensed with aniline derivatives under MWI to produce quinazolinones. As an example in this regard, the synthesis of 6 -substituted benzimidazo[1,2-c]-quinazolines 8 was accomplished through the cyclocondensation of 2(2-aminophenyl)benzimidazole (7) with ortho-esters in $\mathrm{N}, \mathrm{N}$ dimethyl acetamide (DMAC) using MWI and in the absence of the catalyst (Scheme 4) (Khajavi et al., 1999a). Products 8 were obtained, which showed a relatively higher yield compared to under classical heating. A comparison of two reaction conditions showed the emphasis on MWI as the main factor in improving the product yields in 2-6 min, which involved a prolonged reaction time. The reaction also occurred in the absence of a solvent.
Azizian et al. reported a strategy to rapidly prepare novel polyheterocyclic compounds 10,6-substituted quinazolino[4,3b] quinazolin-8-ones, through fusing 2-(o-aminophenyl)-4(3H)quinazolinone (9) with a range of ortho-esters under solvent-free MW conditions in the absence of organic or inorganic reagents (Scheme 5) (Azizian et al., 2004b). The strategy offered several advantages comprising cleaner reaction profiles, short reaction times, simple work-up procedures, and high yield of products, making it a useful tool for the synthesis of target products.

\section{Benzaldehydes}

Benzaldehydes have also been condensed and cyclized with various amines under MW conditions to synthesize quinazolinones. For example, Kumar et al. accomplished the 
<smiles>CC1=NS[SH](=[Se])=C1Cl</smiles>

25<smiles>CCOc1nc(C#N)nc2ccc([N+](=O)[O-])cc12</smiles>

28

SCHEME 10 | MW-assisted synthesis of 28 from 27.<smiles>COC(OC)N(C)N(C)C(=O)OCCN(C)C=Nc1ccc([N+](=O)[O-])cc1C#N</smiles><smiles>O=[N+]([O-])c1ccc2ncnc(Nc3cccc(Br)c3)c2c1</smiles>

SCHEME 11 | MW-assisted synthesis of $\mathbf{3 2}$ from $\mathbf{3 0}$ and $\mathbf{3 1}$.

synthesis of biologically important quinazoline derivatives using a domestic microwave oven (Kumar et al., 2004). The advantage of this process is better yields, shorter reaction times, lower energy inputs, and an easy work-up procedure, as well as it being less expensive and high-yielding. The aza-Wittig reaction of $\mathrm{N}$-imidoyliminophosphorane (11) with aldehyde derivatives under domestic MWI at $300 \mathrm{~W}$ for a period of 3-4 min led to the formation of the desired quinazolines $\mathbf{1 2}$ in good yields (Scheme 6).

Later, Kumar et al. synthesized quinazolines 12 via the MWassisted direct condensation of $\mathrm{N}$-arylamidine $\mathbf{1 3}$ with aldehydes, without their prior conversion to iminophosphoranes, in the absence of any Lewis acid catalyst (Kumar et al., 2005). This methodology could be employed to synthesize 2-secamino substituted quinazoline derivatives $\mathbf{1 4}$ and benzo $[g]$ quinazolines 15 through the condensation of guanidines and $N$-naphthalen1-yl-benzamidine with different aldehydes, respectively (Scheme 7).

A useful strategy to synthesize new quinazoline derivatives was developed by Maitraie et al. (2006). 2,6-Dicyanoaniline derivatives $\mathbf{1 6}$ on the reaction with Grignard reagents produced imine regioisomers 17 and 18, which, after separation and identification, reacted with various aldehydes under MWI with $450 \mathrm{~W}$ to provide novel quinazolines $\mathbf{1 9}$ and $\mathbf{2 0}$, respectively. 


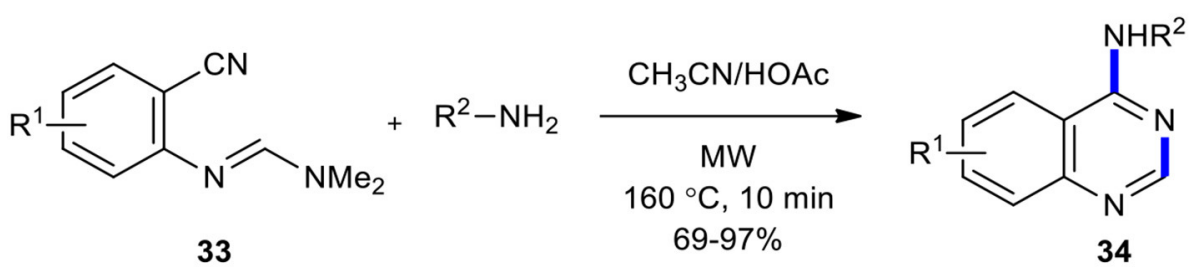

SCHEME 12 | MW-assisted synthesis of 4-aminoquinazolines $\mathbf{3 4}$ from $\mathbf{3 3}$ and amines.

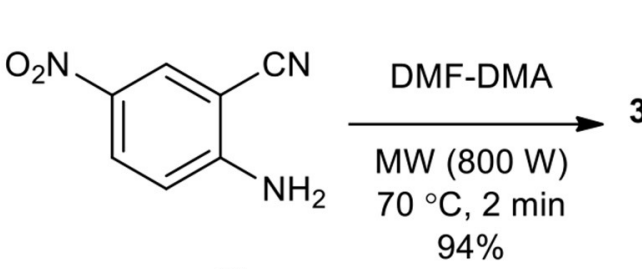

29<smiles>CN(C)C=Nc1ccccc1C#N</smiles>

36

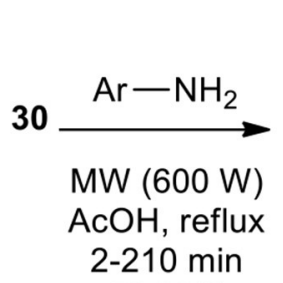

$50-99 \%$<smiles>O=[N+]([O-])c1ccc2ncnc(N[Ga])c2c1</smiles>

35

SCHEME 13 | MW-assisted synthesis of $\mathbf{3 5}$ and $\mathbf{3 7}$ from $\mathbf{2 9}$ and 36, respectively.

Interestingly, when the same reaction was conducted under $300 \mathrm{~W}$ power of MWI, 2-dihydroquinazolines 21 and 22 were exclusively obtained (Scheme 8). Notably, quinazolines were obtained at a comparatively higher yield than the 1,2dihydroquinazolines.

Portela-Cubillo et al. showed that MWI in the case of the reaction of 2-(aminoaryl)alkanone $O$-phenyl oxime (23) with aldehydes in the presence of emimPF 6 as a catalyst and $\mathrm{ZnCl}_{2}$ as a co-catalyst in toluene is a suitable source of heating for the synthesis of quinazolines 24 in good to excellent yields (71-91\%) (Scheme 9) (Portela-Cubillo et al., 2008). $\mathrm{ZnCl}_{2}$ in this reaction acted as a promoter which improved the yield of the products when less reactive carbonyl compounds were used. The notable features of this strategy involved mild reaction conditions, high yields, short reaction times, and no need for acids, bases, or metal catalysts. In addition, unlike other radical-mediated protocols, no initiators were required and no by-products contaminated the process.

\section{Alcohols}

Condensation of alcohols with imino-1,2,3-dithiazole 27 to 4alkoxyquinazoline using MWI has been reported. Besson et al. employed MWI for the synthesis of 4-alkoxyquinazoline 28 through the reaction of the imino-1,2,3-dithiazole 27, prepared form aniline 25 and 4,5-dichloro-1,2,3-dithiazolium chloride (26), in the presence of sodium hydride in $\mathrm{EtOH}$ (Scheme 10) (Besson et al., 2000). Compound 28 was probably obtained via the addition of the alcohol to the cyano group, which was accompanied by cyclization and aromatization. Here, MWI was used as a powerful source of energy for accelerating the reactions and was cleaner compared to conventional heating (Besson and Rees, 1996; Besson et al., 2000).

\section{Aliphatic and Aromatic Amines}

Aliphatic and aromatic amines have been employed as reactants to afford quinazolinones. Tsou et al. presented the synthesis of 6-nitro-4-(3-bromophenylamino)quinazoline (32) (Tsou et al., 2001). They reacted market purchasable 5-nitroanthranilonitrile (29) with $\mathrm{N}, \mathrm{N}$-dimethylformamide dimethyl acetal (DMFDMA) as a reactant and solvent to give $\mathrm{N}$-(2-cyano-4nitrophenyl)- $N, N$-dimethylimidoformamide (30). The latter was then reacted with 3-bromoaniline (31) in $\mathrm{AcOH}$ under reflux to produce the desired compounds (32) (Scheme 11). 
<smiles>N#Cc1nc2ccc(N)c(C#N)c2s1</smiles>

38

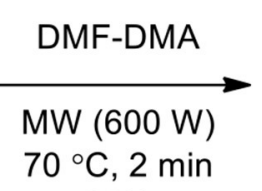

$86 \%$<smiles>N#Cc1nc2ccc3ncnc(NC(=O)[O-])c3c2s1</smiles>

SCHEME 14 | MW-assisted synthesis of $\mathbf{4 0}$ from $\mathbf{3 9}$ and anilines.
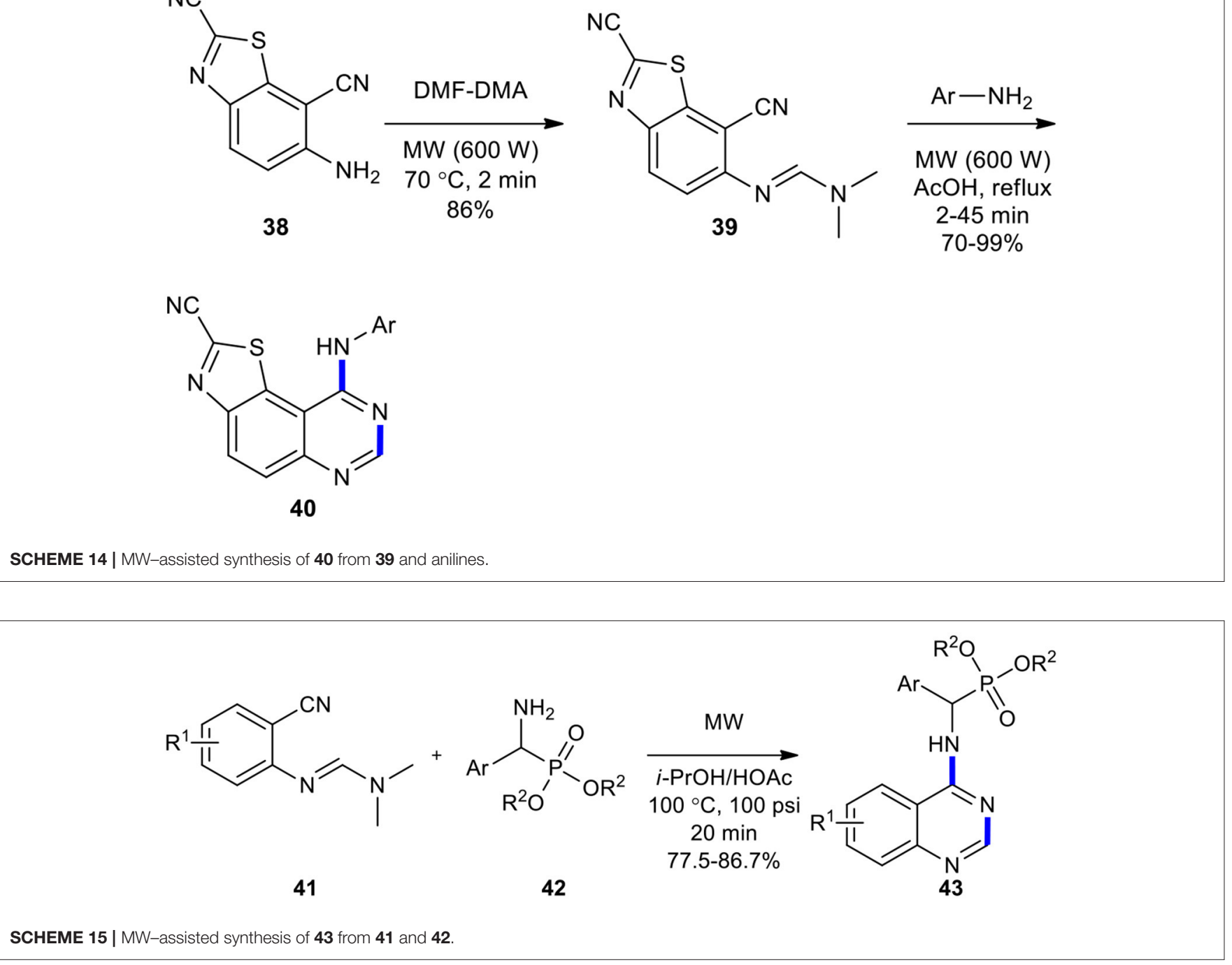

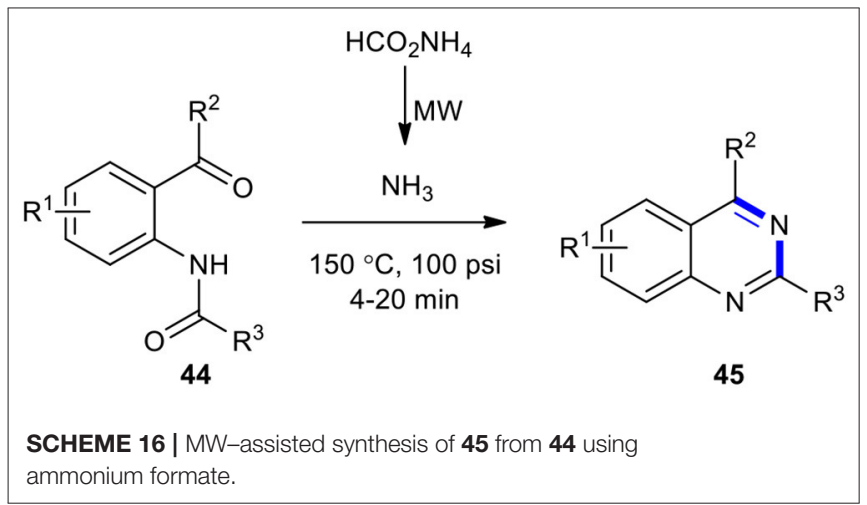

A simple, efficient, straightforward, and high-yielding strategy for the preparation of 4-aminoquinazoline derivatives 34 employing MW chemistry was reported (Yoon et al., 2004). The

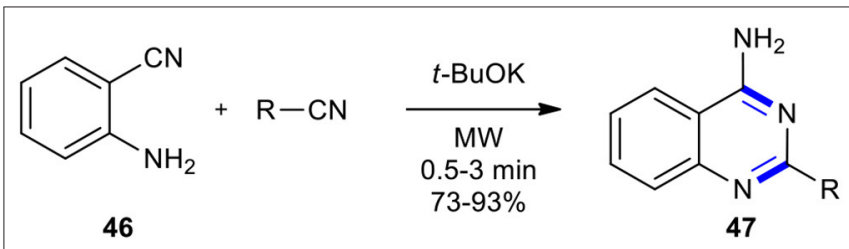

SCHEME 17 | MW-assisted synthesis of $\mathbf{4 7}$ from $\mathbf{4 6}$ and nitriles.

resulting products 34 were formed when the reaction between $N$ (2-cyanophenyl)- $N, N$-dimethylformamidine derivatives 33 and amines was conducted under the optimized reaction conditions $\left(\mathrm{CH}_{3} \mathrm{CN} / \mathrm{HOAc}, \mathrm{MW}, 160^{\circ} \mathrm{C}, 10 \mathrm{~min}\right)$ (Scheme 12).

Foucourt et al. (2010) re-investigated the MW conditions of Tsou's reaction (Tsou et al., 2001) with the aim to define a well-established protocol, enabling a high level of reproducibility as well as easy scaling-up to a multi-gram 
<smiles>[R]C#N</smiles>

48

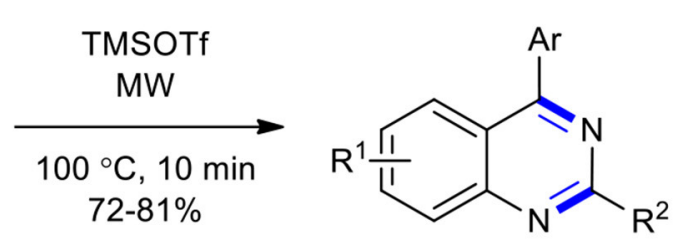

49

SCHEME 18 | MW-assisted synthesis of $\mathbf{4 9}$ from $\mathbf{4 8}$ and nitriles.

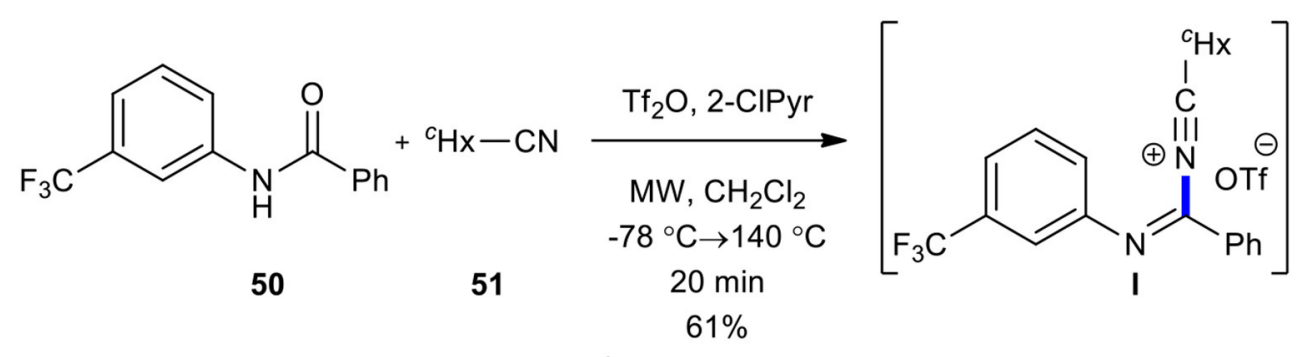<smiles>[X]c1nc(-c2ccccc2)nc2cc(C(F)(F)F)ccc12</smiles>

${ }^{c} \mathrm{Hx}=$ cyclohexyl

52<smiles>COc1ccc(NC(=O)[13C](C)(C)C)cc1</smiles>

53

51

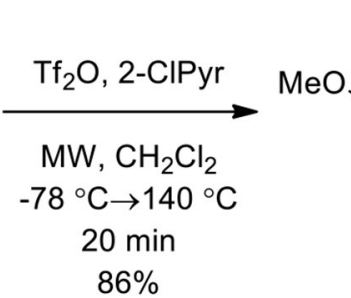<smiles>[R15]c1nc([X])c2cc(C)ccc2n1</smiles>

54

SCHEME 19 | MW-assisted synthesis of $\mathbf{5 2}$ and $\mathbf{5 4}$ from $\mathbf{5 0}$ and $\mathbf{5 1}$, respectively.<smiles>[R]C(=O)NC1=C(C(=O)O)C=C[R1]([H])C=C1</smiles><smiles>[R]c1nc([R])n2c3c(c(Cl)nc12)C=C[R1]C=C3</smiles>

58

SCHEME 20 | MW-assisted synthesis of $\mathbf{5 8}$ from $\mathbf{5 5}$ and $\mathbf{5 6}$ (or $\mathbf{5 7}$ ) using $\mathrm{POCl}_{3}$ as condensing reagent.

scale. They synthesized 4-anilino-6-nitroquinazolines 35 from 5 -nitroanthranilonitrile (29) on a multi-gram scale through the MW-assisted condensation and Dimroth rearrangement. The best result in the synthesis of the intermediate $\mathbf{3 0}$ was carried out in only 2 min under MWI at atmospheric pressure at $70^{\circ} \mathrm{C}$, which gave the products in almost quantitative yields. They 


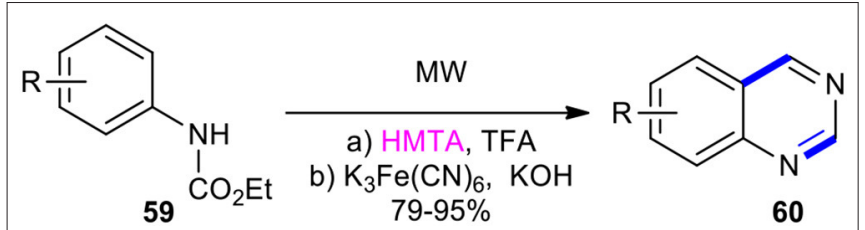

SCHEME 21 | MW-assisted synthesis of $\mathbf{6 0}$ from $\mathbf{5 9}$ and HMTA. also synthesized 4-arylaminoquinazolines 37 (Scheme 13). In this MW heating, acetic acid reacted with anilines to generate the corresponding acetamides and gave cleaner products. This methodology was also used to access Azixa, a microtubule destabilizing agent and apoptosis inducer, in two steps in $64 \%$ overall yields.

Foucourt et al. could also develop their strategy for the efficient and simple production of a forty molecule library of novel 6,6,5-tricyclic thiazolo[5,4-f]-quinazoline scaffold as interesting DYRK1A inhibitors (Foucourt<smiles>Nc1cc[R]#cc1C(=O)Br</smiles>

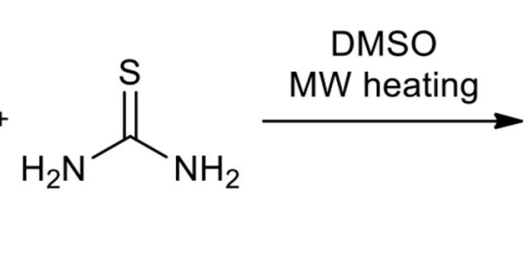<smiles>O=[R6]C1=NC=NC(Br)=C2C=C[R]#CC=C12</smiles>

SCHEME 22 | MW-assisted synthesis of $\mathbf{6 2}$ from $\mathbf{6 1}$ using thiourea in dimethyl sulfoxide.<smiles>[X]c1c([X])c(F)c(C#N)c(F)c1[X]</smiles>

63<smiles>[R]SC([Y])=[NH2+]</smiles>

64

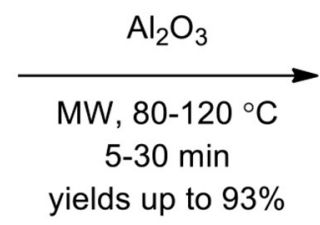

yields up to $93 \%$

SCHEME 23 | MW-assisted cyclization of 63 with 64 using basic alumina to synthesize 65 .

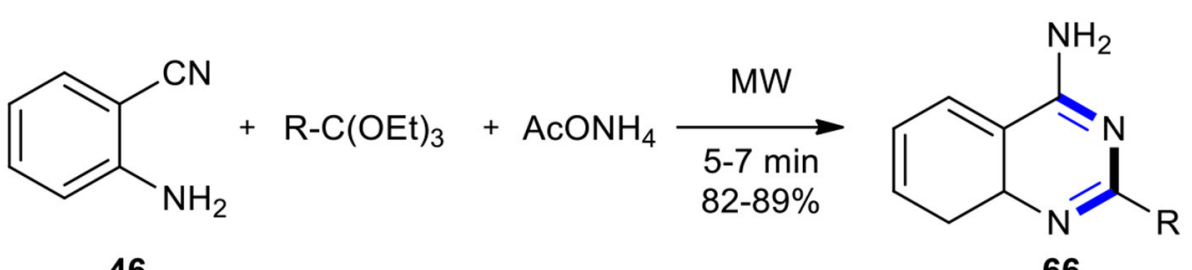

46<smiles>[R]Sc1nc(N)c2c(F)c([X])c([Y])c([X])c2n1</smiles>

65

24 | MW-assisted MCR of 46, ortho-esters, and $\mathrm{AcONH}_{4}$ to produce 66.

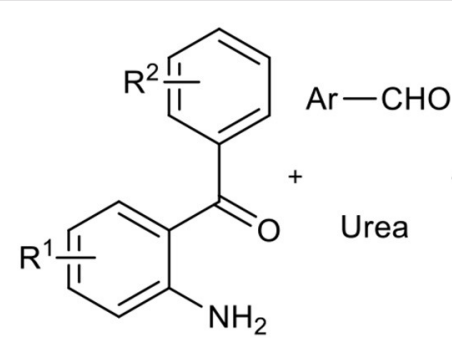

67

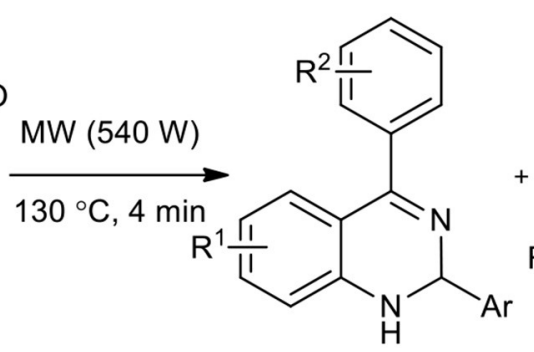

68<smiles>[R17]c1cccc(-c2nc([Al])nc3cc[R1]cc23)c1</smiles>

69

SCHEME 25 | MW-assisted MCR of $\mathbf{6 7}$, aldehydes, and urea to afford 69. 
et al., 2014). The synthesis of the target molecules was started with 6-aminobenzo[d]thiazole-2,7-dicarbonitrile (38) which, upon reaction with DMF-DMA under MWI at $\quad 70^{\circ} \mathrm{C}$, yielded (E)-N'-(2,7-dicyanobenzo[d]thiazol6 -yl)-N,N-dimethylformimidamide (39) in good yield (86\%). Next, formimidamide $\mathbf{3 9}$ was cyclized to

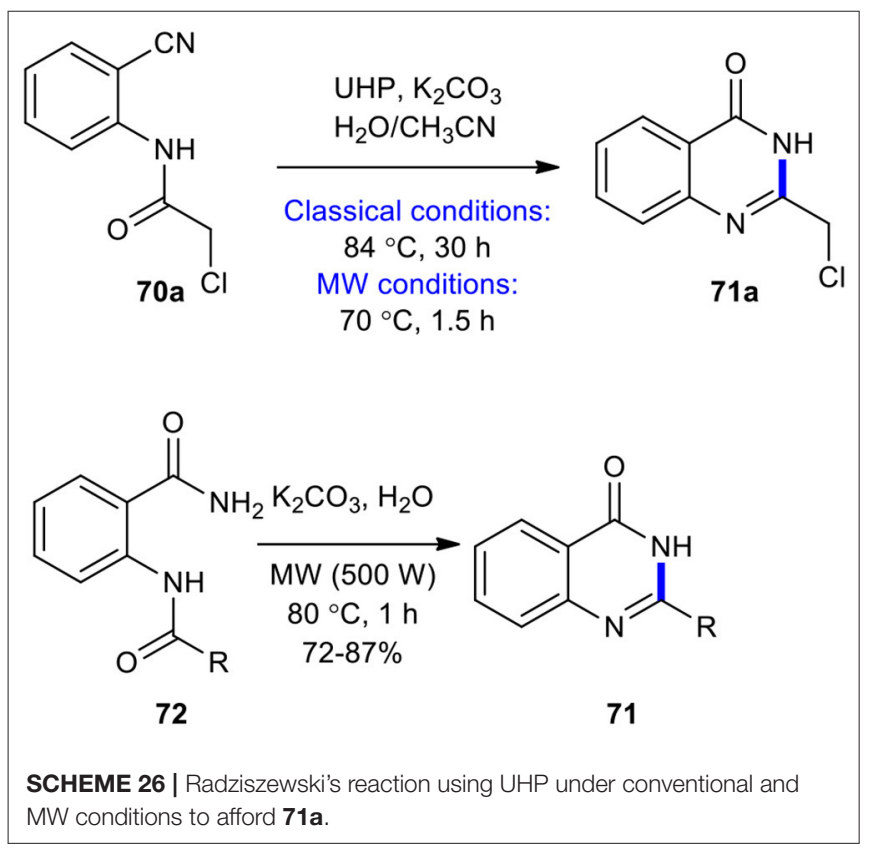

thiazolo $[5,4-f]$ quinazoline-2-carbonitriles 40 , the expected compounds, in 70-99\% yields via MW-assisted thermalsensitive Dimroth rearrangement using appropriate anilines in acetic acid at $118^{\circ} \mathrm{C}$ for $2-45 \mathrm{~min}$ (Scheme 14).

MW technology was employed as an efficient, mild, and environmentally friendly method to increase yields and shorten reaction times in the synthesis of (quinazolin-4ylamino)methylphosphonates 43 (Luo et al., 2012). The desired products 43 were easily prepared in higher yields compared with a conventional mode of heating when $N^{\prime}$-(substituted2-cyanophenyl)- $N, N$-dimethylformamidines 41 was reacted with dialkyl amino (phenyl)methylphosphonates 42 under the optimized reaction conditions (MWI, $i$ - $\mathrm{PrOH} / \mathrm{HOAc}, 100^{\circ} \mathrm{C}$, $20 \mathrm{~min}$ ) (Scheme 15).

\section{Ammonium Formate}

Ammonium formate $\left(\mathrm{HCOONH}_{4}\right)$ have been employed as substrates for the synthesis of quinazolinones under MW conditions. For example, 2,4-disubstituted quinazolines 45 were obtained upon treatment of acylamides 44 with $\mathrm{HCOONH}_{4}$ as a source of $\mathrm{NH}_{3}$ under MW activation at $150^{\circ} \mathrm{C}$ for $4-20 \mathrm{~min}$ (Ferrini et al., 2007). Heating of the reaction probably led to the decomposition of $\mathrm{HCOONH}_{4}$ and generation of the imine which was cyclized in the acid environment owing to the presence of excess $\mathrm{HCOONH}_{4}$. A temperature of $150^{\circ} \mathrm{C}$ and the presence of the acid afforded the requisite quinazoline 45 (Scheme 16).

\section{Nitriles}

Nitriles have been used as reactants in the synthesis of quinazolinone derivatives. A research group in the Universidad<smiles>[R]C(N)C(=O)Nc1ccccc1C(=O)Nc1ccccc1C(C)=O</smiles>

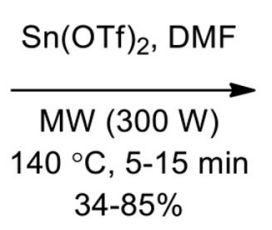

$34-85 \%$<smiles>[R]C1NC(=O)c2ccccc2-n2c1nc1ccccc1c2=O</smiles>

74

SCHEME 27 | MW-assisted direct double cyclization of $\mathbf{7 3}$ to afford $\mathbf{7 4}$.<smiles>[R]c1cc(C(=O)N2CCc3c([nH]c4ccccc34)C2=N)c(N)c([R])c1[R]</smiles>

SCHEME 28 | MW-assisted intramolecular azido-reductive cyclization of $\mathbf{7 5}$ to afford $\mathbf{7 6}$. 
<smiles>Nc1ccccc1C(=O)O</smiles>

77
$\mathrm{MW}$

$(210-385 \mathrm{~W})$

$+\mathrm{RHN}-\mathrm{CHO}$

$\mathrm{R}=\mathrm{H}, \mathrm{Ph}$

4-10 min

$88-98 \%$<smiles>[R]n1cnc2ccccc2c1=O</smiles>

78

SCHEME 29 | MW-assisted Niementowski reaction to afford $\mathbf{7 8}$<smiles></smiles>

79

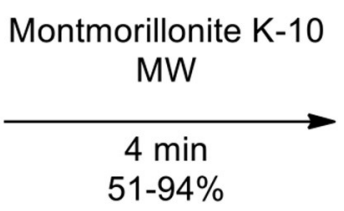

$51-94 \%$<smiles></smiles>

80

SCHEME 30 | MW-assisted Niementowski reaction of $\mathbf{7 9}$ and formamide using MK-10 to afford $\mathbf{8 0}$

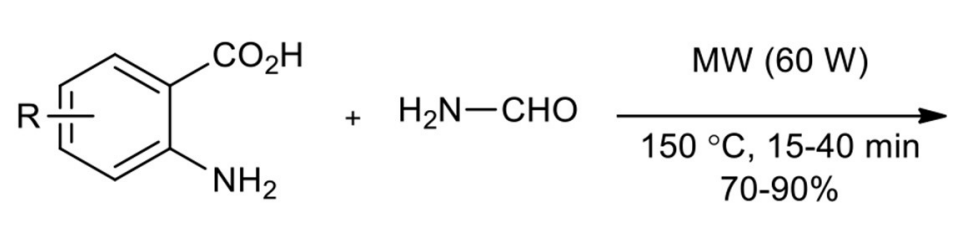

81<smiles>[R]=[Pt]c1ccc2nc[nH]c(=O)c2c1</smiles>

82

SCHEME 31 | MW-assisted Niementowski reaction using an excess of formamide to afford $\mathbf{8 2}$
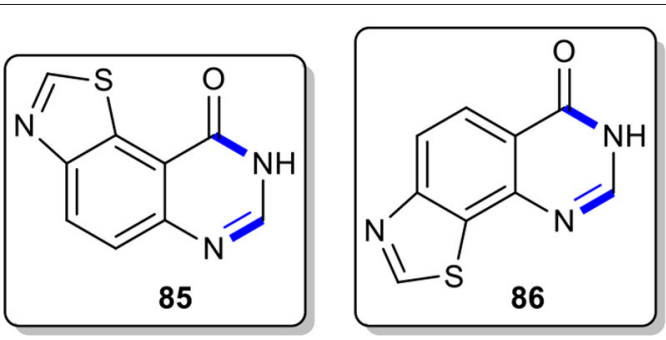<smiles>Nc1cc[n+]([O-])cc1C(=O)O</smiles>

83
$+\mathrm{H}_{2} \mathrm{~N}-\mathrm{CHO}$

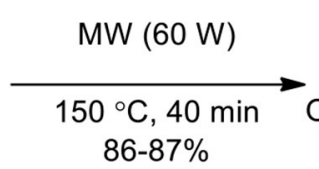

$86-87 \%$<smiles></smiles>

SCHEME 32 | The synthesis of $\mathbf{8 4}$ through MW-assisted Niementowski reaction toward $\mathbf{8 5}$ and $\mathbf{8 6}$

de Santiago de Compostela synthesized 4-aminoquinazolines 47 by the reaction of anthranilonitrile (46) with various aromatic nitriles in the presence of a catalytic amount of $t$-BuOK as a base in a domestic microwave oven as a heating device in the absence of solvent (Seijas et al., 2000). The products 47 were obtained in good to excellent yields and in a very short irradiation time (Scheme 17).

A solvent-free, transition-metal-free, rapid, and efficient reaction to prepare 2,4-disubstituted quinazolines $49 \mathrm{via}$ the Lewis-acid-catalyzed activation of nitriles and intramolecular 


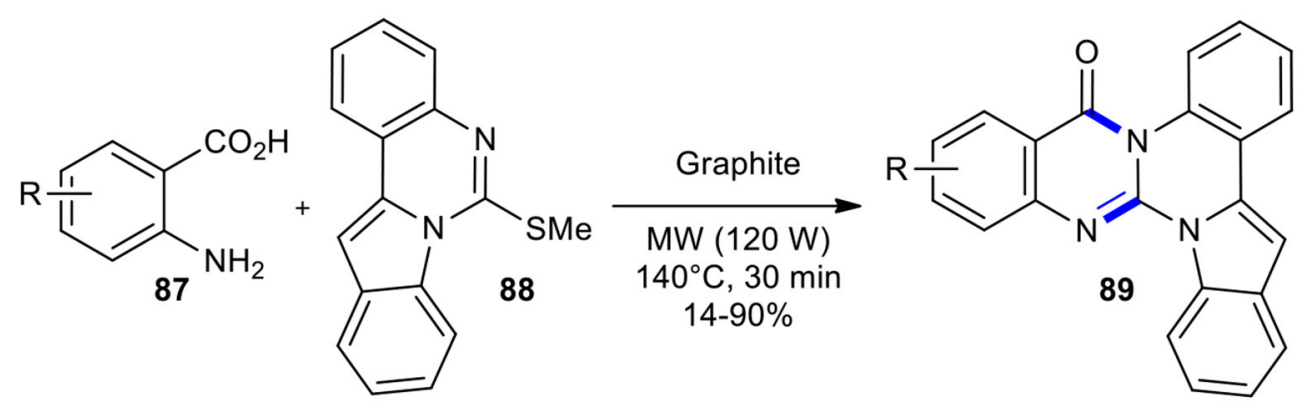

SCHEME 33 | MW-assisted synthesis of $\mathbf{8 9}$ from $\mathbf{8 7}$ and $\mathbf{8 8}$.

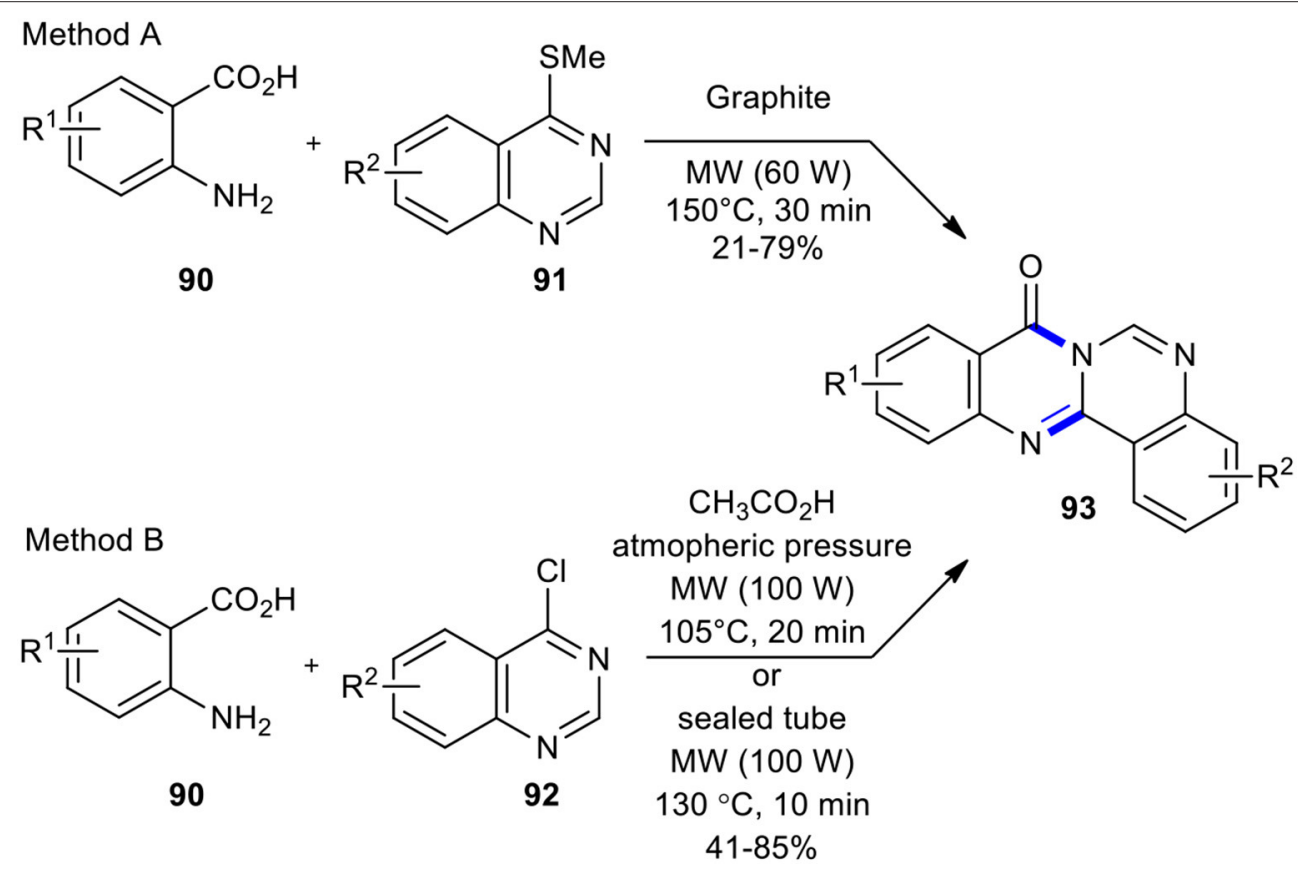

SCHEME 34 | MW-assisted synthesis of $\mathbf{9 3}$ from 91 or $\mathbf{9 3 .}$

cyclization in a one-pot reaction sequence was developed (Saikia et al., 2018). The reaction was performed in the presence of a catalytic amount of trimethylsilyltrifluoromethane sulfonate (TMSOTf) under MWI. Nitriles, employed as a nitrogen source and activated by TMSOTf, were reacted with 2-aminophenyl carbonyl compounds $\mathbf{4 8}$. The best result was achieved when $\mathbf{4 8}$ was treated with nitrile and TMSOTf under MWI at reflux $100^{\circ} \mathrm{C}$ for $10 \mathrm{~min}$ (Scheme 18). The significant features of this approach included clean and mild reaction conditions, very short reaction times, and a broad substrate scope.

Movassaghi and Hill compared conventional heating and MWI in the condensation of amides with cyclohexanecarbonitrile as a nucleophile to construct an azaheterocycle scaffold (Hill and Movassaghi, 2008). The condensation of amide $\mathbf{5 0}$ with cyclohexanecarbonitrile (51) in the presence of trifluoromethanesulfonic anhydride $\left(\mathrm{Tf}_{2} \mathrm{O}\right)$ and 2-chloropyridine (2-ClPyr) in the sealed reaction vessel in
$\mathrm{CH}_{2} \mathrm{Cl}_{2}$ under $\mathrm{MWI}$ heating at a lower temperature $\left(-78^{\circ} \mathrm{C}\right)$ of $140^{\circ} \mathrm{C}$ for $20 \mathrm{~min}$ afforded the expected quinazoline 52 (Scheme 19). The above synthetic route could complete the conversion of the sterically hindered substrate, amide 53, into the desired quinazoline 54. This approach was found to be superior in comparison with heating in an oil bath. The MWI also shortened the reaction times and increased the yield of the products.

The one-step synthesis of a new tricyclic product, 5-chloroimidazo[1,5-a]quinazolines $\mathbf{5 8}$, was reported by $\mathrm{Li}$ et al. via the reaction between $N$-acylanthranilic acids 55 and 2-amino acetamides 56 (or 2-amino-acetonitriles $57)$ in the presence of phosphorus oxychloride $\left(\mathrm{POCl}_{3}\right)$ as a condensing reagent under MWI (Scheme 20) (Li et al., 2009). The introduction of EWG at the 5-position of 2-acetamidobenzoic acid improved the yield of the expected products. 
<smiles>CCOC1=N[C@@H](C)C(=O)N2[C@@H]1C[C@H]1c3ccccc3N(C(C)=O)[C@H]12</smiles><smiles>[Y16][13CH3]</smiles>

SCHEME 35 | MW-assisted modified Niementowski condensation of $\mathbf{9 4}$ to afford $\mathbf{9 5}$ and $\mathbf{9 6}$

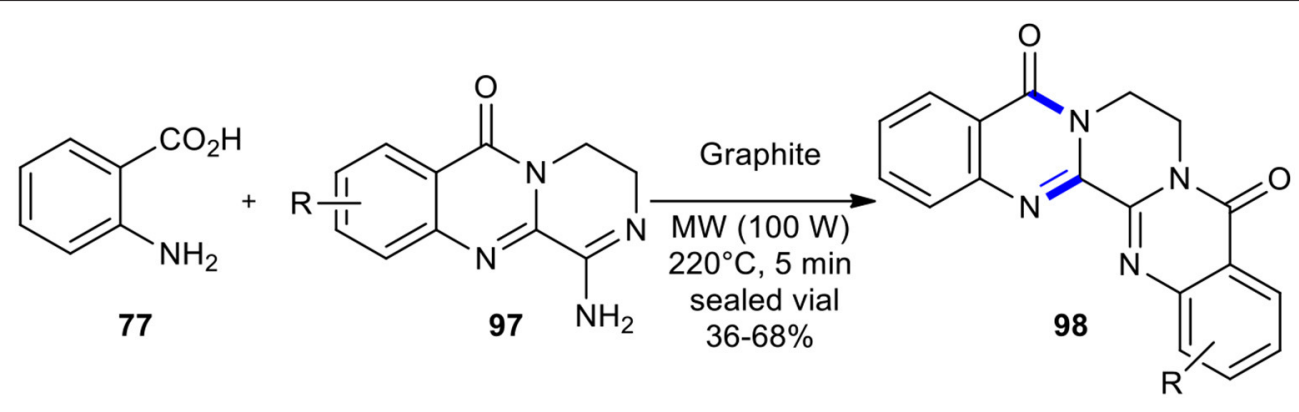

SCHEME 36 | MW-assisted modified Niementowski condensation of $\mathbf{9 7}$ to afford $\mathbf{9 8}$

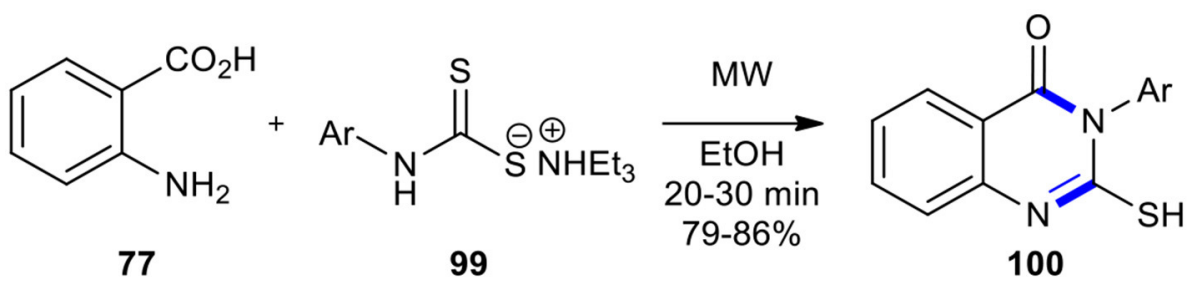

SCHEME 37 | MW-assisted modified Niementowski condensation of 99 to afford 100

\section{HMTA}

Hexamethylenetetramine (HMTA) has been condensed with ethyl phenylcarbamates under MW conditions to synthesize the quinazolinones. As an example, Chilin et al. established the benefits of using MWI in the one-pot synthesis of the quinazoline scaffold as a high-yielding and user-friendly protocol. This method used ethyl phenylcarbamates $\mathbf{5 9}$ as a simple and easily available starting material (Chilin et al., 2007). The reaction 
<smiles>O=c1[nH]c2ccccc2c(=O)o1</smiles>

101<smiles>[R]c1c2c(nc3ccccc13)C(=O)NC2</smiles>

102

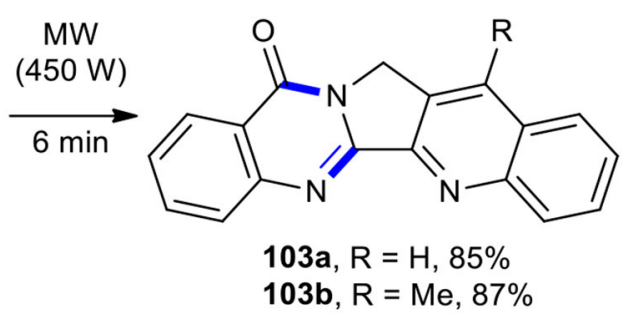

SCHEME 38 | Niementowski modification of Friedlander synthesis of 102.

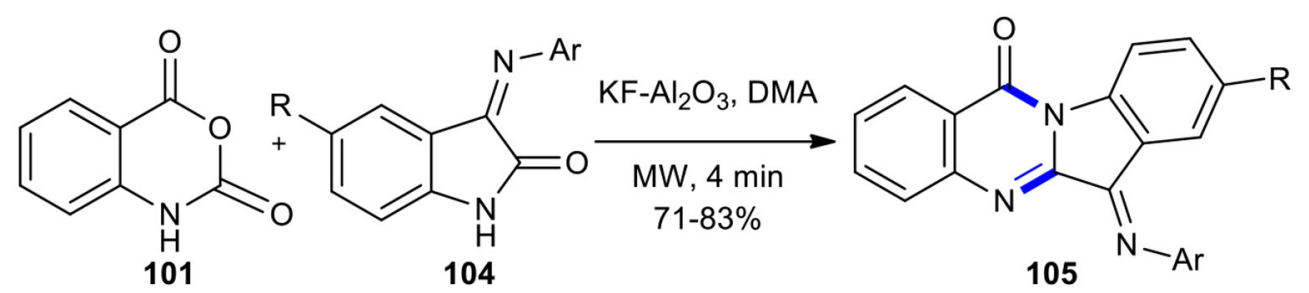

SCHEME 39 | MW-assisted Niementowski modification of the Friedlander synthesis of 104.<smiles>CN(O[Mg])c1cc[cH+]ccc1C(N)=O</smiles>

SCHEME 40 | MW-assisted Niementowski modification of the Friedlander synthesis of 106.

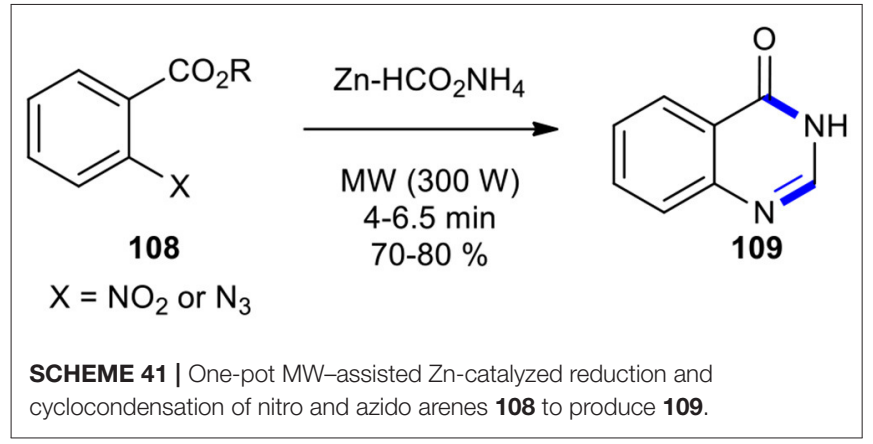

of compounds 59 with HMTA in trifluoroacetone (TFA) to carry out aminomethylation and intramolecular cyclization furnished the dihydropyrimidine ring, which was subjected to oxidative dehydrogenation upon exposure to $\mathrm{K}_{3} \mathrm{Fe}(\mathrm{CN})_{6}$ in aqueous ethanolic $\mathrm{KOH}$ to obtain the desired quinazolines 60 (Scheme 21).

\section{Thiourea}

Thiourea has been used as an efficient reagent for condensation with 2 -aminobenzophenones to create the 4 -aryl substituted quinazoline derivatives. A very simple and facile synthetic route for the direct conversion of substituted 2-aminobenzophenones 61 into 4-substituted quinazolines 62 under MWI in the presence of thiourea in dimethyl sulfoxide (DMSO) as a solvent and reagent was reported (Wang et al., 2016). The reaction was carried out through thermal decomposition of thiourea to generate carbodiimide and hydrogen sulfide, which were, respectively, reacted with 2-aminobenzophenone and DMSO to furnish 4-phenylquinazolin-2(1H)-imine intermediate and methanethiol (or other sulfur-containing molecules) as a complementary reducing agent. The reaction of 4-phenylquinazolin-2(1H)-imine intermediate with the sulfur-containing reducing agents formed 4-phenyl-1,2dihydroquinazolin-2-amine which was subjected to the elimination of ammonia to complete the synthesis of substituted quinazoline derivatives 62 (Scheme 22).

An inexpensive, environmentally benign, and efficient protocol was developed for the synthesis of the fluorinated 2-alkylthio-4-aminoquinazoline scaffold, with a broader sulfurcontaining substrate scope, that combined the use of MWI and basic alumina, acting as the solid support agented base promoter (Liu et al., 2018a). The synthesis of 2-alkylthio-4aminoquinazolines 65 was achieved by MW-assisted cyclization 


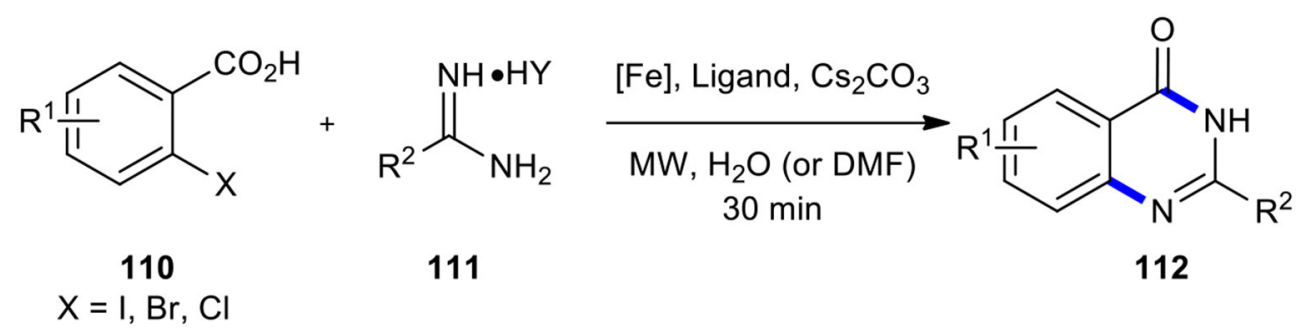

SCHEME 42 | MW-assisted iron-catalyzed cyclization of $\mathbf{1 1 0}$ with $\mathbf{1 1 1}$ to afford $\mathbf{1 1 2 .}$

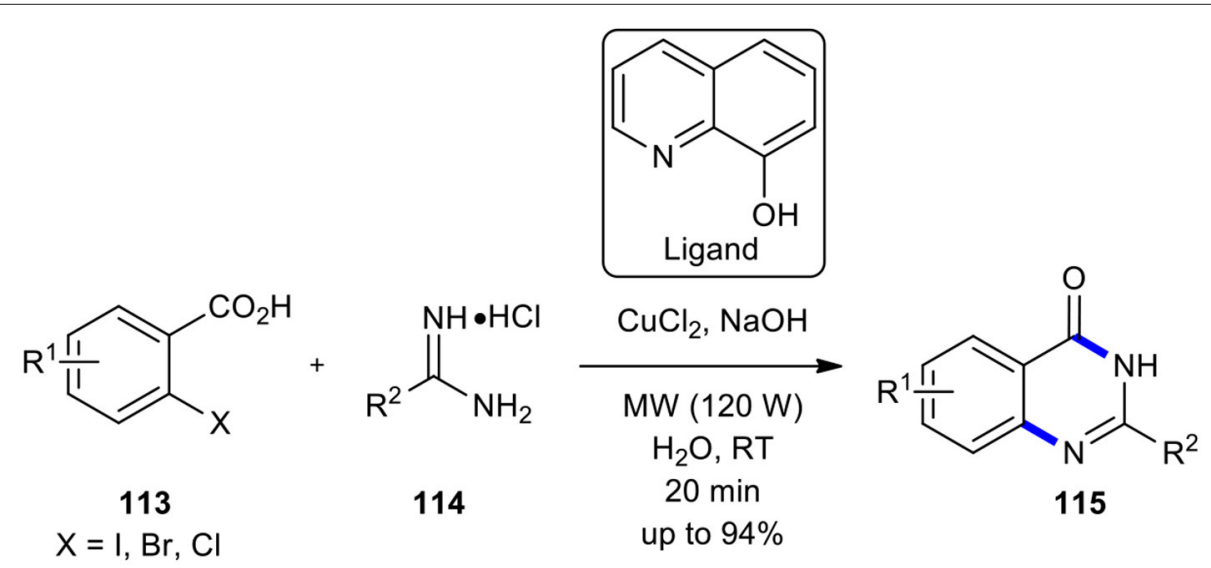

SCHEME 43 | MW-assisted copper-catalyzed cyclization of $\mathbf{1 1 3}$ with $\mathbf{1 1 4}$ to afford $\mathbf{1 1 5}$.

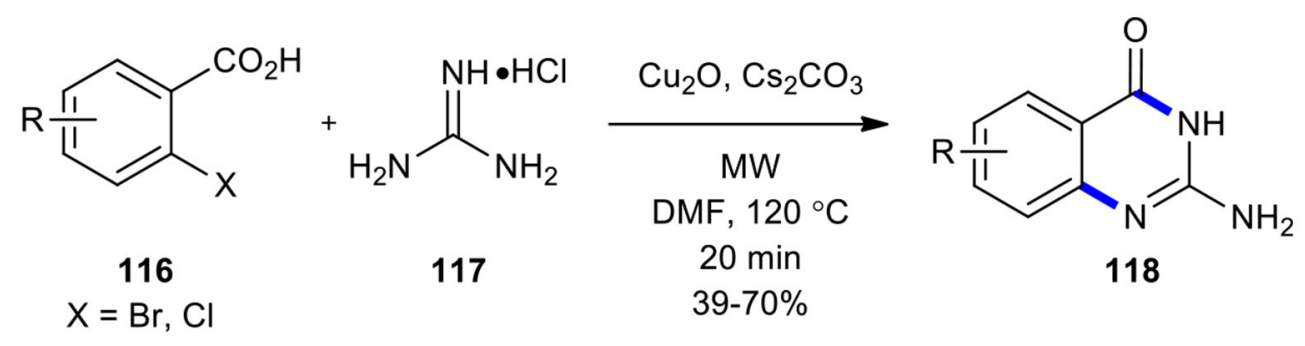

SCHEME 44 | MW-assisted copper-catalyzed cyclization of $\mathbf{1 1 6}$ with $\mathbf{1 1 7}$ to produce $\mathbf{1 1 8}$.<smiles>Nc1ccccc1C(=O)Nc1nc2ccccc2[nH]1</smiles>

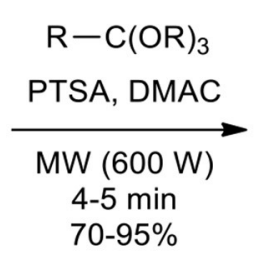<smiles>[R]c1nc2ccccc2c(=O)n1-c1nc2ccccc2[nH]1</smiles>

SCHEME 45 | MW-assisted synthesis of 120 from 119 and ortho-esters using PTSA.

of $o$-fluorobenzonitriles 63 with $S$-alkyl isothiouronium salts 64 and basic alumina at 80 or $120^{\circ} \mathrm{C}$ for 5-30 min (Scheme 23). The use of MWI could considerably improve product yields.

\section{Three-Component Reaction}

Multicomponent reaction (MCR) is an attractive synthetic strategy where three or more substrates combine to form a single 


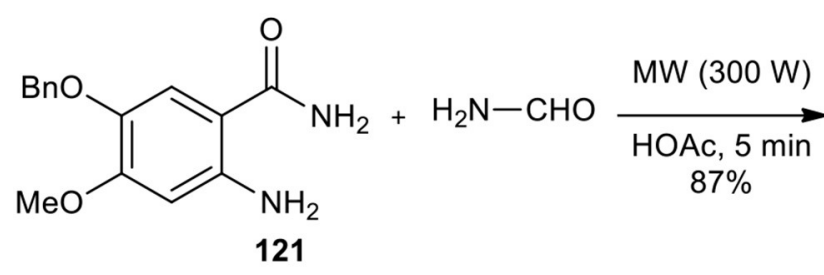<smiles>CCCCN1CN=Cc2cc(OC)c(OC(C)C)cc2C1=O</smiles><smiles>CCCCCCCOc1cc2ncnc(Nc3ccc(F)c(Cl)c3)c2cc1OCCCN1CCOCC1</smiles>

SCHEME 46 | MW-assisted synthesis of 122 from 121 and formamide.

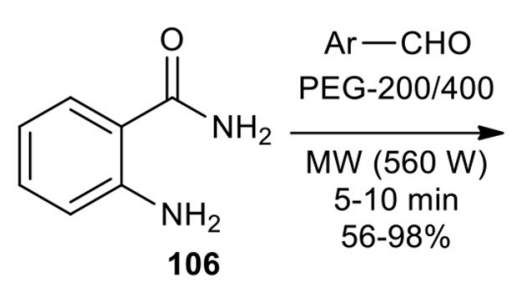

106<smiles>C[C@@H]1NC(=O)c2ccccc2N1</smiles>

Intermediate<smiles>[Y10]c1nc2ccc(OC)cc2c(=O)[nH]1</smiles>

SCHEME 47 | MW-assisted synthesis of 124 using PTSA in PEG as a solvent.<smiles></smiles>

SCHEME 48 | MW-assisted synthesis of 125 using $\mathrm{SbCl}_{3}$.

product in a one-pot fashion. MCR is a useful and powerful tool that has been used for the rapid and efficient synthesis of various complex molecules and natural products (Armstrong et al., 1996; Toure and Hall, 2009). Moreover, it is characterized by its environmental friendliness, atom economy, high yields, time efficiency, and low waste production. As a type of MCR, one-pot condensation of aminobenzonitrile (or anthranilic acid and its derivatives), ortho-esters (or formic acid), and amines under MWI is one of the most straightforward procedures for the construction of quinazoline and quinazolinone derivatives.
Rad-Moghadam and Samavi used MW technology to develop a facile and rapid method for the synthesis of 4aminoquinazolines (Rad-Moghadam and Samavi, 2006). The synthesis was accomplished in a few minutes through a one-pot multi-component reaction between 2-aminobenzonitrile (46), ortho-esters, and ammonium acetate $\left(\mathrm{AcONH}_{4}\right)$ under solventfree and MW conditions, leading to the desired products 66, 2-alkyl-4-aminoquinazolines, in good yields (Scheme 24). $\mathrm{AcONH}_{4}$ was employed as a separate synthon for the first time for $N-3$ in the synthesis of 4 -aminoquinazolines. The results were compared with that of a multi-component reaction under solvent-free conditions. MW conditions with conventional heating (refluxing absolute ethanol) showed a preference for the first system.

When 2-aminobenzophenones $\mathbf{6 7}$ were reacted with aldehydes and urea as an environmentally benign source of ammonia through one-pot three-component reaction under $\mathrm{MW}$ conditions $\left(540 \mathrm{~W}\right.$ and $\left.130^{\circ} \mathrm{C}\right)$, a library of 2,4-disubstituted-1,2-dihydroquinazolines 68 as a major product with a small amount of quinazolines 69 as a minor product were obtained (Scheme 25) (Sarma and Prajapati, 2011). Their 

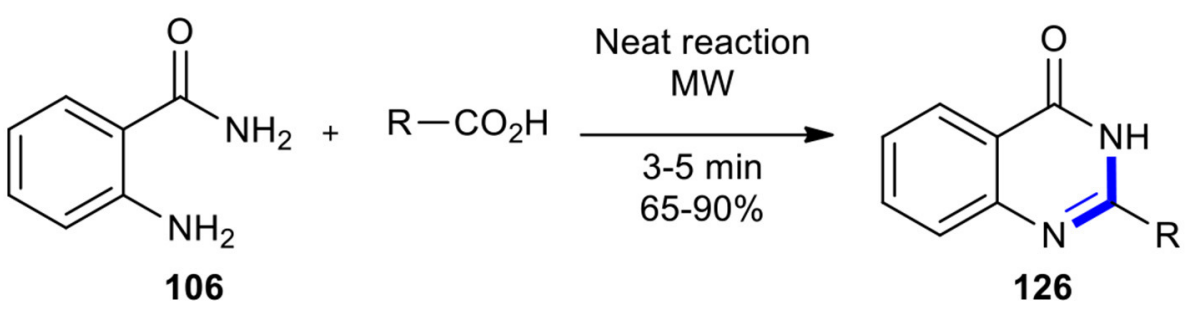

SCHEME 49 | MW-assisted synthesis of 126 from 106 and carboxylic acids.

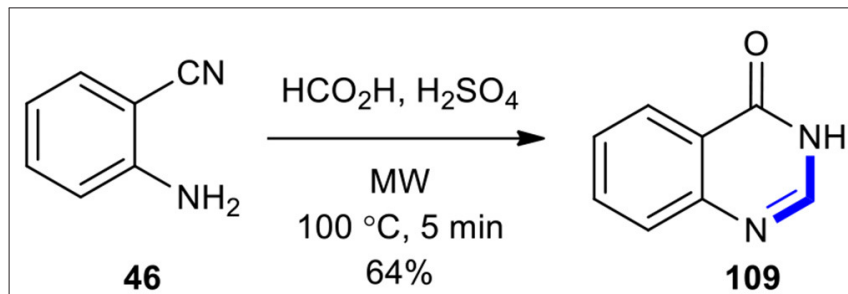

SCHEME 50 | MW-assisted synthesis of $\mathbf{1 0 9}$ from $\mathbf{4 6}$ and formic acid.

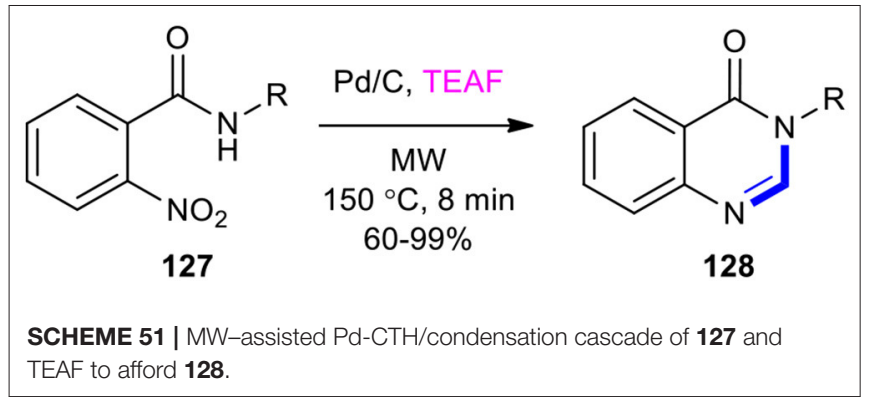

methodology also employed ammonium acetate as a good source of ammonia in place of urea. The salient features of this method were that it was rapid, simple, and clean, and had no need for a solvent or catalyst.

\section{SYNTHESIS OF QUINAZOLINONE DERIVATIVES}

\section{Radziszewski's Reaction Using UHP}

The Radziszewski reaction is an organic reaction which involves the oxidation of nitriles using alkaline hydroperoxide (Radziszewski, 1885). Performing the reaction on 0 amidobenzonitriles may result in the formation of quinazolin4-(3H)-ones (Bogert and Hand, 1902). The Radziszewski reaction as a useful and efficient strategy has been employed in the synthesis of quinazolinones under MW conditions. For example, MWI was used in the cyclization of 2-chloro$\mathrm{N}$-(2-cyanophenyl)acetamide (70a) and 2-amidobenzamide derivatives $\mathbf{7 2}$ to quinazolinones (Kabri et al., 2009). It is noteworthy that compounds $\mathbf{7 0}$ and $\mathbf{7 2}$ were obtained as a solid since they could be directly converted into the target molecules.
Compound 70a was subjected to Radziszewski's reaction in the presence of urea hydrogen peroxide (UHP) as a safe, mild, and non-hazardous oxidizing agent in the mixture of acetone $/ \mathrm{H}_{2} \mathrm{O}$ $(1: 1, \mathrm{v} / \mathrm{v})$ to afford 2-chloromethylquinazolin-4(3H)-one 71a. The reaction was performed under MW and classical conditions. In classical conditions, the product 71a was formed in a 55\% yield after $30 \mathrm{~h}$ reaction time at $84^{\circ} \mathrm{C}$, whereas, under $\mathrm{MW}$ conditions $(500 \mathrm{~W}, 70$ ? C, $1.5 \mathrm{~h})$, the same product was obtained in a $78 \%$ yield. Cyclization of derivatives 72 to quinazolin-4(3H)-ones 71 was accomplished when $\mathrm{K}_{2} \mathrm{CO}_{3}$ in water was used under MWI at 80 ? C for $1 \mathrm{~h}$ at a power of $500 \mathrm{~W}$, obtaining the expected compounds in good yields (Scheme 26).

\section{Double Cyclization}

A double cyclization reaction was employed in the synthesis of natural products containing quinazolinone under MW conditions. For example, the direct double cyclization of tripeptides 73 using $\mathrm{Sn}(\mathrm{OTf})_{2}$ in DMF and MWI at $140^{\circ} \mathrm{C}$ to access the structurally more challenging members, quinazolinobenzodiazepines 74, including sclerotigenin, asperlicin $\mathrm{C}$, and circumdatin $\mathrm{F}$ natural products and their analogous compounds, in 5-15 min was accomplished within a week to good yields (34-85\%) (Scheme 27) (Tseng et al., 2009). Tin(II) triflate in this dehydrative cyclization reaction could serve as an effective Lewis acid.

\section{Intramolecular Azido-Reductive Cyclization}

Intramolecular azido-reductive cyclization strategy has previously been employed in the synthesis of natural products under MW conditions. For example, Kamal et al. developed a simple, mild, and efficient synthetic route to synthesize rutaecarpine, euxylophoricines $\mathrm{A}$ and $\mathrm{C}$, and several analogs by using an intramolecular azido-reductive cyclization assisted by MWI of the corresponding substituted azido cyclic amides 75 as precursors (Kamal et al., 2011). The reduction of azido functionality in 2,3,4,9-tetrahydro- $\beta$-carbolin-1-one derivatives 75 with triphenylphosphine $\left(\mathrm{PPh}_{3}\right)$ or nickel boride $\left(\mathrm{Ni}_{2} \mathrm{~B}\right)$ as a reducing reagent in $\mathrm{HCl}-\mathrm{MeOH}$ using a CEM Discovery $\mathrm{MW}$ reactor furnished the expected quinazolinones 76 in excellent yields (80-90\%) (Scheme 28). 


\section{Niementowski Quinazoline Synthesis}

The Niementowski quinazoline synthesis involves the reaction of anthranilic acids with amides to construct 4-oxo-3,4dihydroquinazolines ( $3 \mathrm{H}$-quinazolin-4-ones). It is the most commonly used synthetic method to form the $3 \mathrm{H}$-quinazolin4-one ring. This synthetic route generally involves lengthy and tedious conditions as well as high temperatures. MWI as a powerful technique is capable of improving and reducing reaction times and increasing the yield of the reaction more than the purely thermal heating source. The first highly accelerated Niementowski reaction of anthranilic acid (77) with formamide (or formanilide) using a house-hold unmodified microwave oven under solvent-free conditions was reported by Khajavi et al., leading to the high purity of quinazolinone derivatives 78 (Scheme 29) (Khajavi et al., 1998). The salient features of this method included operational simplicity and a simple workup procedure.

As a general, efficient, and useful method, the combination of supported reagents and MWI was used in solvent-free conditions to prepare the requested quinazolines $\mathbf{8 0}$ through Niementowski quinazoline synthesis (Balalaie et al., 2001). The reaction of anthranilic acids 79 with formamide under MW conditions for $4 \mathrm{~min}$ was achieved using acidic alumina, silica gel, and montmorillonite K-10 (MK-10). Among acidic solid-supported reagents, montmorillonite K-10 gave the best yield (Scheme 30). Solvent-free conditions, good yields, short reaction times, and a simple set-up and work-up procedure are advantages of this method.

The Niementowski reaction under MWI (60 W) was employed for the synthesis of $3 H$-quinazolin-4-one core $\mathbf{8 2}$ using an excess of formamide ( 5 equiv) as a fusion accelerator in a fixed temperature $\left(150^{\circ} \mathrm{C}\right)$ (Scheme 31) (Alexandre et al., 2002). The expected products $\mathbf{8 2}$ were obtained in very good yields without any by-products.

Alexandre et al. described an original synthetic route to the rare $8 H$-thiazolo[5,4- $f$ ]quinazolin-9-one $(85)$ and the novel $7 H$-thiazolo[4,5- $h$ ]quinazolin-6-one (86), starting with the formation of $3 \mathrm{H}$-nitroquinazolin-4-ones 84 (Alexandre et al., 2003a). The MW-assisted Niementowski condensation using formamide under $\mathrm{MW}$ conditions $\left(60 \mathrm{~W}, 150^{\circ} \mathrm{C}\right)$ for $40 \mathrm{~min}$ annulated rapidly the quinazolin-4-one rings 84 which, in several steps, were converted into products 85 and $\mathbf{8 6}$, with different functional group in different positions (Scheme 32).

Domon et al. prepared new triazabenzo[a]indeno[1,2c] anthracen-5-ones and triazabenzo $[a]$ indeno-[1,2-c]naphtacen5-one 89 using MWI in dry media (Domon et al., 2001). Cyclization of anthranilic acid derivatives 87 using indoloquinazoline derivative $\mathbf{8 8}$ was performed with an<smiles>[R][Y]1ccc(CO)cc1</smiles>

SCHEME 52 | MW-assisted synthesis of $\mathbf{1 3 0}$ from $\mathbf{1 0 6}$ and $\mathbf{1 2 9}$ using $\mathrm{NaCl}$ and TBHP.<smiles>[R]c1nc2ccccc2c(=O)[nH]1</smiles>

SCHEME 53 | MW-assisted highly accelerated Niementowski reaction of $\mathbf{1 0 6}$ and $\mathbf{1 3 1}$ to afford $\mathbf{1 3 2}$.<smiles>[R]N=C=S</smiles>

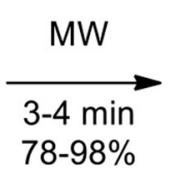<smiles>[R]Nc1nc2ccccc2c(=O)[nH]1</smiles>

134

SCHEME 54 | MW-assisted Niementowski reaction of $\mathbf{1 0 6}$ and $\mathbf{1 3 3}$ to afford 134. 
excess of anthranilic acid, adsorbed on graphite, using MWI $(120 \mathrm{~W})$ at $140^{\circ} \mathrm{C}$ for $30 \mathrm{~min}$ (Scheme 33). Interestingly, they realized that the direct condensation of anthranilic acids with thioamides may be very difficult or unsuccessful; hence, they converted the mercapto group of thioquinazolines into a better leaving group. Their method gave products 89 in various yields without any by-products. Although MWI shortened the reaction time and provided a cleaner reaction compared to the same reaction in purely thermal procedures, it should have been performed at a higher temperature $\left(140^{\circ} \mathrm{C}\right)$ due to graphite/MW interaction.

To access $8 H$-quinazolino[4,3- $b]$ quinazolin-8-ones 93, Alexandre et al. introduced two different leaving groups on the quinazoline ring (Scheme 34) (Alexandre et al., 2003b).
In method A, 4-(thiomethyl)quinazolines 91 was condensed with anthranilic acids 90 on graphite under the optimized reaction conditions ( $\left.\mathrm{MW}, 60 \mathrm{~W}, 150^{\circ} \mathrm{C}, 30 \mathrm{~min}\right)$. In method $\mathrm{B}$, the use of chlorine instead of thiomethyl group offered more straightforward access to target molecules $\mathbf{9 3}$ and afforded better yields than method A. It is noteworthy that method B employed acetic acid as a solvent while method A occurred in solvent-free conditions.

The reaction of anthranilic acid with lactim ethers is one of the methods to synthesize the quinazoline scaffold. This reaction was relatively neglected in the past, due to its low yields and the possibility of epimerization of stereocenters adjacent to carbonyl groups (Rajappa and Advani, 1973, 1974; Caballero et al., 1998) when performed under thermal and solvent-free

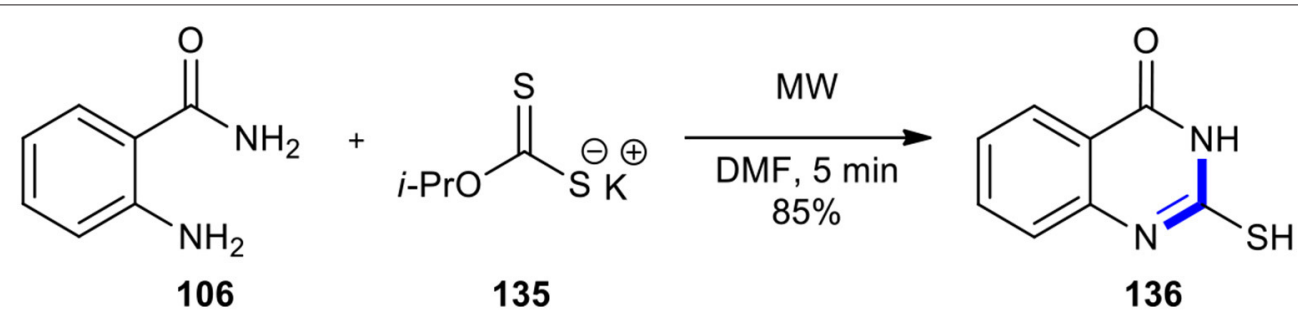

SCHEME 55 | MW-assisted Niementowski reaction of $\mathbf{1 0 6}$ and $\mathbf{1 3 5}$ to afford 136.<smiles>[R]NCCC(C)C</smiles>

137<smiles>[R]c1nc2ccccc2c(=O)n1[R]</smiles>

138

SCHEME 56 | MW-assisted synthesis of $\mathbf{1 3 8}$ from $\mathbf{1 3 7}$ and amines in DMAC.

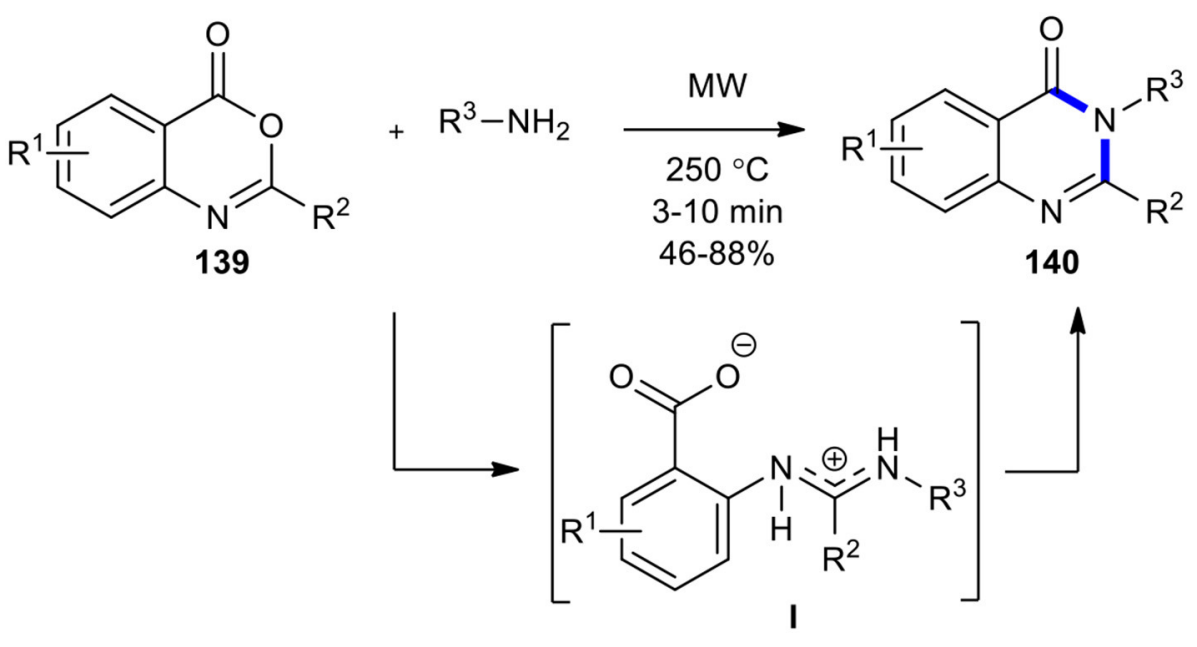

SCHEME $\mathbf{5 7}$ | MW-assisted synthesis of $\mathbf{1 4 0}$ from $\mathbf{1 3 9}$ and amines. 
conditions. Cledera et al. improved the earlier protocol by utilizing MWI in the cyclocondensation of anthranilic acid with lactim ethers, preparing pyrazino[2,1-b]quinazoline-3,6-diones (Cledera et al., 2004). When the tetracyclic ardeemin fragment 94 was reacted with anthranilic acid (77) under MW conditions $(600 \mathrm{~W})$ for $3 \mathrm{~min}$, a $6: 1$ mixture of the diastereoisomeric deprenylardeemins 95 and 96 in $48 \%$ overall yield was obtained (Scheme 35). The results showed that the optimized reaction conditions not only improved yield and shortened the reaction time but also improved stereochemical integrity compared to the conventional conditions.

Novel tetraaza-pentaphene-5,8-dione derivatives 98 could be synthesized from anthranilic acid (77) and the 2,3condensed (3H)-quinazolin-4-ones 97 via a $\mathrm{MW}$-assisted modified Niementowski condensation under pressure at $220^{\circ} \mathrm{C}$ (Scheme 36) (de Fatima Pereira et al., 2005).

An efficient method for forming a series of 3-aryl 2thioderivatives of quinazolinone $\mathbf{1 0 0}$ through the $\mathrm{MW}$-promoted cyclocondensation of anthranilic acid (77) with thio carbamate salt of variously substituted anilines $\mathbf{9 9}$ in either solvent (ethanol) or solvent-free conditions was achieved (Scheme 37) (Patil et al., 2012). The result showed that during the operation of MWI, better yields were obtained in the presence of a solvent or solventless system although, under solvent-free conditions, the reaction time was shortened from 20-30 to 2-3 min. As expected, the MWI, compared to conventional heating, significantly reduced the reaction time and improved the reaction yield.

\section{Niementowski Modification of Friedlander Synthesis}

The use of isatoic anhydride in place of anthranilic acid in the Niementowski reaction results in the Niementowski modification of Friedlander synthesis. The Niementowski modification of Friedlander synthesis has been employed in the synthesis quinazolinone scaffold. Yadav and Reddy reported the total synthesis of the cytotoxic alkaloid luotonin A (103a) for the first time in high yields based on the reaction of isatoic anhydride (101) with 3-oxo- $1 H$-pyrrolo[3,4-b] quinoline (102) under MWI and solvent-free conditions (Yadav and Reddy, 2002). Using the present reaction conditions, methyl-substituted luotonin A (103b) was produced in good yield (87\%) (Scheme 38). This process was new, efficient, simple, clean, rapid, and higher yielding than the reported strategies for the preparation of luotonin A. This approach used inexpensive reagents in this synthesis.

Azizian et al. previously prepared quinazolinone derivatives from isatin-3-imine and isatoic anhydride using MWI (Azizian et al., 2004a). The MW-assisted condensation of isatin-3-imines 104 with isatoic anhydride (101) using KF on alumina as a reusable catalyst in DMA in 4 min resulted in the formation of the new 6-arylimino-6H-indolo[2,1-b] quinazolin-12-ones 105 (Scheme 39). The reaction proceeded through ring-opening and cyclization.

Later, the same group used an MW-assisted Niementowski modification of the Friedlander synthesis (Pater, 1971) to prepare 2-(o-aminophenyl)-4(3H)-quinazolinone (107) (Azizian et al., 2004b). When isatoic anhydride (107) was reacted with anthranilamide (106), the nucleophilic attack of the $o$-amino group of the anthranilamide opened the isatoic anhydride ring which upon reaction with $\mathrm{Na}_{2} \mathrm{CO}_{3}$ (eq.) gave 2-(o-aminophenyl)4(3H)-quinazolinone (107) (Scheme 40).

\section{Metal-Catalyzed Cyclization of Benzoic Acids}

Catalysis is the process of enhancing the rate of a chemical reaction by adding a substance known as a catalyst (McNaught and Wilkinson, 1997; Masel, 2001). Generally, metal catalysts are recognized as the most important factors in increasing<smiles>O=c1oc(-c2ccccc2)nc2c1C=C[R1]C=C2</smiles>

141<smiles>[R]c1ccc2nc(-n3c(-c4ccccc4)nc4c(c3=O)C=C[R1]C=C4)sc2c1</smiles>

143<smiles>[R][X]1ccc2sc(N)nc2c1</smiles>

142

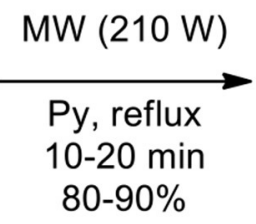

$80-90 \%$

SCHEME 58 | MW-accelerated solution-phase synthesis of 143 from 141 and 142 
catalyzed organic transformations. Particularly, transition metalcatalyzed reactions are fundamental for the convenient and effective synthesis of a wide range of organic compounds (Beller et al., 1998; Bates, 2012). The area of transition metal catalysis indisputably had an immense impact on basic research in academia and chemical industries, thus in turn having an effect on modern society and our daily life. That is wellrecognized through several awarded Nobel Prizes during the twentieth century, stretching from Nobel Prize (2020) for the synthesis of ammonia to Richard Suzuki, Heck, and Negishi, who shared the 2010 the prize for their outstanding endeavors and achievements in transition metal-catalyzed cross-coupling reactions (Johansson Seechurn et al., 2012). Although the aforementioned reactions are considered as the most important transition-metal catalyses, a plethora of vital reactions can be effectively catalyzed by various transition metals including reductive elimination, oxidative addition, and transmetallation. Transition metal catalysis has also found extensive applications in the convenient and efficient synthesis of a wide variety of heterocyclic systems (Ma et al., 2017; Ramanathan and Liu, 2017; Tiwari and Bhanage, 2017; Chatterjee et al., 2018; Saikia et al., 2018; Chen et al., 2020; Debabrata et al., 2020; Ghosh et al., 2020; Janardhanan et al., 2020; Jiang et al., 2020; Kanwal et al., 2020; Kojima and Matsunaga, 2020; Li and Zhang, 2020; Nagata and Obora, 2020; Neto and Zeni, 2020a,b; Pal et al., 2020; Ratmanova et al., 2020; Sahiba and Agarwal, 2020; Sonawane et al., 2020; Xuan et al., 2020). However, the literature survey revealed only an example of zinc (Shi et al., 2004), a limited number of iron-catalyzed (Melvin et al., 1992; Valderrama et al., 1999; Kanth et al., 2006; Yin et al., 2012; Gopalaiah et al., 2017, 2019; Raut and Bhanage, 2017; Eidi et al., 2018), and relatively more copper-catalyzed reactions, leading to the synthesis of quinazoline and quinazolinone derivatives (Melvin et al., 1992; Chatterjee et al., 2018; Potuganti et al., 2018; Liang et al., 2019; Rodrigues et al., 2019; Donthiboina et al., 2020). The number of zinc, iron, and copper-catalyzed synthesis of quinazoline and quinazolinone derivatives were decreased when the literature survey was narrowed down to the choice of those reactions, performed specifically under MWI as an unconventional and environmentally benign source of energy, in accordance with the title of this review.

In this regard, the 2-nitro- and 2-azido substituted benzoic acid derivatives have been employed as substrates for the synthesis of quinazolinones. A simple, efficient, and mild method for the synthesis of $(3 H)$-quinazolinone (109) under solvent-free conditions based on the MW-mediated reduction

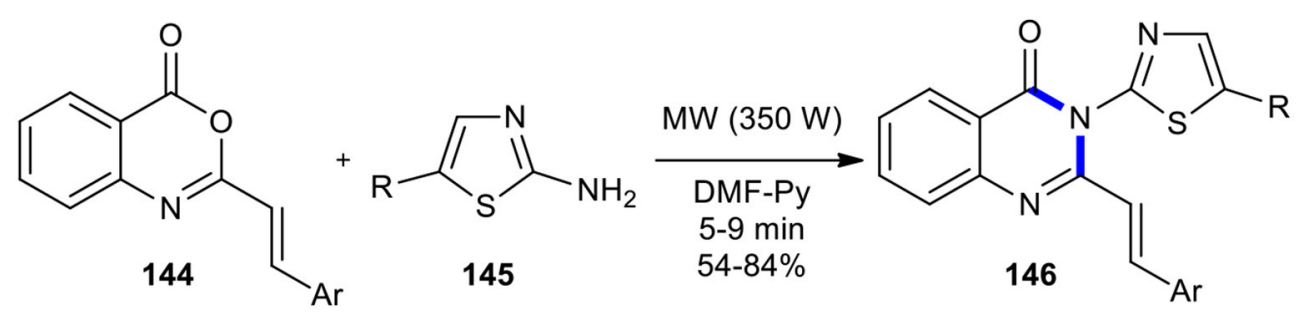

SCHEME 59 | MW-assisted synthesis of $\mathbf{1 4 6}$ from 144 and 145

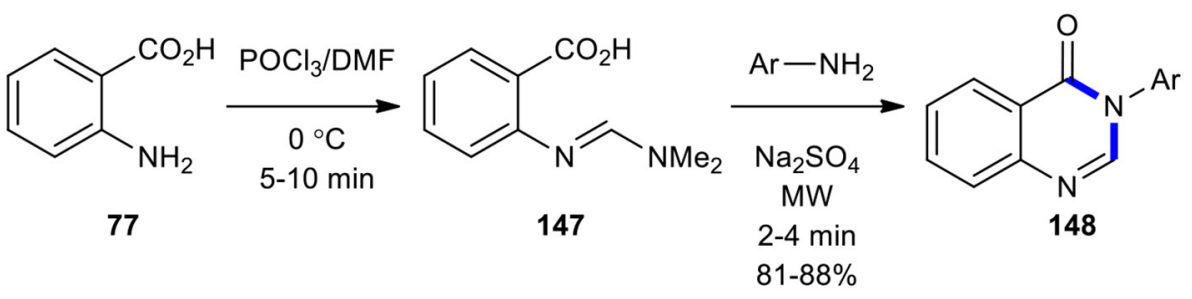

SCHEME 60 | MW-assisted synthesis of $\mathbf{1 4 8}$ from 147 and anilines.<smiles>CC(=O)Nc1ccccc1C(=O)O</smiles>

$55 a$<smiles>NC(=O)C(N)c1ccccc1</smiles>

$56 a$

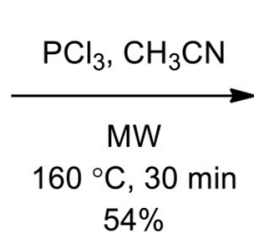

$54 \%$<smiles>Cc1nc2ccccc2c(=O)n1C(C#N)c1ccccc1</smiles>

149

SCHEME 61 | MW-assisted synthesis of 149 from 55 a and $56 \mathbf{a}$ using $\mathrm{PCl}_{3}$. 
of nitro and azido arenes to $\mathrm{N}$-arylformamides using $\mathrm{Zn}$ and ammonium formate $\left(\mathrm{Zn}-\mathrm{HCO}_{2} \mathrm{NH}_{4}\right)$ was developed by Kamal et al. (2004). To produce $(3 H)$-quinazolinone 109, the 2substituted azido- or nitrobenzoic acids $\mathbf{1 0 8}$ were transformed into their corresponding $\mathrm{N}$-arylformamides 109 by employing $\mathrm{Zn}-\mathrm{HCO}_{2} \mathrm{NH}_{4}$ under $\mathrm{MWI}$ at $300 \mathrm{~W}$ (Scheme 41). In this reaction, $\mathrm{Zn}$ acted as an efficient and inexpensive catalyst, while $\mathrm{HCO}_{2} \mathrm{NH}_{4}$ was decomposed to formamide, which in the

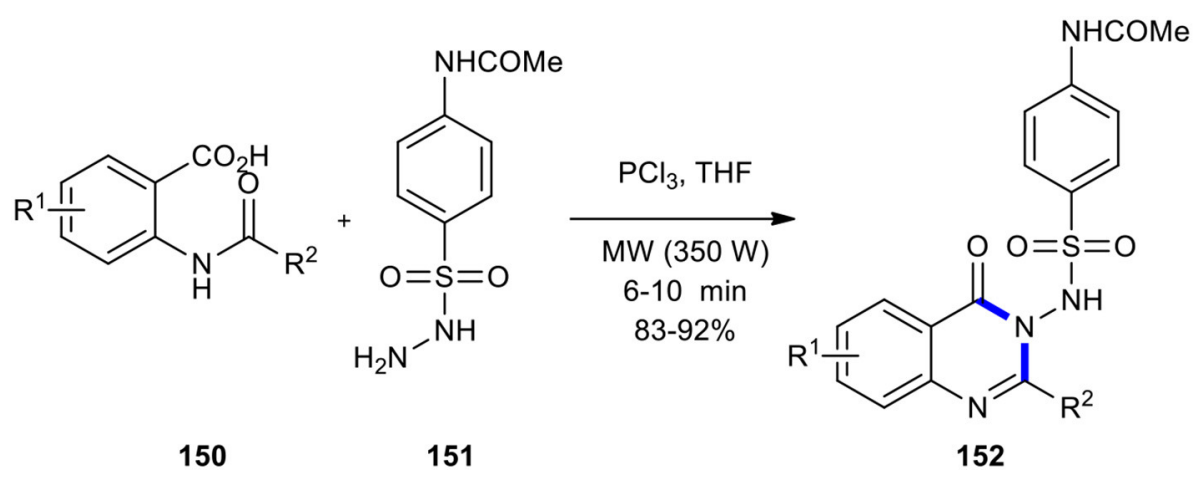

SCHEME 62 | MW-assisted synthesis of 152 from 150 and 151 using $\mathrm{PCl}_{3}$.<smiles>Cc1ccccc1NC(=O)CCl</smiles><smiles>COc1ccccc1-n1c(Cn2cnc3c(N)ncnc32)nc2cccc(C)c2c1=O</smiles>

SCHEME 63 | MW-assisted synthesis of $\mathbf{1 5 5}$ and further transformation into $\mathbf{1 5 6}$ and 157.
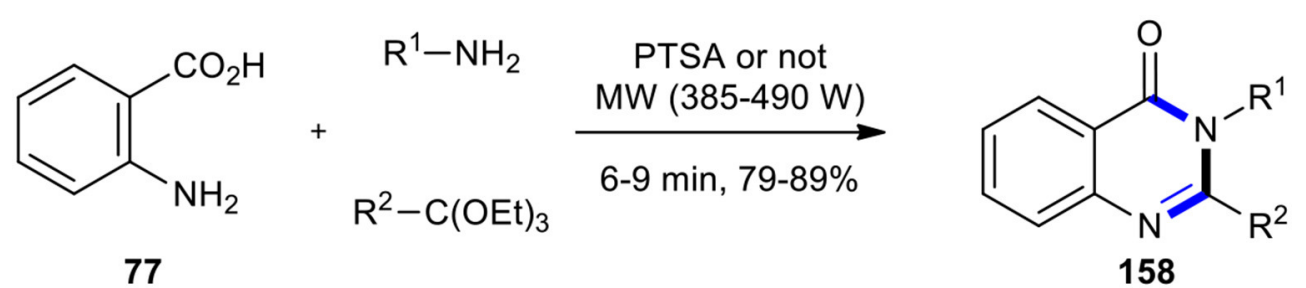

SCHEME 64 | MW-assisted MCR of 77, amine, and ortho-esters using PTSA to produce 158. 
following was condensed with the anthranilic acid. It is important to note that the reaction in the absence of MWI afforded amines instead of arylformamides.

As described above, apart from palladium and other transition metals, copper and iron species are catalysts of choice in the synthetic community. In general, they are advantageous, expedient, cost-effective, and relatively less toxic. Thus, iron (Correa et al., 2008; Li et al., 2013; Ghorai et al., 2017) and copper-catalyzed (Monnier and Taillefer, 2013) organic transformations have recently received enormous attention from synthetic organic research groups; they especially are the catalysts of choice for organic transformations requiring, $\mathrm{C}-\mathrm{N}$ bond formation. In this regard, in recent years, applications of copper and iron-catalyzed transformations have overgrown and still are developing. They have been used in the synthesis of a wide variety of heterocyclic systems, especially $N$-heterocycles. In this regard, they have been used as effective catalysts in the synthesis of quinazoline and quinazolinone derivatives under different reaction conditions, involving conventional heating or green sources of energy such as ultrasound or MWI.

The reaction of 2-halobenzoic acids and ammonia as a source of nitrogen catalyzed either iron or copper in the presence of a base such as $\mathrm{Cs}_{2} \mathrm{CO}_{3}$ and $\mathrm{NaOH}$ leads to the construction of quinazolinones (Zhang et al., 2009; Ke et al., 2018; Radhakrishnan et al., 2018). However, in these reactions, stoichiometric amounts of bases were often necessary, and in some cases using ligands was also essential (Ley and Thomas, 2003; Corbet and Mignani, 2006). Since the scope of this review is limited to underlining the synthesis of quinazolinone and quinazolinone derivatives, successfully performed under MWI as a green source of energy (Zhou et al., 2008; Liu et al., 2009; Zhang et al., 2009; Xu and Fu, 2011, 2012; Xu et al., 2011; Sreenivas et al., 2012), in the following we try to describe the synthesis of the above-mentioned heterocycles being successfully conducted in the presence of either Fe or Cu species under MWI.

The 2-halobenzoic acids have been employed as substrates for transition metal-mediated cross-coupling and cyclization with urea derivatives to synthesize the 2-substituted quinazolinones in a single-pot operation. For example, Zhang et al. performed the reaction of substituted 2 -halobenzoic acids 110 with amidines 111 in the presence of a $\mathrm{Fe}$ species, ligand, and base in a suitable solvent using MW heating to obtain quinazolinone derivatives 112 (Scheme 42) (Zhang et al., 2009). Worth noting is that the above reaction was conducted diversely with or without ligand in water or DMF, which afforded the respective products in moderate to high yields. As expected, 2-iodobenzoic acids were more reactive than 2-bromobenzoic acids and 2chlorobenzoic acids. The features of this method included being green, rapid, highly efficient, versatile, inexpensive, and environmentally friendly, especially when water as a solvent is used.

Copper continues to be one of the most employed and popular transition metal catalysts in synthetic organic chemistry. Furthermore, to its economic and environmental benefit over other transition metal catalysts, it is also abundant. Thus, nowadays, copper catalysis has attracted enormous attention from synthetic organic chemists. Several review articles collected and described the recent progress made in pleasing and exceptional copper catalysis in all areas of synthetic transformations (Monnier and Taillefer, 2013; Guo et al., 2015; Thapa et al., 2015; Tandon, 2019; Ghiazza and Tlili, 2020). Copper-based catalysts are also extensively employed in different chemical industries (Punniyamurthy and Rout, 2008). In this line, $\mathrm{Ke}$ et al. used copper as a catalyst instead of iron in the reaction of 2-halobenzoic acids with amidines (Ke et al., 2018). The synthesis of 37 examples of quinazolinones 115 was achieved in good to excellent yields (up to 94\%) in 20 min when the

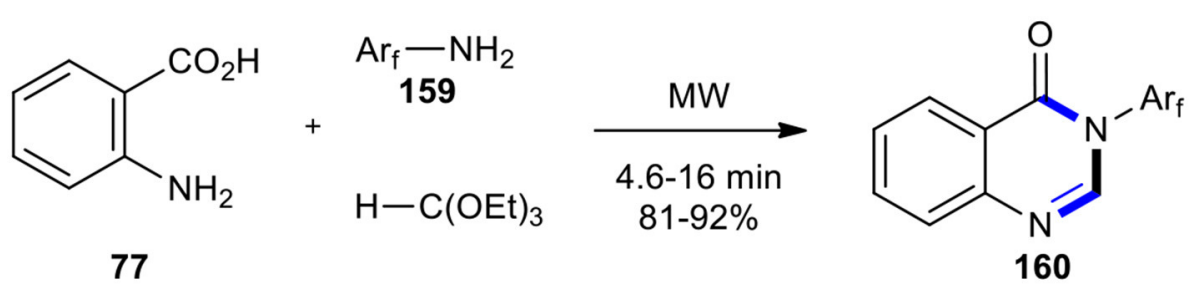

SCHEME 65 | MW-assisted MCR of 77, 159, and triethoxymethane to create $\mathbf{1 6 0 .}$

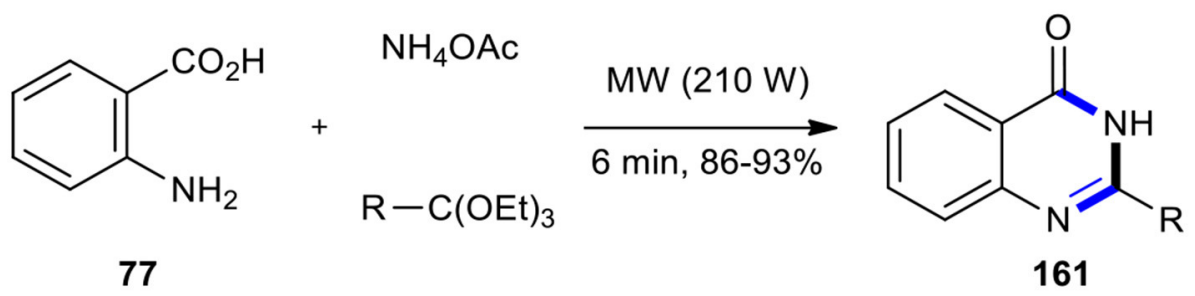

SCHEME 66 | MW-assisted MCR of 77, ammonium acetate, and ortho-esters to synthesize 161. 
substituted 2-halobenzoic acids $\mathbf{1 1 3}$ were coupled with amidines 114 in the presence of $\mathrm{CuCl}_{2}$, ligand, and $\mathrm{NaOH}$ in water under MWI at $120 \mathrm{~W}$ at room temperature (Scheme 43). The remarkable features of this strategy were using an inexpensive and commercially available and environmentally benign copper catalyst, activation at low temperatures, and there being no need for an inert atmosphere. Worth noting is that the relative reactivity of 2-halobenzoic acids was similar to that of Zhang's method, using iron species as catalyst (Zhang et al., 2009).

In the following, $\mathrm{Cu}$-catalyzed one-pot coupling and cyclization leading to the construction of $N$-heterocycles was studied (Radhakrishnan et al., 2018). The reaction of 2-halobenzoic acids 116 with guanidine hydrochloride (117) using MWI resulted in the formation of 2-aminoquinazoline analogs 118 (Scheme 44). The target products 118 were obtained in one-pot with high yield without the need of any additional ligand. $\mathrm{Cu}_{2} \mathrm{O}$ and $\mathrm{Cs}_{2} \mathrm{CO}_{3}$ proved to the best catalyst and base, respectively, for the $\mathrm{MW}$-assisted $\mathrm{Cu}(\mathrm{I})$-catalyzed reaction to form $\mathrm{C}-\mathrm{N}$ bond. The advantages of $\mathrm{C}-\mathrm{N}$ bond formation strategy are the same as described for Ke's method (Ke et al., 2018); there was also no need for any ligand.

\section{Cyclocondensation Using Different Methods}

MWI has been employed to promote cyclocondensation of various nitrogen-containing precursors with orthoesters, aldehydes, carboxylic acids, TEAF, benzyl alcohols, amines, thioamides, isothiocyanates, and potassium isopropyldithiocarbonate, as described below.

\section{Ortho-esters}

Ortho-esters have been condensed with 2-carbonyl substituted aniline derivatives under MW conditions to create variously substituted quinazolinones and their heterocycle-appended hybrids. Hazarkhani and Karimi synthesized a variety of new 3 (2-benzimidazolyl)-2-alkyl-4-(3H)-quinazolinones 120 in good to high yields in a facile and rapid manner through the reaction of 2-amino- $\mathrm{N}$-(1-H-benzimidazol-2-yl)benzamide (119) with a set of ortho-esters under MWI $(600 \mathrm{~W})$ in the presence of $p$ toluenesulphonic acid ( $p$-TsOH or PTSA) in DMAC (Scheme 45) (Hazarkhani and Karimi, 2003).

Numerous methods for the construction of the quinazolinone skeleton based on the cyclocondensation of 2-aminobenzamides with orto-esters using MWI have been reported in the literature. A variety of conditions in the absence of a solvent to the quinazolinone skeleton have been used. These make use of solid catalyst systems such as $\left(\mathrm{SiO}_{2} / \mathrm{H}_{2} \mathrm{SO}_{4}\right)$ (Montazeri and Rad-Moghadam, 2004), montmorillonite K-10 (Dabiri et al., 2004b), $\mathrm{AlCl}_{3} / \mathrm{ZnCl}_{2}-\mathrm{SiO}_{2}$ (Dabiri et al., 2005), and HY-zeolite (Bakavoli et al., 2007; Montazeri et al., 2012a), as well as organocatalysts, including pentafluorophenylammonium triflate (PFPAT) (Montazeri et al., 2012b).

\section{Aldehydes}

Anthraniamide derivatives have also been condensed with various aldehydes under MW conditions to afford quinazolinones. The highly accelerated Niementowski synthesis of quinazolin-4(3H)-one using $\mathrm{MW}$ heating protocol as a key step was successfully applied for the construction of an important and key anticancer drug, Iressa (123) (Li et al., 2007). The 6,7-disubstituted quinazolin-4(3H)-one 122 was prepared in an $87 \%$ isolated yield from a 5-benzyloxy-4-methoxy-2aminobenzamide (121) and formamide under the acidic catalytic amount of acetic acid by MWI at $300 \mathrm{~W}$ for $5 \mathrm{~min}$, termed as the Niementowski synthesis. After several steps, the key intermediate $\mathbf{1 2 2}$ was converted into Iressa (123) as a pale yellow solid (Scheme 46). This method could improve the reaction conditions from $5 \mathrm{~h}$ of heating at $190^{\circ} \mathrm{C}$ to $5 \mathrm{~min}$ using MWI.
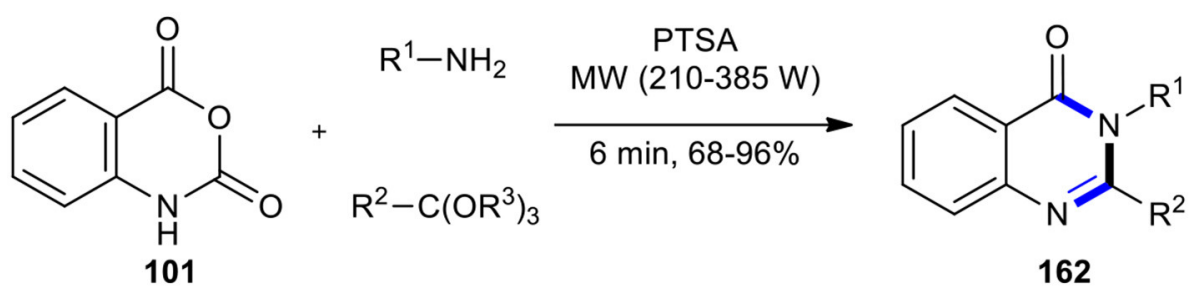

SCHEME 67 | MW-assisted MCR of 101, amines, and ortho-esters using PTSA to afford 162.

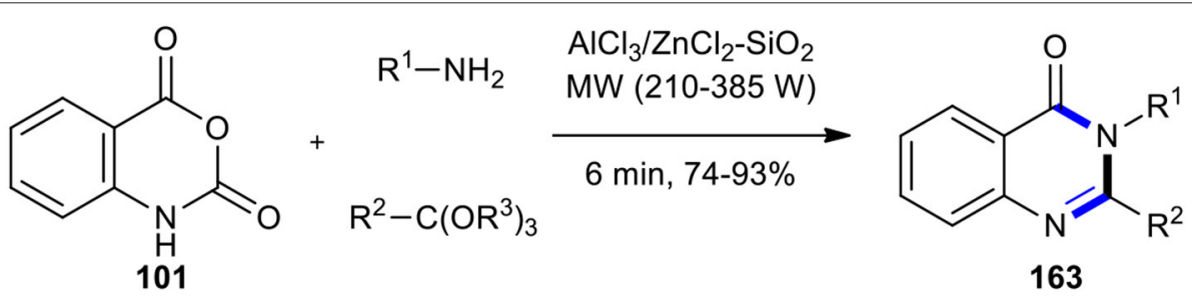

SCHEME 68 | MW-assisted MCR of 101, amines, and ortho-esters using $\mathrm{AlCl}_{3} / \mathrm{ZnCl}_{2}-\mathrm{SiO}_{2}$. 
The condensation of anthranilamide (106) with different aromatic aldehydes in the presence of PTSA in polyethylene glycol (PEG-200/400) as a green solvent without the use of an oxidant under $\mathrm{MW}$ conditions $(560 \mathrm{~W}$ in a domestic microwave oven) for 5-10 min afforded the corresponding 2-aryl- or 2-hetaryl-4(3H)-quinazolinones $\mathbf{1 2 4}$ in good to excellent yields with high purity (Scheme 47) (Deligeorgiev et al., 2010). This method provided several benefits, including novel environmentally friendly conditions, having a simple work-up procedure, carrying out the reactions in very short times, and isolating products only by filtration.

Recently, Kang et al. reported the MW-assisted synthesis of quinazolin-4(3H)-one derivatives 125 within several minutes under solvent-free and mild conditions (Kang et al., 2018). The products could be obtained in good to excellent yields when anthranilamide (106) was condensed with various aldehydes in the presence of a catalytic amount of commercially available antimony (III) trichloride $\left(\mathrm{SbCl}_{3}\right)$ (Scheme 48).

\section{Carboxylic Acids}

Carboxylic acids have also been employed as reactants with 2-substituted anilines to afford quinazolino-4-one derivatives. $\mathrm{MW}$-assisted cyclocondensation of 2-aminobenzamide (106) with carboxylic acids was achieved in 3-5 min under solventfree conditions to afford a series of 2-substituted quinazolin4(3H)-ones 126 as represented in Scheme 49 (Rahimizadeh et al., 2004). This transformation was 40-80 times faster than under conventional heating methods and obtained products in higher yields.

The acid-catalyzed cyclization with formic acid was used to synthesize the $3 \mathrm{H}$-quinazolin-4-one (109) by the employment of MWI (Saari et al., 2011). The product 109 was obtained in a $64 \%$ yield from the reaction of 2-cyanoaniline (46) with formic acid and sulfuric acid under MWI at $100^{\circ} \mathrm{C}$ for $5 \mathrm{~min}$ (Scheme 50).

\section{TEAF}

Triethylamine-formic acid mixture (TEAF) has been used as a substrate for transition metal-catalyzed transfer hydrogenation and condensation with $o$-nitrobenzamides to produce the quinazolinones in a single-pot operation. For example, a highly efficient one-pot method for the synthesis of quinazolin4(3H)-one derivatives $\mathbf{1 2 8}$ was developed using the Pdcatalyzed transfer hydrogenation $(\mathrm{CTH}) /$ condensation cascade of $o$-nitrobenzamides 127 and azeotropic TEAF under MWI at $150^{\circ} \mathrm{C}$ for $8 \mathrm{~min}$ (Scheme 51) (Zhu et al., 2015). In this reaction, TEAF played a dual role as a good hydrogen source for the CTH reduction and as a source of mono-carbon for the subsequent cyclocondensation.

\section{Benzyl Alcohols}

Benzyl alcohols have also been condensed with $o$-aminobenzamide derivatives under MW conditions to afford quinazolinones. A new water-assisted strategy to quinazolinones 130 was developed through the reaction of $o$-aminobenzamides (106) with benzyl alcohols 129 using sodium chloride as a salting-out agent and tert-butyl hydroperoxide (TBHP) as an oxidant under metal-, ligand-, base-free and MW conditions (Scheme 52) (Dandia et al., 2018). The production of 130 was examined under MWI and conventional heating conditions. The superior salting-out effect of sodium chloride was observed when the reaction was performed under MW conditions, compared to the conventional method. Among varying MWI power (300, 400 , and $500 \mathrm{~W}$ ) and temperatures, the $400 \mathrm{~W}$ power at $80^{\circ} \mathrm{C}$ gave the best result to carry out the maximum conversion to the expected product.

\section{Thioamides, Isothiocyanates, and Potassium Isopropyldithiocarbonate}

Thioamides, isothiocyanates, and potassium isopropyldithiocarbonate have also been employed as reactants to effect cyclocondensation of anthranilamide derivatives to afford quinazolinones. Khajavi et al. previously employed the thioamides for the highly accelerated Niementowski reaction under MWI (Khajavi et al., 1998). They condensed anthranilic acid (106) with thioamides (thiobenzamide or thioacetamide) 131 in DMAC using a house-hold unmodified microwave oven to generate 2-substituted-4-(3H)-quinazolinones 132. The latter were obtained through a simple work-up procedure (Scheme 53). The conventionally thermalized approach for this reaction needed longer reaction times and resulted in the formation of 132 in lower yields.

Tavallaii et al. previously reacted 2-aminobenzamide (106) with isothiocyanates (or isocyanates) 133 to access 2-(alkylamino) and 2-(arylamino)-4(3H) quinazolinones 134 (Tavalaie et al., 2007). The production of target molecules 134 was completed in high yields (78-98\%) by applying MWI under solvent-free conditions, providing the best yields in a faster time in comparison to the conventional heating methods (Scheme 54).

Kumar and Dubey in 2012 described a protocol which provided the safe, simple, rapid, inexpensive, and environmentally friendly process to 2-mercapto-quinazolinone

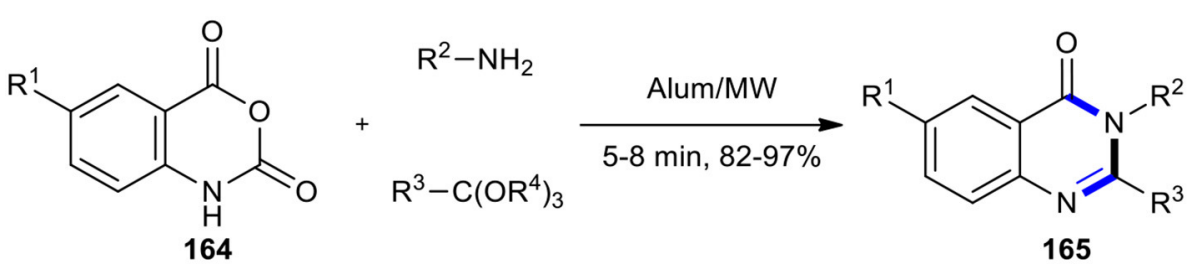

SCHEME 69 | MW-assisted MCR of 164, amines, and ortho-esters using Alum to afford 165 
(136) via the treatment of anthranilamide (106) as a bifunctional molecule with potassium isopropyldithiocarbonate (135) in a minimum quantity of DMF as solvent under MWI (Scheme 55) (Kumar and Dubey, 2012). While the reaction took 5 hours under reflux conditions, it lasted 5 min under MWI. Owing to high stability at higher temperatures and staying at room temperature for months, isopropyldithiocarbonate was used as a stable reagent in this method. These reaction conditions could also be applied to the transformation of various 1,2-bifunctional molecules to afford mercapto derivatives of benzimidazoles, benzothiazole and benzoxazole, and oxadiazoles.

\section{Aliphatic and Aromatic Amines}

Benzoxazinones and their open-chain derivatives have also been employed as substrates for the synthesis of quinazolinones under MW conditions. For example, Khajavi et al. reported an efficient and practical synthesis of a number of variously substituted 4(3H)-quinazolinones 138 (Khajavi et al., 1999b). This transformation included the MWI in the combination of benzoxazinones 137 with amines in DMAC, enabling efficient access to this important class of heterocycles (Scheme 56). The MW-assisted chemistry provided increased product yields and shortened reaction times.

2,3-Disubstituted 3H-quinazolin-4-ones 140 with a broad chemistry scope were synthesized by Liu's research group by employing MWI on benzoxazinones $\mathbf{1 3 9}$ with amines (Liu et al., 2005b). Benzoxazinones 139 prepared by the condensation of anthranilic acids and either acyl chlorides or carboxylic acids using $\mathrm{P}(\mathrm{PhO})_{3}$ were, in turn, condensed with amines to provide the transient amidine salt species (I). This intermediate rapidly cyclized under the optimized MW conditions at $250^{\circ} \mathrm{C}$ in 3$10 \mathrm{~min}$, yielding the expected 2,3-disubstituted $3 \mathrm{H}$-quinazolin-4ones 140 (Scheme 57).
Laddha and Bhatnagar employed the MW-accelerated solution-phase method to 6,8-disubstituted 2-phenyl-3(benzothiazol-2-yl)-4-[3H]-quinazolinones 143, bearing various substituents on the benzothiazole ring (Laddha and Bhatnagar, 2008). The synthesis involved the cyclocondensation of 2-phenyl-4H-benzo[ $d][1,3]$ oxazine-4-ones $\mathbf{1 4 1}$ with 2aminobenzothiazoles $\mathbf{1 4 2}$ in dry pyridine under MWI at $210 \mathrm{~W}$ and reflux temperature (Scheme 58). This procedure proceeded very cleanly and formed products in a fast and easy work-up procedure without any traces of side products, presenting the advantage of a high rate and better yields than the conventional procedure.

Various 2-styryl benzoxazinone derivatives 144 were utilized with 2-aminothiazoles 145 using pyridine-DMF as a co-solvent under MWI in the synthesis of newer 3-thiazole substituted 2-styryl-4(3H)-quinazolinones 146 (Jagani et al., 2012). The products 146 were obtained in good yields within an appropriate time of MWI at $350 \mathrm{~W}$ (Scheme 59). It is interesting to know that the reaction either in pyridine as a solvent proceeded sluggishly or in DMF reduced yields.

Priya et al. prepared compound 147 by the reaction of anthranilic acid (77) with Vilsmeier reagent $\left(\mathrm{DMF} / \mathrm{POCl}_{3}\right)$ (Heravi et al., 2018). They then reacted 147 with differently substituted anilines under MW for 2-4 min to synthesize 4-(3H)quinazolinone derivatives 148 in good yields (Scheme 60) (Priya et al., 2011). The use of MWI in this reaction shows its value in providing increased yields in short reaction times.

In 1946, Grimmel's research group reported the synthesis of quinazolinones through the treatment of $\mathrm{N}$-acetylanthranilic acids with aromatic amines using the condensing agents including $\mathrm{POCl}_{3}$, phosphorus trichloride $\left(\mathrm{PCl}_{3}\right)$, or thionyl chloride $\left(\mathrm{SOCl}_{2}\right)$ in toluene or xylene (Grimmel et al., 1946). This method has been frequently used to synthesize a wide

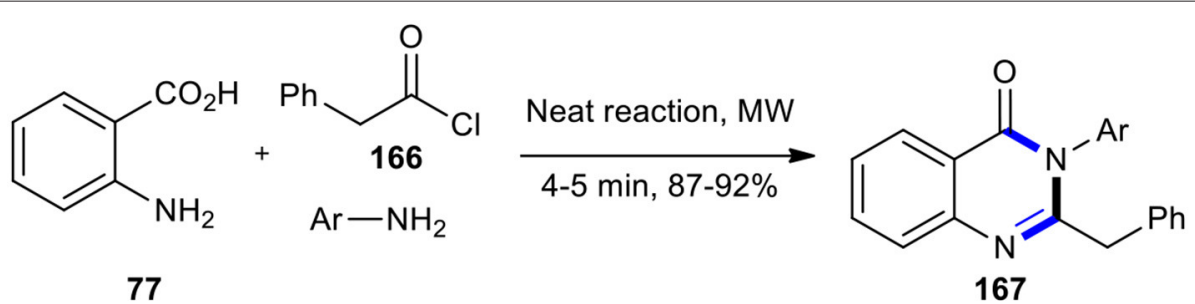

SCHEME 70 | MW-assisted MCR of 77, 166, and anilines to afford 167.

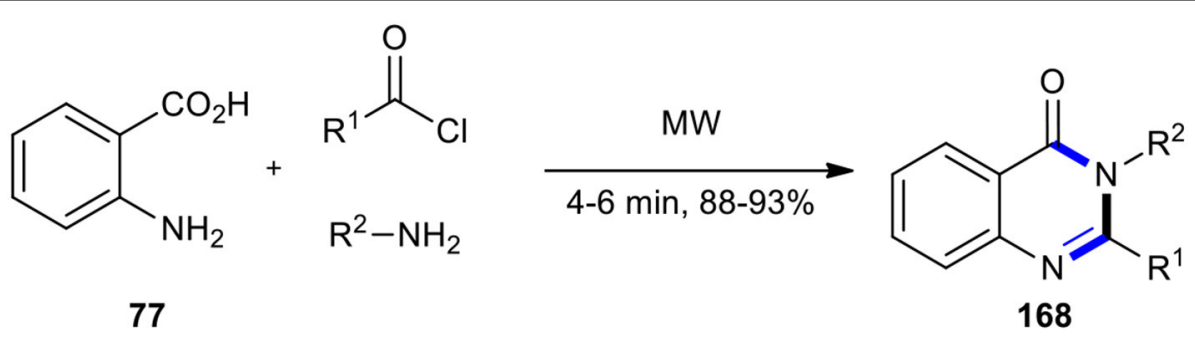

SCHEME $\mathbf{7 1}$ | MW-assisted MCR of $\mathbf{7 7}$, acyl chlorides, and amines to afford $\mathbf{1 6 8 .}$ 
range of quinazolinone derivatives (Wolfe et al., 1990; van Zyl, 2001; Bhatti and Seshadri, 2004; Storelli et al., 2005; Giri et al., 2009). In 2009, MWI was used to synthesize 2-(2-methyl4-oxoquinazolin-3(4H)-yl)-2-phenylacetonitrile (149) (Li et al., 2009). When $N$-acetylanthranilic acid (55a) was reacted with the amino group of 2-amino-2-phenylacetamide (56a) using $\mathrm{PCl}_{3}$ as a condensing reagent in acetonitrile under MWI at $160^{\circ} \mathrm{C}$ for $30 \mathrm{~min}$, quinazolinone was formed with concomitant carboxamide dehydration to give 2-(2-methyl-4-oxoquinazolin$3(4 H)$-yl)-2-phenylacetonitrile (149) in a 54\% yield (Scheme 61).

Jagani et al. (2011) optimized Grimmel's method (Grimmel et al., 1946) using MWI to construct $\mathrm{N}$-(4( $N$-(4-oxo-2-methyl/aryl-substituted quinazolin-3(4H)yl)sulfamoyl)phenyl)acetamides 152, allowing the improvement of rate and yields. The quinazolinone products 152 were synthesized by the reaction between $N$-acetylanthranilic acids 150 and 4-acetamidobenzenesulfonyl hydrazide (151) in the presence of an amount of $\mathrm{PCl}_{3}$ in THF as a solvent under MW conditions (350 W) (Scheme 62).

A protocol that involved an environmentally friendly MW-assisted cyclization reaction to construct 2-(chloromethyl)5-methyl-3-(o-tolyl)quinazolin-4(3H)-one (155) toward the medicinally important purine quinazolinone scaffold was devised and presented (Sawant et al., 2012). The reaction of compound 153 with 2-methyl aniline (154) and $\mathrm{PCl}_{3}$ as a cyclizing agent under $\mathrm{MW}$ conditions $(350 \mathrm{~W})$ at $50^{\circ} \mathrm{C}$ for $3 \mathrm{~min}$ yielded 2-(chloromethyl)-5-methyl-3-o-tolylquinazolin-4(3H)one (155) in excellent yield (>95\%). Compound 155 without purification was subjected to a coupling reaction with adenine to give the expected molecules 156 and 157 (Scheme 63).

\section{Three-Component Reaction}

MCR, as one of the most straightforward strategies, has been extensively employed under MWI for the synthesis
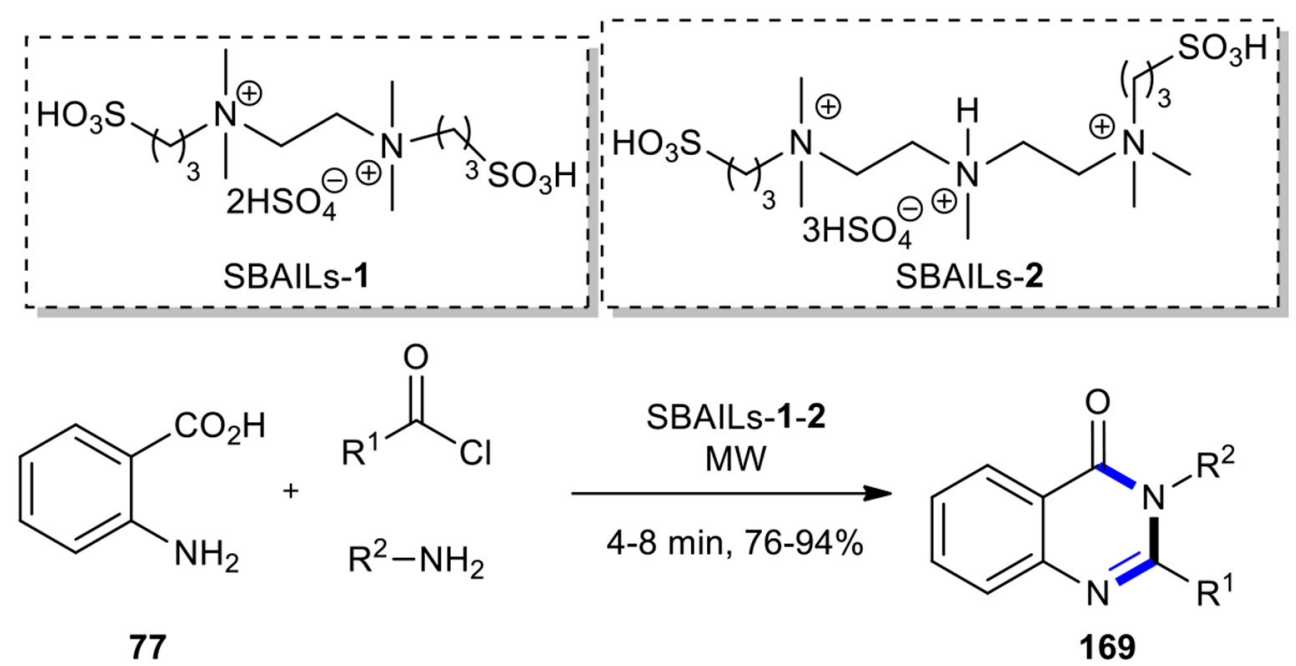

SCHEME 72 | MW-assisted MCR of $\mathbf{7 7}$, acyl chlorides, and amines using SBAlLs-1 and 2.

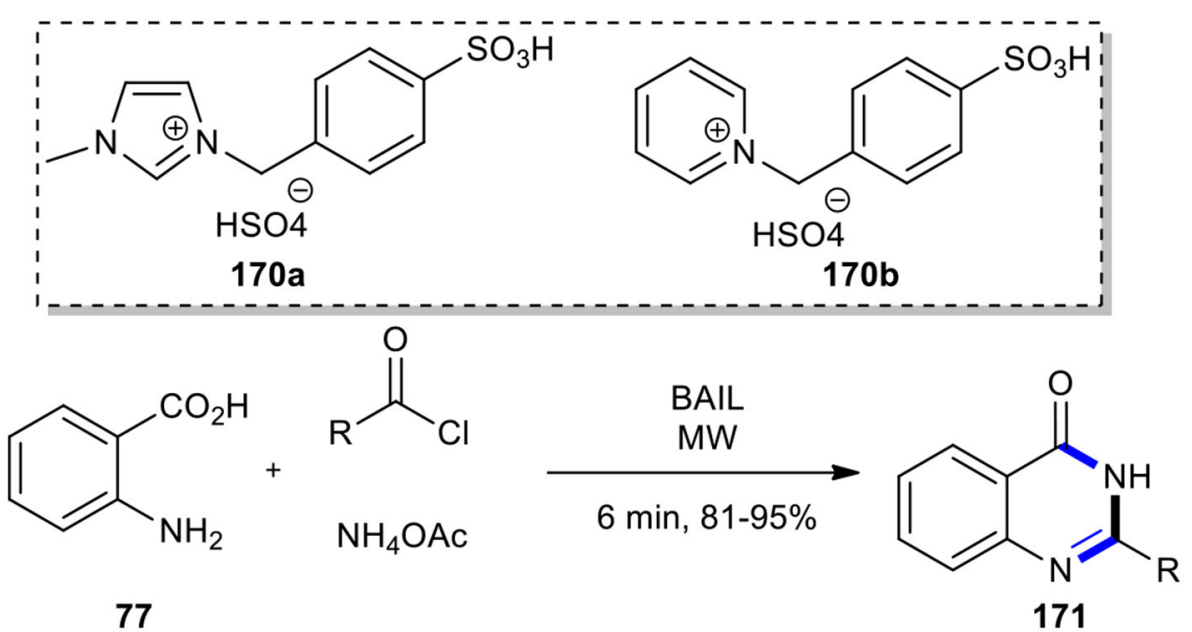

SCHEME 73 | MW-assisted MCR of 77, acyl chlorides, and $\mathrm{NH}_{4} \mathrm{OAc}$ using BAIL to afford $\mathbf{1 7 1}$. 
of quinazolinone derivatives. For example, the preparation of substituted quinazolin-4(3H)-one derivatives $\mathbf{1 5 8}$ by the one-pot three-component cyclocondensation of anthranilic acid (77) with an amine and formic acid (or ortho-esters) under MWI was reported by Rad-Moghadam and Khajavi (Scheme 64) (Rad-Moghadam and Khajavi, 1998). Formic acid and amines were used in place of amides or amidines utilized in the Niementowski reaction, providing 3-substituted4(3H)quinazolinones 158 instead of the resulting 2-substituted derivative. The reaction was completed in a few minutes in the absence of solvent or any dehydrating agents. As a result, the reaction with ortho-esters required a catalytic amount of PTSA. The reaction occurred within a much reduced time under MWI with respect to the conventional heating procedure (Leiby, 1985).<smiles>[R]C1Nc2cc[n+](CC)c(CC)c2C(=O)O1</smiles>

172<smiles>[R19]CCC[R1]1ccc2nc([R])n([R])c(=O)c2c1</smiles>

173

SCHEME $\mathbf{7 4}$ | MW-assisted MCR of 172, carboxylic acids, and amines to afford $\mathbf{1 7 3 .}$

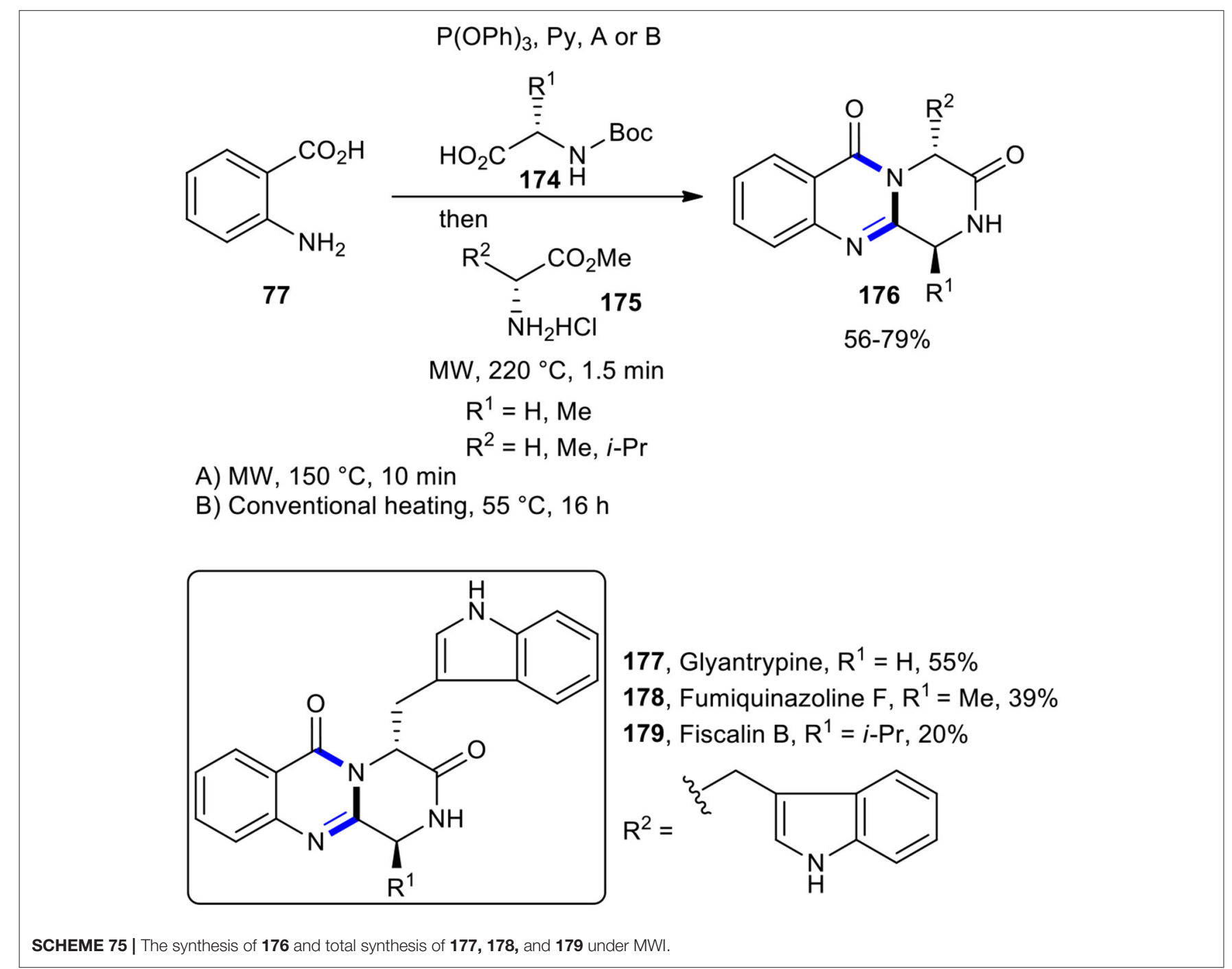


A modification of the above method, which is environmentally friendly, involved the synthesis of fluorine-containing $4(3 \mathrm{H})$ quinazolinones 160 using fluorinated anilines 159 in the absence of a solvent and catalysts (Scheme 65) (Wenli et al., 2011).

The demand for increasingly clean and efficient chemical synthesis of 4- $(3 H)$-quinazolinone from anthranilic acid, amines, and ortho-esters or formic acid under MW conditions paved the way for the use of $\mathrm{Yb}(\mathrm{OTf})_{3}$ (Wang et al., 2003), $\mathrm{NaHSO}_{4}{ }^{-}$ $\mathrm{SiO}_{2}$ (Das and Banerjee, 2004), silica gel/ $/ \mathrm{FeCl}_{3}$ (Chari et al., 2006), $\mathrm{La}\left(\mathrm{NO}_{3}\right)_{3}, \mathrm{Bi}(\mathrm{TFA})_{3}-[\mathrm{nbp}] \mathrm{FeCl}_{4}$ (Khosropour et al., 2006), Nafion-H (perfluorinated resin supported sulfonic acid) (Lingaiah et al., 2006), H-Y-zeolites (Bakavoli et al., 2007), Keggin-type heteropolyacids (HPAs) (Ighilahriz et al., 2008), and silica sulfuric acid (SSA) (Koroji et al., 2018) as solid supported catalysts and PTSA (Narasimhulu et al., 2006) and $\mathrm{SnCl}_{4}$ (Oskooie et al., 2007) as catalysts. It is noteworthy that the use of ammonium acetate as a source of amine in the condensation with anthranilic acid (77) and ortho-esters under MWI in the absence of a solvent yielded the corresponding 2-substituted quinazolin$4(3 H)$-ones 161 in a few minutes (Scheme 66) (Rad-Moghadam and Mohseni, 2003).

One of the methods for the synthesis of substituted (3H)-quinazolin-4-one derivatives involved a one-pot threecomponent condensation of isatoic anhydride (101) with amines and ortho-esters. In 2014, Dabiri et al. developed this method by employing MWI in the presence of PTSA as a catalyst, resulting in the formation of 2,3-disubstituted 4(3H)-quinazolinones 162 in good to excellent yields (Scheme 67) (Dabiri et al., 2004a). They also compared the resulting products synthesized under the two conditions of MW and classical heating, which indicated the superiority of MW conditions. The method offered several advantages including a cleaner reaction, short reaction times, a high yield of products, and an easy experimental work-up procedure.

Later, the application of the $\mathrm{AlCl}_{3} / \mathrm{ZnCl}_{2}-\mathrm{SiO}_{2}$ Lewis acid system instead of PTSA under both MWI and conventional heating methods was studied by the same group. Disubstituted $(3 \mathrm{H})$-quinazolin-4-ones $\mathbf{1 6 3}$ were synthesized in good yields under conventional conditions, although slightly higher yields were obtained under MWI (Scheme 68) (Dabiri et al., 2005). It should be noted that the work-up of products under both conditions was very easy since they were washed with hot ethanol and then filtrated and recrystallized.

$\mathrm{KAl}\left(\mathrm{SO}_{4}\right)_{2} \bullet 12 \mathrm{H}_{2} \mathrm{O}$ (Alum) is an inexpensive and nontoxic reagent which is very soluble in water and is also recyclable. Its ability as an effective catalyst was demonstrated in the MW-assisted synthesis of 2-alkyl and 2-aryl-4(3H)-quinazolinones. Twenty 2,3-disubstituted4(3H)-quinazolinones 165 were synthesized through a three-component reaction between isatoic anhydrides 164, ortho-esters, and amines (Scheme 69) (Mohammadi and Sadat Hossini, 2011). The high yield of products and simple

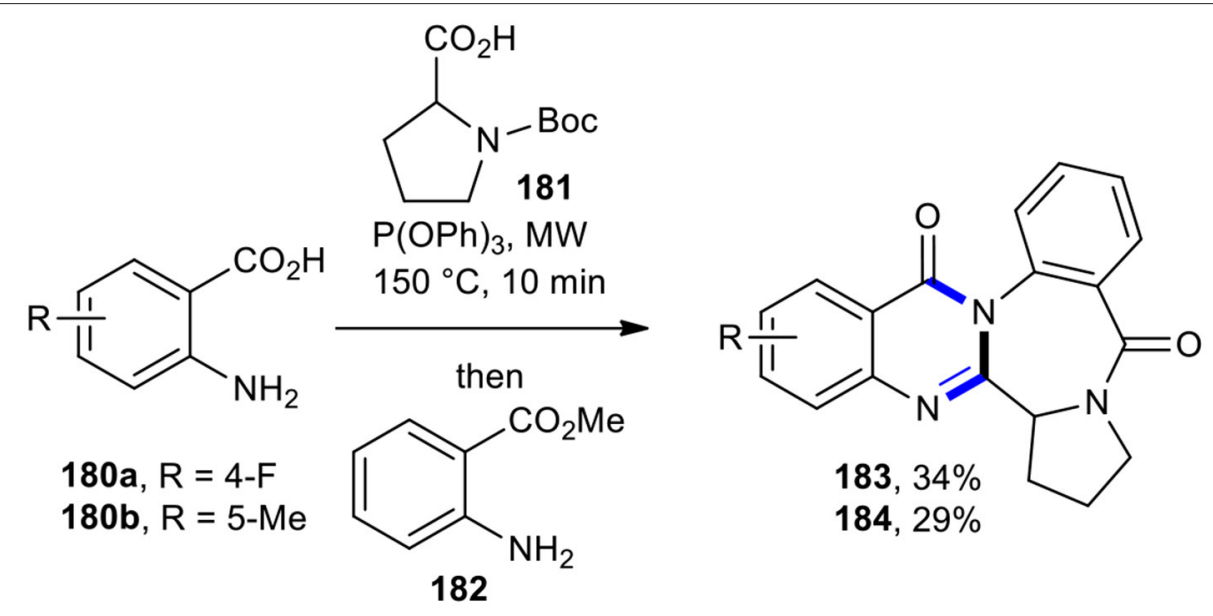

SCHEME 76 | MW-assisted synthesis of circumdatin E analogs 183 and 184.

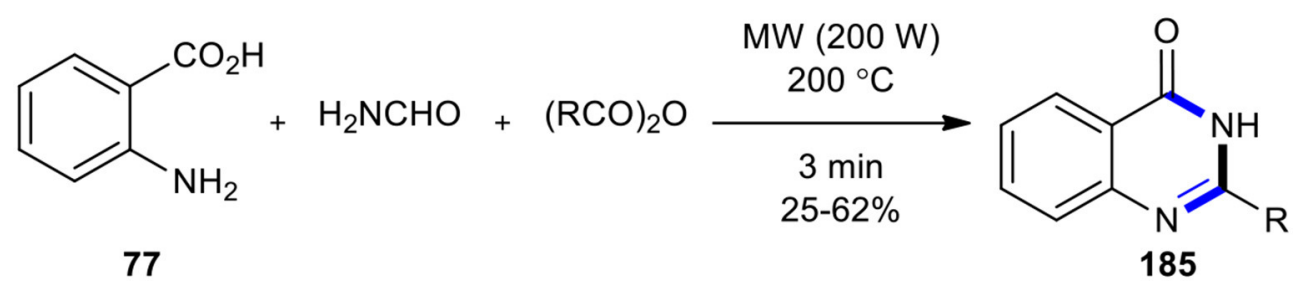

SCHEME 77 | MW-assisted MCR of 77, carboxylic anhydride, and formamide to afford 185. 

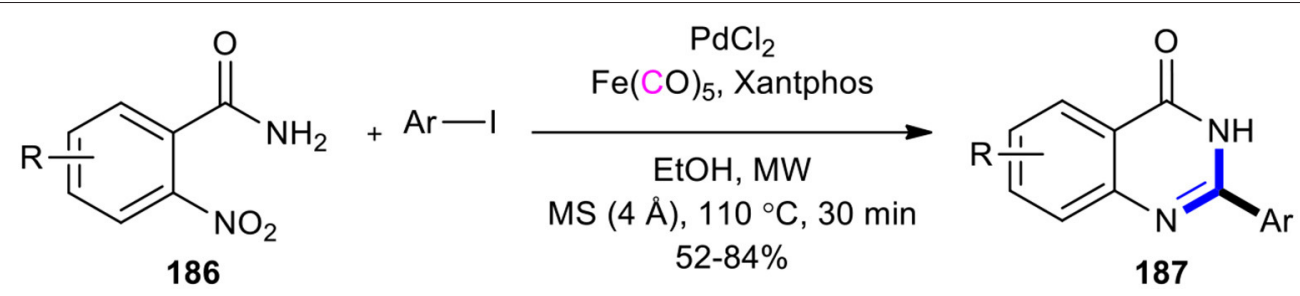

SCHEME 78 | MW-assisted iron pentacarbonyl mediated carbonylation of aryl iodides.

experimental work-up procedures are the salient features of this method.

The synthesis of fluorinated 2,3-disubstituted quinazolin4(3H)-ones 167 was reported by Dandia et al. by developing a "green chemistry procedure" using a neat one-pot threecomponent cyclocondensation under MW conditions (Dandia et al., 2004). Treatment of anthranilic acid (77) with phenyl acetyl chloride (166) and substituted anilines in the microwave oven at $640 \mathrm{~W}$ for 4-5 min without using any solvent, dehydrating agent, or support produced the target molecules 167 (Scheme 70). The MW chemistry in this reaction allowed significant rate enhancement and good to excellent yields, compared to the conventional procedure.

An approach that utilized anthranilic acid and formamide to the synthesis of quinazolin-4(3H)-one core was improved by using the neat MW-assisted three-component reaction of anthranilic acid (77), acyl chlorides, and amines (Dandia et al., 2005). The reaction was completed in a shorter time with a facile work-up procedure, making it a general protocol to produce the expected molecules $\mathbf{1 6 8}$ with a range of acid chlorides and amines. Using MWI at 640 watts, the reaction between anthranilic acid, acid chlorides, and amines furnished 2-benzyl-3aryl-quinazolin-4-[3H]-ones $\mathbf{1 6 8}$ in high yields and reduced the time (Scheme 71).

After a decade, the same procedure in the presence of two long-chain double $\mathrm{SO}_{3} \mathrm{H}$-functionalized acidic ionic liquids, SBAILs-1 and 2, as reusable catalysts, was reported (Scheme 72) (Li et al., 2015). Although the authors have expanded the production of 2,3-disubstituted 4(3H)-quinazolinone derivatives 169 , one product formed $\left(\mathrm{R}^{1}=\mathrm{Ph}, \mathrm{R}^{2}=4-\mathrm{Cl}-\mathrm{C}_{6} \mathrm{H}_{5}\right)$, which was produced from the previous method (Dandia et al., 2005), with a lesser yield (Li et al., 2015).

Two new Brønsted acidic ionic liquids, including 1-(4sulfonic)-benzyl-3-methylimidazolium hydrogen sulfate (170a) and $N$-(4-sulfonic)-benzyl-pyridium hydrogen sulfate (170b), were utilized as catalyst and reaction medium, respectively, to lead to the synthesis of 2-substituted-4(3H)-quinazolinones 171 in satisfactory yields ( $\mathrm{Li}$ et al., 2010). The reaction proceeded through a one-pot three-component reaction under MW conditions for $6 \mathrm{~min}$, starting from anthranilic acid (77), acyl chlorides, and ammonium acetate (Scheme 73).

Liu et al. developed a practical and efficient protocol that employed an MW-assisted one-pot three-component reaction for the synthesis of various 2,3-disubstituted $3 \mathrm{H}$-quinazolin-4ones 173, starting from anthranilic acids 172, carboxylic acids, and amines (Scheme 74) (Liu et al., 2005b). The use of MWassisted chemistry increased the product yields and shortened the reaction times.

This MW-assisted one-pot methodology could be adapted for the synthesis of 4-quinazoline-3,6-diones $\mathbf{1 7 6}$ and also for the total synthesis of a number of natural products containing core, accommodating an expanded array of carboxylic acids and amines (Liu et al., 2005c). Using selected Boc-amino acids and amino acid esters under MWI, total synthesis of the alkaloids glyantrypine (177), fumiquinazoline F (178), and fiscalin B (179) was accomplished in overall yields of 55,39 , and $20 \%$, respectively (Scheme 75).

Liu's research group synthesized circumdatin E analogs 183 and 184 by using MW-assisted one-pot three-component sequential reactions (Liu et al., 2005a). The subjection of anthranilic acids $180 \mathrm{a}$ and $180 \mathrm{~b}$ to MWI three-component reaction with $N$-Boc-proline $(\mathbf{1 8 1})$ using $\mathrm{P}(\mathrm{OPh})_{3}$ reagent in pyridine at $150^{\circ} \mathrm{C}$ in $10 \mathrm{~min}$, followed by the addition of methyl anthranilate (182) and further conditions (MW, $230^{\circ} \mathrm{C}, 15 \mathrm{~min}$ ), resulted in the formation of the expected compounds $\mathbf{1 8 3}$ and 184 as analogs of circumdatin E in 34 and 29\% yields, respectively (Scheme 76).

Wan et al. reported Pd-catalyzed aminocarbonylations of aryl halides by the employment of MW-accelerated decomposition of formamide to ammonia $\left(\mathrm{NH}_{3}\right)$ and carbon monoxide $(\mathrm{CO})$ (Wan et al., 2003). After a couple of years, Nouira et al. achieved this reaction by using $\mathrm{NH}_{3}$ as the sole synthon for introducing a nitrogen atom in a heterocyclic ring via MWassisted three-component reactions with anthranilic acid (77) and carboxylic anhydride, leading to the fast and safe synthesis of some quinazolin-4-one derivatives 185 (Scheme 77) (Nouira et al., 2008). Their work confirmed that the use of MWI may lead to different behaviors of reactants, depending on parameters such as power input, reached temperature, and pressure in the vials. Using modern MW technology, full control and fine-tuning of these parameters can be achieved.

Lin et al. discovered a rapid, direct, and practical method for the construction of a quinazolinone scaffold by using iron pentacarbonyl $\left(\mathrm{Fe}(\mathrm{CO})_{5}\right)$ as a reducing agent and $\mathrm{CO}$ source under MW and base-free conditions (Lin et al., 2017). The process involved the $\mathrm{Pd} / \mathrm{Fe}(\mathrm{CO})_{5}$-catalyzed reduction of $o$-nitrobenzamides to $o$-aminobenzamides, followed by reductive carbonylation of aryl iodides into amide intermediates and subsequent intramolecular ring closure. To access 2-substituted quinazolinones 187, various $o$-nitrobenzamides 186 and aryl 
iodides using various palladium catalysts, ligands, and solvents were employed. The best reaction conditions were found to use $\mathrm{Pd}(\mathrm{Cl})_{2}$ as a catalyst, xantphos as a ligand, and ethanol as a solvent at $110^{\circ} \mathrm{C}$ in $30 \mathrm{~min}$ under MWI in good yields (Scheme 78).

\section{CONCLUSIONS}

In this review, we highlighted the application of MWI in the synthesis of quinazolines and quinazolinones. Routes and strategies used here have opened a gateway to the wider applications of MW chemistry in both academia and industry. Several quinazoline and quinazolinone derivatives were provided with a broad substrate scope in a variety of MW systems, e.g. the domestic microwave oven. Many reactions were examined under both MW and conventional heating conditions in which the superiority of MW conditions was demonstrated. MWI acted as a powerful technique that could reduce the reaction times (more often a few minutes), enhance the yield of the products, increase the purity of the resulting product, and decrease the usage of organic solvents and by-products more than the conventional heating procedure. The salient features of MW reactions in these syntheses include environmental friendliness, more economic value, good atom economy, and simple experimental workup procedure. Due to previous features and the lack of a need for solvents, reagents, and ligands in many cases, MW technology was able to promote the principles of green chemistry. It should be noted that the reactions may occur under the

\section{REFERENCES}

Abramovitch, R. A. (1991). Applications of microwave energy in organic chemistry. A review. Org. Prep. Proced. Int. 23, 683-711. doi: 10.1080/00304949109458244

Alexandre, F.-R., Berecibar, A., and Besson, T. (2002). Microwave-assisted Niementowski reaction. Back to the roots. Tetrahedron Lett. 43, 3911-3913. doi: 10.1016/S0040-4039(02)00619-6

Alexandre, F.-R., Berecibar, A., Wrigglesworth, R., and Besson, T. (2003a). Efficient synthesis of thiazoloquinazolinone derivatives. Tetrahedron Lett. 44, 4455-4458. doi: 10.1016/S0040-4039(03)01026-8

Alexandre, F.-R., Berecibar, A., Wrigglesworth, R., and Besson, T. (2003b). Novel series of $8 \mathrm{H}$-quinazolino[4,3-b]quinazolin-8-ones via two Niementowski condensations. Tetrahedron 59, 1413-1419. doi: 10.1016/S0040-4020(03)00053-X

Armstrong, R. W., Combs, A. P., Tempest, P. A., Brown, S. D., and Keating, T. A. (1996). Multiple-component condensation strategies for combinatorial library synthesis. Acc. Chem. Res. 29, 123-131. doi: 10.1021/ar9502083

Azizian, J., Mohammadi, A. A., and Ardakani, F. (2004a). A simple and efficient synthesis of new 6-arylimino-6H-indolo[2,1-b]quinazolin-12-ones under microwave irradiation. Heterocycles 63, 791-795. doi: 10.3987/COM-03-9937

Azizian, J., Mohammadi, A. A., Karimi, A. R., and Mohammadizadeh, M. R. (2004b). Synthesis of some new 6-substituted quinazolino[4,3b]quinazolin-8-ones under solvent-free conditions. J. Chem. Res. 2004, 435-437. doi: 10.3184/0308234041423736

Bacher, A. (2016). Microwave Chemistry in Organic Synthesis. Los Angeles, CA: UCLA.

Bakavoli, M., Sabzevari, O., and Rahimizadeh, M. (2007). HY-zeolites induced heterocyclization: highly efficient synthesis of substituted-quinazolin4(3H)ones under microwave irradiation. Chin. Chem. Lett. 18, 533-535. doi: 10.1016/j.cclet.2007.03.029 conditions of the MW heating or at room temperature, indicating the significant effect of temperature on the reaction. In many reactions, it is shown that focused MWI with proper control of power and temperature is more important and efficient than multimode MWI or conventional heating sources. Most of the strategies developed for the synthesis of quinazoline and quinazolinone derivatives under MWI were successfully achieved under metal-free conditions. The merits of metal-free reactions involve the absence of a costly metal catalyst and supporting ligands, comparatively milder reaction conditions, insensitivity to moisture, and easy workup procedures. Few examples of synthesis of quinazoline and quinazolinone derivatives using transition metals such as zinc, iron, and copper were described.

\section{AUTHOR CONTRIBUTIONS}

MH has been invited by the editor, developed the idea, and drafted the presented manuscript and worked on it. LM presented the idea and wrote the manuscript. All authors contributed to the article and approved the submitted version.

\section{ACKNOWLEDGMENTS}

The authors are thankful to the Alzahra University Research Council for partial financial assistance. $\mathrm{MH}$ also appreciates the financial support from the Iran National Science Foundation (9400159), granted via an individually granted research chair.
Balalaie, S., Sharifi, A., Ahangarian, B., and Kowsari, E. (2001) Microwave enhanced synthesis of quinazolines in solvent-free condition. Heterocycl. Commun. 7, 337-340. doi: 10.1515/HC.2001. 7.4.337

Bates, R. (2012). Organic Synthesis Using Transition Metals. New York, NY: John Wiley \& Sons. doi: 10.1002/9781119942863

Beller, M., Riermeier, T. H., and Stark, G. (1998). Transition Metals for Organic Synthesis. Weinheim: VCH. doi: 10.1002/9783527619399

Besson, T., and Chosson, E. (2007). Microwave-assisted synthesis of bioactive quinazolines and quinazolinones. Comb. Chem. High Throughput Screen. 10, 903-917. doi: $10.2174 / 138620707783220356$

Besson, T., Guillard, J., and Rees, C. W. (2000). Multistep synthesis of thiazoloquinazolines under microwave irradiation in solution. Tetrahedron Lett. 41, 1027-1030. doi: 10.1016/S0040-4039(99)02221-2

Besson, T., and Rees, C. W. (1996). New route to 4-alkoxyquinazoline2-carbonitriles. J. Chem. Soc. Perkin Trans. 1, 2857-2860. doi: 10.1039/p19960002857

Bhatti, H. S., and Seshadri, S. (2004). Synthesis and fastness properties of styryl and azo disperse dyes derived from 6-nitro substituted 3aryl-2-methyl-4(3H)-quinazolinone. Color. Technol. 120, 151-155. doi: $10.1111 / j .1478-4408.2004 . t b 00221 . x$

Bogdal, D., Penczek, P., Pielichowski, J., and Prociak, A. (2003). Microwave assisted synthesis, crosslinking, and processing of polymeric materials. Adv. Polym. Sci. 163, 194-263. doi: 10.1007/b11051

Bogert, M. T., and Hand, W. F. (1902). The synthesis of alkylketodihydroquinazolines from anthranilic nitrile. J Am. Chem. Soc. 24, 1031-1050. doi: 10.1021/ja02025a001

Caballero, E., Avendaño, C., and Menéndez, J. C. (1998). On the fate of the tryptophan stereocenter during the synthesis of hexacyclic analogues of N-acetylardeemin. Tetrahedron Asymmetry 9, 3025-3038. doi: 10.1016/S0957-4166(98)00307-3 
Caddick, S. (1995). Microwave assisted organic reactions. Tetrahedron 51, 10403-10432. doi: 10.1016/0040-4020(95)00662-R

Chandregowda, V., Kush, A. K., and Reddy, G. C. (2009). Synthesis and in vitro antitumor activities of novel 4-anilinoquinazoline derivatives. Eur. J. Med. Chem. 44, 3046-3055. doi: 10.1016/j.ejmech.2008.07.023

Chari, M. A., Shobha, D., and Mukkanti, K. (2006). Silica gel/ $\mathrm{FeCl}_{3}$ : an efficient and recyclable heterogenous catalyst for one step synthesis of $4(3 \mathrm{H})$ quinazolinones under solvent free conditions. Catal. Commun. 7, 787-790. doi: $10.1016 /$ j.catcom.2006.02.026

Chatel, G., and Varma, R. S. (2019). Ultrasound and microwave irradiation: contributions of alternative physicochemical activation methods to green chemistry. Green Chem. 21, 6043-6050. doi: 10.1039/C9GC02534K

Chatterjee, T., Kim, D. I., and Cho, E. J. (2018). Base-promoted synthesis of 2-aryl quinazolines from 2-aminobenzylamines in water. J. Org. Chem. 83, 7423-7430. doi: 10.1021 /acs.joc.8b00327

Chen, Z., Wang, L.-C., and Wu, X.-F. (2020). Carbonylative synthesis of heterocycles involving diverse CO surrogates. Chem. Commun. 56, 6016-30. doi: 10.1039/D0CC01504K

Chilin, A., Marzaro, G., Zanatta, S., and Guiotto, A. (2007). A microwave improvement in the synthesis of the quinazoline scaffold. Tetrahedron Lett. 48, 3229-3231. doi: 10.1016/j.tetlet.2007.03.027

Cledera, P., Sanchez, J. D., Caballero, E., Avendano, C., Ramos, M. T., and Menendez, J. C. (2004). Solvent-free cyclocondensation of lactim ethers with anthranilic acid under microwave irradiation. Synlett 2004, 0803-0806. doi: 10.1055/s-2004-817784

Connolly, D. J., Cusack, D., O'Sullivan, T. P., and Guiry, P. J. (2005). Synthesis of quinazolinones and quinazolines. Tetrahedron 61, 10153-10202. doi: 10.1016/j.tet.2005.07.010

Corbet, J.-P., and Mignani, G. (2006). Selected patented cross-coupling reaction technologies. Chem. Rev. 106, 2651-2710. doi: 10.1021/cr0505268

Correa, A., Mancheño, O. G., and Bolm, C. (2008). Iron-catalysed carbonheteroatom and heteroatom-heteroatom bond forming processes. Chem. Soc. Rev. 37, 1108-1117. doi: 10.1039/b801794h

Dabiri, M., Salehi, P., and Khajavi, M. S. (2004a). Microwave-assisted one-pot three component synthesis of some new $4(3 \mathrm{H})$-quinazolinone derivatives. Heterocycles 63, 1417-1421. doi: 10.3987/COM-04-10042

Dabiri, M., Salehi, P., Mohammadi, A. A., and Baghbanzadeh, M. (2005). One-pot synthesis of mono-and disubstituted $(3 \mathrm{H})$-quinazolin-4-ones in dry media under microwave irradiation. Synth. Commun. 35, 279-287. doi: 10.1081/SCC-200048462

Dabiri, M., Salehi, P., Mohammadi, A. A., Baghbanzadeh, M., and Kozehgiry, G. (2004b). Montmorillonite K-10 catalysed solvent-free synthesis of 2, 3disubstituted-4(3H)quinazolinones under microwave irradiation. J. Chem. Res. 2004, 570-572. doi: 10.3184/0308234042563866

Dandia, A., Sharma, R., Indora, A., and Parewa, V. (2018). Kosmotropes perturbation and ambiphilic dual activation: responsible features for the construction of C-N bond towards the synthesis of quinazolin 4(3H)-ones in water. ChemistrySelect 3, 8285-8290. doi: 10.1002/slct.201801224

Dandia, A., Singh, R., and Sarawgi, P. (2004). Green chemical multi-component one-pot synthesis of fluorinated 2,3-disubstituted quinazolin-4(3H)-ones under solvent-free conditions and their anti-fungal activity. J. Fluor. Chem. 125, 1835-1840. doi: 10.1016/j.jfluchem.2004.06.009

Dandia, A., Singh, R., and Sarawgi, P. (2005). Reinvestigation of the synthesis of 2-benzyl-3-aryl-quinazolin-4-[3H]-ones. An improved multicomponent procedure using microwaves. Org. Prep. Proced. Int. 37, 397-402. doi: $10.1080 / 00304940509354972$

Das, B., and Banerjee, J. (2004). Silica-supported sodium hydrogen sulfate and amberlyst-15: two efficient heterogeneous catalysts for single-step synthesis of $4(3 \mathrm{H})$-quinazolinones from anthranilic acid, ortho esters, and amines under solvent free conditions. Chem. Lett. 33, 960-961. doi: 10.1246/cl.2004.960

de Fatima Pereira, M., Picot, L., Guillon, J., Léger, J.-M., Jarry, C., Thiéry, V., et al. (2005). Efficient synthesis of novel pentacyclic 6,7-dihydro5a,7a,13,14-tetraaza-pentaphene-5,8-diones. Tetrahedron Lett. 46, 3445-3447. doi: 10.1016/j.tetlet.2005.03.133

de la Hoz, A., Diaz-Ortiz, A., and Moreno, A. (2005). Microwaves in organic synthesis. Thermal and non-thermal microwave effects. Chem. Soc. Rev. 34, 164-178. doi: 10.1039/B411438H
Debabrata, M., Alessio, B., Giuseppe, F., and Giuseppe, Z. (2020). Transition metal promoted cascade heterocycles synthesis via $\mathrm{C}-\mathrm{H}$ functionalization. Chemistry. doi: 10.1002/chem.202001832

Debray, J., Lévêque, J.-M., Philouze, C., Draye, M., and Demeunynck, M. (2010). Swift and efficient synthesis of 4-phenylquinazolines: involvement of $\mathrm{N}$ heterocyclic carbene in the key cyclization step. J. Org. Chem. 75, 2092-2095. doi: $10.1021 /$ jo902726k

Deligeorgiev, T. G., Kaloyanova, S., Vasilev, A., Vaquero, J.-J., Alvarez-Builla, J., and Cuadro, A. M. (2010). Novel environmentally benign procedure for the synthesis of 2-aryl-and 2-hetaryl-4 (3H)-quinazolinones. Color. Technol. 126, 24-30. doi: 10.1111/j.1478-4408.2010.00223.x

Devi, P., Srivastava, A., Srivastava, K., and Bishnoi, A. (2017). Green approaches towards the synthesis of substituted quinazolines. Curr. Green Chem. 4, 25-37. doi: 10.2174/2213346104666170704153434

Domon, L., Le Coeur, C., Grelard, A., Thiéry, V., and Besson, T. (2001). Efficient modified von Niementowski synthesis of novel derivatives of $5 \mathrm{a}, 14 \mathrm{~b}, 15$ triazabenzo[a]indeno[1,2-c]anthracen-5-one from indolo[1,2-c]quinazoline. Tetrahedron Lett. 42, 6671-6674. doi: 10.1016/S0040-4039(01)01364-8

Donthiboina, K., Mani, G. S., Shankaraiah, N., and Kamal, A. (2020). Iodinemediated oxidative annulation by $\mathrm{C}-\mathrm{C}$ cleavage: a Domino synthetic approach to quinazolinones and benzo[4,5] imidazo[1,2-c]quinazolines. ChemistrySelect 5, 3923-3928. doi: 10.1002/slct.202000682

Eidi, E., Kassaee, M. Z., Nasresfahani, Z., and Cummings, P. T. (2018). Synthesis of quinazolines over recyclable $\mathrm{Fe}_{3} \mathrm{O}_{4} @ \mathrm{SiO}_{2}-\mathrm{PrNH}_{2}-\mathrm{Fe}^{3+}$ nanoparticles: a green, efficient, and solvent-free protocol. Appl. Organomet. Chem. 32, e4573. doi: $10.1002 /$ aoc. 4573

El-Azab, A. S., Al-Omar, M. A., Alaa, A.-M., Abdel-Aziz, N. I., Magda, A.-A., Aleisa, A. M., et al. (2010). Design, synthesis and biological evaluation of novel quinazoline derivatives as potential antitumor agents: molecular docking study. Eur. J. Med. Chem. 45, 4188-4198. doi: 10.1016/j.ejmech.2010.06.013

Fazeli, A., Oskooie, H. A., Beheshtiha, Y. S., Heravi, M. M., Moghaddam, F. M., and Foroushani, B. K. (2013). Synthesis of 1,4-disubstituted 1,2,3triazoles from aromatic a-bromoketones, sodium azide and terminal acetylenes via $\mathrm{Cu} / \mathrm{Cu}(\mathrm{OTf})_{2}$-catalyzed click reaction under microwave irradiation. $Z$. Naturforsch B. 68, 391-396. doi: 10.5560/znb.2013-3043

Ferrini, S., Ponticelli, F., and Taddei, M. (2007). Convenient synthetic approach to 2,4-disubstituted quinazolines. Org. Lett. 9, 69-72. doi: 10.1021/ol062540s

Foucourt, A., Dubouilh-Benard, C., Chosson, E., Corbière, C., Buquet, C., Iannelli, M., et al. (2010). Microwave-accelerated Dimroth rearrangement for the synthesis of 4-anilino-6-nitroquinazolines. Application to an efficient synthesis of a microtubule destabilizing agent. Tetrahedron 66, 4495-4502. doi: $10.1016 /$ j.tet.2010.04.066

Foucourt, A., Hédou, D., Dubouilh-Benard, C., Désiré, L., Casagrande, A.S., Leblond, B., et al. (2014). Design and synthesis of thiazolo[5,4f]quinazolines as DYRK1A inhibitors, part I. Molecules 19, 15546-15571. doi: 10.3390/molecules191015546

Gedye, R., Smith, F., Westaway, K., Ali, H., and Baldisera, L. (1986). The use of microwave ovens for rapid organic synthesis. Tetrahedron Lett. 27, 279-282. doi: 10.1016/S0040-4039(00)83996-9

Ghiazza, C., and Tlili, A. (2020). Copper-promoted/copper-catalyzed trifluoromethylselenolation reactions. Beilstein J. Org. Chem. 16, 305-316. doi: $10.3762 /$ bjoc. 16.30

Ghorai, S. K., Gopalsamuthiram, V. G., Jawalekar, A. M., Patre, R. E., and Pal, S. (2017). Iron catalyzed C-N bond formation. Tetrahedron 73, 1769-1794. doi: 10.1016/j.tet.2017.02.033

Ghosh, P., Ganguly, B., and Das, S. (2020). C-H functionalization of quinazolinones by transition metal catalysis. Org. Biomol. Chem. 18, 4497-518. doi: 10.1039/D0OB00742K

Giri, R. S., Thaker, H. M., Giordano, T., Williams, J., Rogers, D., Sudersanam, V., et al. (2009). Design, synthesis and characterization of novel 2(2, 4-disubstituted-thiazole-5-yl)-3-aryl-3H-quinazoline-4-one derivatives as inhibitors of NF- $\mathrm{KB}$ and AP-1 mediated transcription activation and as potential anti-inflammatory agents. Eur. J. Med. Chem. 44, 2184-2189. doi: 10.1016/j.ejmech.2008.10.031

Gopalaiah, K., Saini, A., and Devi, A. (2017). Iron-catalyzed cascade reaction of $2-$ aminobenzyl alcohols with benzylamines: synthesis of quinazolines by trapping of ammonia. Org. Biomol. Chem. 15, 5781-5789. doi: 10.1039/C7OB01159H 
Gopalaiah, K., Tiwari, A., Choudhary, R., and Mahiya, K. (2019). Straightforward access to 3,4-dihydro-2H-1,2,4-benzothiadiazine 1,1-dioxides and quinazolines via iron-catalyzed aerobic oxidative condensation of amines. ChemistrySelect 4 , 5200-5205. doi: 10.1002/slct.201900850

Griess, P. (1869). Ueber die einwirkung des cyans auf anthranilsäure. Ber. Dtsch. Chem. Ges. 2, 415-418. doi: 10.1002/cber.186900201180

Grimmel, H. W., Guenther, A., and Morgan, J. F. (1946). A new synthesis of 4-quinazolones. J. Am. Chem. Soc. 68, 542-543. doi: 10.1021/ja01208a002

Guo, X.-X., Gu, D.-W., Wu, Z., and Zhang, W. (2015). Copper-catalyzed C-H functionalization reactions: efficient synthesis of heterocycles. Chem. Rev. 115, 1622-1651. doi: $10.1021 / \mathrm{cr} 500410 \mathrm{y}$

Gupta, V., Kashaw, S. K., Jatav, V., and Mishra, P. (2008). Synthesis and antimicrobial activity of some new 3-[5-(4-substituted) phenyl-1,3,4oxadiazole-2yl]-2-styrylquinazoline-4(3H)-ones. Med. Chem. Res. 17, 205-211. doi: 10.1007/s00044-007-9054-3

Hazarkhani, H., and Karimi, B. (2003). A facile synthesis of new 3-(2benzimidazolyl)-2-alkyl-4-(3H)-quinazolinones under microwave irradiation. Tetrahedron 59, 4757-4760. doi: 10.1016/S0040-4020(03)00696-3

Heravi, M., Ghavidel, M., and Heidari, B. (2016). Microwave-assisted Biginelli reaction: an old reaction, a new perspective. Curr. Org. Synth. 13, 569-600. doi: $10.2174 / 1570179413666151218202307$

Heravi, M., and Moghimi, S. (2013). Solid-supported reagents in organic synthesis using microwave irradiation. Curr. Org. Chem. 17, 504-527. doi: 10.2174/1385272811317050007

Heravi, M. M., Ajami, D., Mojtahedi, M. M., and Ghassemzadeh, M. (1999). A convenient oxidative deprotection of tetrahydropyranyl ethers with iron(III) nitrate and clay under microwave irradiation in solvent free conditions. Tetrahedron Lett. 40, 561-562. doi: 10.1016/S0040-4039(98)02355-7

Heravi, M. M., Derikvand, F., and Ranjbar, L. (2010). Sulfamic acid-catalyzed, three-component, one-pot synthesis of $[1,2,4]$ triazolo/benzimidazolo quinazolinone derivatives. Synth. Commun. 40, 677-685. doi: 10.1080/00397910903009489

Heravi, M. M., Ghavidel, M., and Mohammadkhani, L. (2018). Beyond a solvent: triple roles of dimethylformamide in organic chemistry. RSC Adv. 8, 27832-27862. doi: 10.1039/C8RA04985H

Heravi, M. M., Ranjbar, L., Derikvand, F., Alimadadi, B., Oskooie, H. A., and Bamoharram, F. F. (2008). A three component one-pot procedure for the synthesis of $[1,2,4]$ triazolo/benzimidazolo-quinazolinone derivatives in the presence of $\mathrm{H}_{6} \mathrm{P}_{2} \mathrm{~W}_{18} \mathrm{O}_{62} \cdot 18 \mathrm{H}_{2} \mathrm{O}$ as a green and reusable catalyst. Mol. Divers. 12, 181-185. doi: 10.1007/s11030-008-9086-8

Heravi, M. M., Sadjadi, S., Sadjadi, S., Oskooie, H. A., and Bamoharram, F. F. (2009). Rapid and efficient synthesis of 4(3H)-quinazolinones under ultra sonic irradiation using silica-supported Preyssler nano particles. Ultrason. Sonochem. 16, 708-710. doi: 10.1016/j.ultsonch.2009. 02.010

Heravi, M. M., Tavakoli-Hoseini, N., and Bamoharram, F. F. (2011). Brønsted acidic ionic liquids: new, efficient, and green promoter system for the synthesis of $4(3 \mathrm{H})$-quinazolinones. Synth. Commun. 41, 707-714. doi: $10.1080 / 00397911003640108$

Hill, M. D., and Movassaghi, M. (2008). Observations on the use of microwave irradiation in azaheterocycle synthesis. Tetrahedron Lett. 49, 4286-4288. doi: 10.1016/j.tetlet.2008.04.143

Ighilahriz, K., Boutemeur, B., Chami, F., Rabia, C., Hamdi, M., and Hamdi, S. M. (2008). A microwave-assisted and heteropolyacidscatalysed cyclocondensation reaction for the synthesis of $4(3 \mathrm{H})$ quinazolinones. Molecules 13, 779-789. doi: 10.3390/molecules 130 40779

Inoue, I., Oine, T., Yamada, Y., Tani, J., Ishida, R., and Ochiai, T. (1976). 2-Fluoromethyl-3-o-tolyl-6-amino-4(3H)-quinazolinone. United States patent US 3966731 .

Jagani, C. L., Sojitra, N. A., Vanparia, S. F., Patel, T. S., Dixit, R. B., and Dixit, B. C. (2011). A convergent microwave assisted synthesis of 4-amino-N-(4-oxo2-substituted-4H-quinazolin-3-yl) benzenesulfonamide derivatives. Arkivoc 9, 221-237. doi: 10.3998/ark.5550190.0012.916

Jagani, C. L., Sojitra, N. A., Vanparia, S. F., Patel, T. S., Dixit, R. B., and Dixit, B. C. (2012). Microwave promoted synthesis and antimicrobial activity of 3-thiazole substituted 2-styryl-4(3H)-quinazolinone derivatives. J. Saudi Chem. Soc. 16, 363-369. doi: 10.1016/j.jscs.2011.02.001
Janardhanan, J.C., Bhaskaran, R.P., Praveen, V.K., Narayanapillai, M., and P Babu, B. (2020). Recent advances in the transition metal catalyzed synthesis of indazoles. Asian J. Org. Chem. 14, 6638-6650. doi: 10.1039/C6OB00944A

Jiang, X., Wei, X., Lin, F., Zhang, Z., Yao, G., Yang, S., et al. (2020). Substrate-controlled [5+1] annulation of 5-amino- $1 \mathrm{H}$ phenylpyrazoles with alkenes: divergent synthesis of multisubstituted 4,5-dihydropyrazolo[1,5-a]quinazolines. Eur. J. Org. Chem. 2020, 3997-4003. doi: 10.1002/ejoc.202000536

Johansson Seechurn, C. C. C., Kitching, M. O., Colacot, T. J., and Snieckus, V. (2012). Palladium-catalyzed cross-coupling: a historical contextual perspective to the 2010 Nobel Prize. Angew. Chem. Int. Ed. 51, 5062-5085. doi: 10.1002/anie.201107017

Kabri, Y., Gellis, A., and Vanelle, P. (2009). Microwave-assisted synthesis in aqueous medium of new quinazoline derivatives as anticancer agent precursors. Green Chem. 11, 201-208. doi: 10.1039/B816723K

Kamal, A., Reddy, K. S., Prasad, B. R., Babu, A. H., and Ramana, A. V. (2004). Microwave enhanced reduction of nitro and azido arenes to $\mathrm{N}$-arylformamides employing $\mathrm{Zn}-\mathrm{HCOONH}_{4}$ : synthesis of $4(3 \mathrm{H})$ quinazolinones and pyrrolo[2,1-c][1,4]benzodiazepines. Tetrahedron Lett. 45, 6517-6521. doi: 10.1016/j.tetlet.2004.06.112

Kamal, A., Reddy, M. K., Reddy, T. S., Santos, L. S., and Shankaraiah, N. (2011). Total synthesis of rutaecarpine and analogues by tandem azido reductive cyclization assisted by microwave irradiation. Synlett 2011, 61-64. doi: 10.1055/s-0030-1259095

Kang, H., Wang, W., Sun, Q., Yang, S., Jin, J., Zhang, X., et al. (2018). Microwaveassisted synthesis of quinazolin-4(3H)-ones catalyzed by $\mathrm{SbCl}_{3}$. Heterocycl Commun. 24, 293-296. doi: 10.1515/hc-2018-0115

Kanth, S. R., Reddy, G. V., Maitraie, D., Narsaiah, B., Rao, P. S., Kumar, K. R., et al. (2006). Iron(III)chloride catalysed three-component Grieco condensation: synthesis of tetrahydropyrido[2, $\left.2^{\prime}: 3,4\right]$ pyrazolo[1,5a]pyrimidines/quinazolines. J. Fluor. Chem. 127, 1211-1221. doi: 10.1016/j.jfluchem.2006.06.017

Kanwal, I., Mujahid, A., Rasool, N., Rizwan, K., Malik, A., Ahmad, G., et al. (2020). Palladium and copper catalyzed sonogashira cross coupling an excellent methodology for C-C bond formation over 17 years: a review. Catalysts 10:443. doi: 10.3390/catal10040443

Kappe, C. O. (2004). Controlled microwave heating in modern organic synthesis. Angew. Chem. Int. Ed. 43, 6250-6284. doi: 10.1002/anie.200400655

Ke, F., Liu, C., Zhang, P., Xu, J., and Chen, X. (2018). Efficient and selective microwave-assisted copper-catalyzed synthesis of quinazolinone derivatives in aqueous. Synth. Commun. 48, 3089-3098. doi: 10.1080/00397911.2018.1533974

Khajavi, M. S., Afshani, P., and Rad Moghadam, K. (1998). Microwave irradiation promoted the Niementowski reaction preparation of substituted quinazolinones and quinolines. Iran. J. Chem. Chem. Eng. 17, 29-32.

Khajavi, M. S., Rad-Moghadam, K., and Hazarkhani, H. (1999a). A facile synthesis of 6-substituted benzimidazo[1,2-c]-quinazolines under microwave irradiation. Synth. Commun. 29, 2617-2624. doi: 10.1080/00397919908086422

Khajavi, M. S., Sadat Hosseini, S. S., and Montazari, N. (1999b). Microwave irradiation promoted reactions of benzoxazin-4-ones with primary amines. preparation of $4(2=3 \mathrm{H})$-quinazolinones. Iran. J. Chem. Chem. Eng. 18, 30-32.

Khan, I., Ibrar, A., Abbas, N., and Saeed, A. (2014). Recent advances in the structural library of functionalized quinazoline and quinazolinone scaffolds: synthetic approaches and multifarious applications. Eur. J. Med. Chem. 76, 193-244. doi: 10.1016/j.ejmech.2014.02.005

Khan, I., Ibrar, A., Ahmed, W., and Saeed, A. (2015). Synthetic approaches, functionalization and therapeutic potential of quinazoline and quinazolinone skeletons: the advances continue. Eur. J. Med. Chem. 90, 124-169. doi: 10.1016/j.ejmech.2014.10.084

Khosropour, A. R., Mohammadpoor-Baltork, I., and Ghorbankhani, H. (2006). $\mathrm{Bi}(\mathrm{TFA})_{3}-[\mathrm{nbp}] \mathrm{FeCl}_{4}$ : a new, efficient and reusable promoter system for the synthesis of $4(3 \mathrm{H})$-quinazolinone derivatives. Tetrahedron Lett. 47, 3561-3564. doi: $10.1016 /$ j.tetlet.2006.03.079

Kojima, M., and Matsunaga, S. (2020). The merger of photoredox and cobalt catalysis. Trends Chem. 2, 410-426. doi: 10.1016/j.trechm.2020.01.004

Koroji, S., Mohammadi, A. A., and Mehrshad, M. (2018). An efficient onepot three-component synthesis of some new 3-(benzo[d]thiazol-2-yl)-2-alkyl$4(3 \mathrm{H})$-quinazolinones using silica sulfuric acid as a heterogeneous catalyst. $J$. Heterocycl. Chem. 55, 2647-2651. doi: 10.1002/jhet.3312 
Kshirsagar, U. A. (2015). Recent developments in the chemistry of quinazolinone alkaloids. Org. Biomol. Chem. 13, 9336-9352. doi: 10.1039/C5OB01379H

Kumar, N. D., and Dubey, P. K. (2012). An expeditious microwave-assisted synthesis of mercapto benzazoles, quinazolinone and oxadiazoles. Indian J. Chem. 51B, 1619-1622. Available online at: http://nopr.niscair.res.in/handle/ $123456789 / 14985$

Kumar, V., Mohan, C., Gupta, M., and Mahajan, M. P. (2005). A catalyst-and solvent-free selective approach to biologically important quinazolines and benzo[g]quinazoline. Tetrahedron 61, 3533-3538. doi: 10.1016/j.tet.2005.01.118

Kumar, V., Sharma, A., and Mahajan, M. P. (2004). Microwave assisted Aza-Wittig reactions of $\mathrm{N}$-imidoyliminophosphorane with aldehydes: a convenient and selective route to quinazolines. Synth. Commun. 34, 49-53. doi: $10.1081 /$ SCC-120027237

Laddha, S. S., and Bhatnagar, S. P. (2008). Rapid microwave-assisted solution phase synthesis of 6,8-disubstituted 2-phenyl-3-(substituted-benzothiazol-2yl)-4-[3H]-quinazolinones as novel anticonvulsants. Phosphorus Sulfur Relat. Elem. 183, 2262-2273. doi: 10.1080/10426500801957766

Leiby, R. W. (1985). Synthesis of 3-amino-4(3H)-quinazolinones from N(2-carbomethoxyphenyl)imidate esters. J. Org. Chem. 50, 2926-2929. doi: 10.1021/jo00216a023

Ley, S. V., and Thomas, A. W. (2003). Modern synthetic methods for coppermediated C(aryl)-O, C(aryl)-N, and C(aryl)-S bond formation. Angew. Chem. Int. Ed. 42, 5400-5449. doi: 10.1002/anie.200300594

Li, F., Feng, Y., Meng, Q., Li, W., Li, Z., Wang, Q., et al. (2007). An efficient construction of quinazolin-4(3H)-ones under microwave irradiation. Arkivoc 1, 40-50. doi: 10.3998/ark.5550190.0008.105

Li, G., Kakarla, R., Gerritz, S. W., Pendri, A., and Ma, B. (2009). A facile onestep synthesis of 5-chloro-imidazo[1,5-a] quinazoline by microwave irradiation. Tetrahedron Lett. 50, 6048-6052. doi: 10.1016/j.tetlet.2009.08.054

Li, H. Y., Huang, R. Q., Qiu, D. W., Yang, Z., Liu, X., Ma, J. A., et al. (1998). Synthesis and bioactivity of 4-quinazoline oxime ethers. Prog. Nat. Sci. 8, 359-365.

Li, W., and Zhang, J. (2020). Synthesis of heterocycles through denitrogenative cyclization of triazoles and benzotriazoles. Chem. Eur. J. 26, 11931-11945. doi: $10.1002 /$ chem.202000674

Li, W., Zheng, X., and Li, Z. (2013). Iron-catalyzed C-C bond cleavage and C-N bond formation. Adv. Synth. Catal. 355, 181-190. doi: 10.1002/adsc.201200324

Li, X., Lin, Q., and Eli, W. (2010). Microwave-assisted synthesis of 2-substituted$4(3 \mathrm{H})$-quinazolinones in bronsted acidic ionic liquids. Chinese J. Org. Chem. 30, 452-455. Available online at: http://sioc-journal.cn/Jwk_yjhx/EN/Y2010/ $\mathrm{V} 30 / \mathrm{I} 03 / 452$

Li, X., Lin, Q., and Wang, L. (2015). One-pot solvent-free synthesis of 2,3disubstituted $4(3 \mathrm{H})$-quinazolinones catalyzed by long-chain double $\mathrm{SO}_{3} \mathrm{H}$ functionalized Brønsted acidic ionic liquids under microwave irradiation. J. Iran. Chem. Soc. 12, 897-901. doi: 10.1007/s13738-014-0553-0

Liang, E., Wu, Y., Chen, J., Xiong, W., Zhao, J., Yao, X., et al. (2019). Copper-catalyzed aerobic oxidative cyclization protocol for the synthesis of quinazolines via amination of $\mathrm{C}\left(\mathrm{sp}^{3}\right)$ - $\mathrm{H}$ bonds of methylazaarenes. Tetrahedron 75:130783. doi: 10.1016/j.tet.2019.130783

Lidström, P., Tierney, J., Watheyb, B., and Westmana, J. (2001). Microwave assisted organic synthesisd-a review. Tetrahedron 57, 9225-9283. doi: 10.1016/S0040-4020(01)00906-1

Lin, W.-H., Wu, W.-C., Selvaraju, M., and Sun, C.-M. (2017). One-pot synthesis of benzazoles and quinazolinones via iron pentacarbonyl mediated carbonylation of aryl iodides under microwave irradiation. Org. Chem. Front. 4, 392-397. doi: 10.1039/C6QO00733C

Lingaiah, B. V., Ezikiel, G., Yakaiah, T., Reddy, G. V., and Rao, P. S. (2006). Nafion$\mathrm{H}$ : An efficient and recyclable heterogeneous catalyst for the one-pot synthesis of 2,3-disubstituted 4-(3H)-quinazolinones under solvent-free microwave irradiation conditions. Synlett 2006, 2507-2509. doi: 10.1055/s-2006950428

Liu, J., Wang, Y.-L., Zhang, J.-H., Yang, J.-S., Mou, H.-C., Lin, J., et al. (2018a). Phosphatase CDC25B inhibitors produced by basic aluminasupported one-pot gram-scale synthesis of fluorinated 2-alkylthio-4aminoquinazolines using microwave irradiation. ACS omega 3, 4534-4544. doi: 10.1021 /acsomega.8b00640
Liu, J.-F., Kaselj, M., Isome, Y., Chapnick, J., Zhang, B., Bi, G., et al. (2005a). Microwave-assisted concise total syntheses of quinazolinobenzodiazepine alkaloids. J. Org. Chem. 70, 10488-10493. doi: 10.1021/jo051876x

Liu, J.-F., Lee, J., Dalton, A. M., Bi, G., Yu, L., Baldino, C. M., et al. (2005b). Microwave-assisted one-pot synthesis of 2, 3-disubstituted 3H-quinazolin-4ones. Tetrahedron Lett. 46, 1241-1244. doi: 10.1016/j.tetlet.2005.01.008

Liu, J.-F., Ye, P., Zhang, B., Bi, G., Sargent, K., Yu, L., et al. (2005c). Threecomponent one-pot total syntheses of glyantrypine, fumiquinazoline $\mathrm{F}$, and fiscalin B promoted by microwave irradiation. J. Org. Chem. 70, 6339-6345. doi: $10.1021 /$ jo0508043

Liu, R., Li, H., Yang, J., and An, Z. (2018b). Quinazolinones isolated from Aspergillus sp., an endophytic fungus of Astragalus membranaceus. Chem. Nat. Compd. 54, 808-810. doi: 10.1007/s10600-018-2484-y

Liu, X., Fu, H., Jiang, Y., and Zhao, Y. (2009). A simple and efficient approach to quinazolinones under mild copper-catalyzed conditions. Angew. Chem. 121, 354-357. doi: 10.1002/ange. 200804675

Loupy, A. (1993). Les micro-ondes en synthèse organique: une méthodologie propre et performante: Préparation d'échantillons. Spectra Analyse 22, 33-38.

Loupy, A. (1994). Les micro-ondes: leurs applications potentielles dans la chimie des corps gras. Oléagineux Corps gras, Lipides. 1, 62-68.

Luo, H., Hu, D., Wu, J., He, M., Jin, L., Yang, S., et al. (2012). Rapid synthesis and antiviral activity of (quinazolin-4-ylamino)methylphosphonates through microwave irradiation. Int. J. Mol. Sci. 13, 6730-6746. doi: 10.3390/ijms13066730

Ma, J., Wan, Y., Hong, C., Li, M., Hu, X., Mo, W., et al. (2017). ABNOcatalyzed aerobic oxidative synthesis of 2-substituted $4 \mathrm{H}-3,1$-benzoxazines and quinazolines. Eur. J. Org. Chem. 2017, 3335-3342. doi: 10.1002/ejoc.201700384

Maitraie, D., Yakaiah, T., Srinivas, K., Reddy, G. V., Ravikanth, S., Narsaiah, B., et al. (2006). Regioselective addition of Grignard reagents to 2,6dicyanoanilines and cyclization to new quinazoline derivatives under thermal/microwave irradiation conditions. J. Fluor. Chem. 127, 351-359. doi: 10.1016/j.jfluchem.2006.01.003

Majetich, G., and Hicks, R. (1994). Applications of microwave accelerated organic chemistry. Res. Chem. Intermed. 20:61. doi: 10.1163/156856794X00072

Majetich, G., and Hicks, R. (1995). The use of microwave heating to promote organic reactions. J. Microw. Power Electromagn. Energ. 30, 27-45. doi: 10.1080/08327823.1995.11688258

Majumder, A., Gupta, R., and Jain, A. (2013). Microwave-assisted synthesis of nitrogen-containing heterocycles. Green Chem. Lett. Rev. 6, 151-182. doi: $10.1080 / 17518253.2012 .733032$

Masel, R. I. (2001). Chemical Kinetics and Catalysis. New York, NY: Wiley.

McNaught, A. D., and Wilkinson, A. (1997). Compendium of Chemical Terminology. Oxford: Blackwell Science Oxford.

Melvin, J. Y., McCowan, J. R., Towner, R. D., Ho, P. P. K., Phebus, L. A., Ruterbories, K. J., et al. (1992). Structurally novel antiarrhythmic/antioxidant quinazolines. Bioorg. Med. Chem. Lett. 2, 1121-1126. doi: 10.1016/S0960-894X(00)80631-9

Mhaske, S. B., and Argade, N. P. (2006). The chemistry of recently isolated naturally occurring quinazolinone alkaloids. Tetrahedron 62, 9787-9826. doi: $10.1016 /$ j.tet.2006.07.098

Michael, J. P. (2003). Quinoline, quinazoline and acridone alkaloids. Nat. Prod. Rep. 20, 476-493. doi: 10.1039/b208140g

Michael, J. P. (2004). Quinoline, quinazoline and acridone alkaloids. Nat. Prod. Rep. 21, 650-668. doi: 10.1039/b310691h

Mingos, D. M. P., and Baghurst, D. R. (1991). Microwave-assisted reactions and processes. Chem. Soc. Rev 20, 1-47. doi: 10.1039/cs9912000001

Mohammadi, A. A., Askari, S., Rohi, H., and Soorki, A. A. (2014). Design, synthesis, and antibacterial evaluation of some novel $3^{\prime}$-(phenylamino)$1^{\prime}$ H-spiro [indoline-3,2' -quinazoline]-2,4 ( $\left.3^{\prime} \mathrm{H}\right)$-dione derivatives. Synth. Commun. 44, 457-467. doi: 10.1080/00397911.2013.796992

Mohammadi, A. A., and Sadat Hossini, S. (2011). $\mathrm{KAl}\left(\mathrm{SO}_{4}\right)_{2} \cdot 12 \mathrm{H}_{2} \mathrm{O}$ (Alum) catalyzed one-pot three-component synthesis of 2-alkyl and 2-aryl-4(3H)quinazolinone under microwave irradiation and solvent free conditions. Chin. Chem. Lett. 29, 1982-1984. doi: 10.1002/cjoc.201180344

Monnier, F., and Taillefer, M. (2013). "Copper-catalyzed C(aryl)-N bond formation," in Amination and Formation of $s p^{2} C-N$ Bonds, eds M. Taillefer and D. Ma (Berlin, Heidelberg: Springer), 173-204. doi: 10.1007/3418_2013_69 
Montazeri, N., Pourshamsian, K., Fomani, A., and Kalantarian, S. J. (2012a). Synthesis of 2,3-disubstituted-4(3H)-quinazolinones using HY-zeolite as reusable catalyst under microwave irradiation. Asian J. Chem. 24:2805, Available online at: http://www.asianjournalofchemistry.co.in/user/journal/ viewarticle.aspx?ArticleID=24_6_98

Montazeri, N., Pourshamsian, K., Rahgol, M., and Bayazi, M. (2012b). Pentafluorophenylammonium triflate: an efficient, practical and environmental friendly catalyst for synthesis of quinazolin-4(3H)-ones. Asian J. Chem. 24, 5361-5364. Available online at: http://www.asianjournalofchemistry.co.in/ user/journal/viewarticle.aspx?ArticleID=24_11_129

Montazeri, N., and Rad-Moghadam, K. (2004). A convenient synthesis of substituted quinazolin-4(3H)-ones under microwave and solventfree conditions. Phosphorus, Sulfur Relat. Elem. 179, 2533-2536. doi: $10.1080 / 10426500490485606$

Nagata, T., and Obora, Y. (2020). Transition-metal-mediated/catalyzed synthesis of pyridines, pyrimidines, and triazines by $[2+2+2]$ cycloaddition reactions. Asian J. Org. Chem. 9, 1532-1547. doi: 10.1002/ajoc.202000240

Nain, S., Singh, R., and Ravichandran, S. (2019). Importance of microwave heating in organic synthesis. Adv. J. Chem. A. 2, 94-104. doi: 10.29088/SAMI/AJCA.2019.2.94104

Nandy, P., Vishalakshi, M. T., and Bhat, A. R. (2006). Synthesis and antitubercular activity of Mannich bases of 2-methyl-3H-quinazolin-4-ones. Indian J. Heterocycl. Chem. 15, 293-294. Available online at: https://www.scopus. com/inward/record.uri?eid=2-s2.0-33747797083\&partnerID=40\&md5= e71ece6ed4e8ebce925122620b81eb22

Narasimhulu, M., Mahesh, K. C., Reddy, T. S., Rajesh, K., and Venkateswarlu, Y. (2006). Lanthanum (III) nitrate hexahydrate or p-toluenesulfonic acid catalyzed one-pot synthesis of $4(3 \mathrm{H})$-quinazolinones under solvent-free conditions. Tetrahedron Lett. 47, 4381-4383. doi: 10.1016/j.tetlet.2006. 04.096

Neto, J., and Zeni, G. (2020a). Alkynes and nitrogen compounds: useful substrates for the synthesis of pyrazoles. Chem. Eur. J. 26:8175-8189. doi: $10.1002 /$ chem. 202083761

Neto, J. S. S., and Zeni, G. (2020b). A decade of advances in the reaction of nitrogen sources and alkynes for the synthesis of triazoles. Coord. Chem. Rev. 409:213217. doi: 10.1016/j.ccr.2020.213217

Nobel Prize (2020). The Nobel Prize in Chemistry 1918. Available online at: http:// nobelprize.org/nobel_prizes/chemistry/laureates/1918/index.html

Nouira, I., Kostakis, I. K., Dubouilh, C., Chosson, E., Iannelli, M., and Besson, T. (2008). Decomposition of formamide assisted by microwaves, a tool for synthesis of nitrogen-containing heterocycles. Tetrahedron Lett. 49, 7033-7036. doi: 10.1016/j.tetlet.2008.09.135

Oskooie, H. A., Baghernezhad, B., and Heravi, M. M. (2007). $\mathrm{SnCl}_{4}$ center dot $4 \mathrm{H}(2) \mathrm{O}$ as an efficient catalyst for the synthesis of $4(3 \mathrm{H})$-quinazolinone derivatives. Indian J. Heterocy. Chem. 17, 95-96. Available online at: https://link.springer.com/articles/cas-redirect/1\%3ACAS\%3A528\%3ADC \%252BD2sXht1Wktr7E

Pal, T., Lahiri, G. K., and Maiti, D. (2020). Copper in efficient synthesis of aromatic heterocycles with single heteroatom. Eur. J. Org. Chem. doi: 10.1002/ejoc.202000688. [Epub ahead of print].

Pater, R. (1971). 2-Aryl-4(3H)quinazolinones. J. Heterocycl. Chem. 8, 699-702. doi: $10.1002 /$ jhet.5570080501

Pathania, D., Sechi, M., Palomba, M., Sanna, V., Berrettini, F., Sias, A., et al. (2014). Design and discovery of novel quinazolinedione-based redox modulators as therapies for pancreatic cancer. Biochim. Biophys. Acta 1840, 332-343. doi: 10.1016/j.bbagen.2013.08.005

Patil, S., Jadhav, S. D., Shejwal, R. V., and Deshmukh, M. B. (2012). Microwave-assisted cyclocondensation for the synthesis of 3-aryl-2thioquinazolin-4(3H)-ones. Asian J. Chem. 24, 1858-1860. Available online at: http://www.asianjournalofchemistry.co.in/user/journal/viewarticle.aspx? ArticleID $=24 \_4$-99

Pessoa-Mahana, H., Pessoa-Mahana, C. D., Salazar, R., Valderrama, J. A., Saez, E., and Araya-Maturana, R. (2004). Solvent-free synthesis of 6arylbenzimidazo[1,2-c] quinazolines under microwave irradiation. Synthesis 2004, 436-440. doi: 10.1055/s-2004-815924

Portela-Cubillo, F., Scott, J. S., and Walton, J. C. (2008). 2-(Aminoaryl) alkanone O-phenyl oximes: versatile reagents for syntheses of quinazolines. Catal. Commun.25, 2935-2937. doi: 10.1039/b803630f
Potuganti, G. R., Indukuri, D. R., and Alla, M. (2018). An efficient onepot multicomponent synthesis of tetracyclic quinazolino[4,3-b]quinazolines by sequential $\mathrm{C}-\mathrm{N}$ bond formation and copper-mediated aerobic oxidative cyclization. Synlett 29, 1717-1722. doi: 10.1055/s-0036-1591578

Priya, M. G. R., Zulykama, Y., Girija, K., Murugesh, S., and Perumal, P. T. (2011). Synthesis of 4-(3H)-quinazolinones by microwave assisted tandem reaction and evaluation of their antibacterial and antifungal activities. Indian J. Chem. 50B, 98-102. doi: 10.1002/chin.201118143

Punniyamurthy, T., and Rout, L. (2008). Recent advances in copper-catalyzed oxidation of organic compounds. Coord. Chem. Rev. 252, 134-154. doi: 10.1016/j.ccr.2007.04.003

Radhakrishnan, K., Das, S., and Kundu, L. M. (2018). Synthesis of size-expanded nucleobase analogues for artificial base-pairing using a ligand-free, microwave-assisted copper(I)-catalyzed reaction. ChemistrySelect 3, 13098-13102. doi: 10.1002/slct.2018 02455

Rad-Moghadam, K., and Khajavi, M. S. (1998). One-pot synthesis of substituted quinazolin-4(3H)-ones under microwave irradiation. J. Chem. Res. 11, 702-703. doi: $10.1039 / \mathrm{a} 802853 \mathrm{~b}$

Rad-Moghadam, K., and Mohseni, M. (2003). An expeditious and solvent-free route to the synthesis of 2-substituted quinazolin-4(3H)-ones under microwave conditions. J. Chem. Res. 2003, 487-488. doi: 10.3184/030823403103174632

Rad-Moghadam, K., and Samavi, L. (2006). One-pot three-component synthesis of 2-substituted 4-aminoquinazolines. J. Heterocycl. Chem. 43, 913-916. doi: $10.1002 /$ jhet. 5570430415

Radziszewski, B. (1885). Ueber die oxydation mittelst wasserstoffsuperoxyd. ?Ber. Dtsch. Chem. Ges. 18, 355-356. doi: 10.1002/cber.18850180171

Rahimizadeh, M., Tavallai, Z., and Bakavoli, M. (2004). Microwave irradiation in solvent-free conditions: preparation of 2 -substituted $4(3 \mathrm{H})$-quinazolinones by heterocyclisation of 2-aminobenzamide with carboxylic acids. Indian J. Chem. 43B, 679-681. doi: 10.1002/chin.200428167

Rajappa, S., and Advani, B. G. (1973). Iminoethers-III: Tetracyclic quinazolones derived from cyclodipeptide mono iminoethers. Tetrahedron 29, 1299-1302. doi: 10.1016/S0040-4020(01)83147-1

Rajappa, S., and Advani, B. G. (1974). Conformational studies on tricyclic quinazolones derived from cyclodipeptides incorporating sarcosine. J. Chem. Soc. Perkin Trans. 1, 2122-2124. doi: 10.1039/p19740002122

Rajasekaran, A., Rajamanickam, V., and Darlinquine, S. (2013). Synthesis of some new thioxoquinazolinone derivatives and a study on their anticonvulsant and antimicrobial activities. Eur. Rev. Med. Pharmacol. Sci. 17, 95-104. Available online at: https://www.europeanreview.org/article/1108

Ramanathan, M., and Liu, S.-T. (2017). Preparation of quinazolines via a $2+2+2$ annulation from aryldiazonium salts and nitriles. J. Org. Chem. 82, 8290-8295. doi: 10.1021/acs.joc.7b01325

Ratmanova, N. K., Andreev, I. A., Leontiev, A. V., Momotova, D., Novoselov, A. M., Ivanova, O. A., et al. (2020). Strategic approaches to the synthesis of pyrrolizidine and indolizidine alkaloids. Tetrahedron 76:131031. doi: $10.1016 /$ j.tet.2020.131031

Raut, A. B., and Bhanage, B. M. (2017). Cuprous oxide nanoparticle supported on iron oxide $\left(\mathrm{Cu}_{2} \mathrm{O}-\mathrm{Fe}_{3} \mathrm{O}_{4}\right)$ : magnetically separable and reusable nanocatalyst for the synthesis of quinazolines. ChemistrySelect 2, 10055-10060. doi: 10.1002/slct.201701251

Rodrigues, R., Tran, L. Q., Darses, B., Dauban, P., and Neuville, L. (2019). Copper-promoted tandem three-component access to quinazolin-4(H)-imines and benzimidazo[1,2-c]quinazolines. Adv. Synth. Catal. 361, 4454-4460. doi: $10.1002 /$ adsc. 201900658

Rohini, R., Reddy, P. M., Shanker, K., Hu, A., and Ravinder, V. (2010). Antimicrobial study of newly synthesized 6-substituted indolo[1,2-c]quinazolines. Eur. J. Med. Chem. 45, 1200-1205. doi: 10.1016/j.ejmech.2009.11.038

Saari, R., Törm,ä, J.-C., and Nevalainen, T. (2011). Microwave-assisted synthesis of quinoline, isoquinoline, quinoxaline and quinazoline derivatives as CB2 receptor agonists. Bioorg. Med. Chem. 19, 939-950. doi: 10.1016/j.bmc.2010.11.059

Saeedi, M., Beheshtiha, Y. S., and Heravi, M. M. (2011). Synthesis of novel tetrahydro[4,5]imidazo[2,1-b]-chromeno[4,3,2-de]quinazoline and benzothiazol-2-ylaminoxanthenone derivatives. Heterocycles 83, 1831-1841. doi: $10.3987 / \mathrm{COM}-11-12201$ 
Sahiba, N., and Agarwal, S. (2020). Recent advances in the synthesis of perimidines and their applications. Top. Curr. Chem. 378, 1-47. doi: $10.1007 /$ s41061-020-00307-5

Saikia, U. P., Borah, G., and Pahari, P. (2018). Lewis-acid-catalysed activation of nitriles: a microwave-assisted solvent-free synthesis of 2,4-disubstituted quinazolines and 1,3-diazaspiro[5.5]undec-1-enes. Eur. J. Org. Chem. 2018, 1211-1217. doi: 10.1002/ejoc.201701585

Sarma, R., and Prajapati, D. (2011). Microwave-promoted efficient synthesis of dihydroquinazolines. Green Chem. 13, 718-722. doi: 10.1039/c0gc00838a

Sasmal, S., Balaji, G., Reddy, H. R. K., Balasubrahmanyam, D., Srinivas, G., Kyasa, S., et al. (2012). Design and optimization of quinazoline derivatives as melanin concentrating hormone receptor 1 (MCHR1) antagonists. Bioorg. Med. Chem. Lett. 22, 3157-3162. doi: 10.1016/j.bmcl.2012.03.050

Sawant, S. D., Srinivas, M., Reddy, G. L., Rao, V. V., Singh, P. P., and Vishwakarma, R. A. (2012). One-pot multicomponent synthesis of medicinally important purine quinazolinone derivatives. Tetrahedron Lett. 53, 6195-6198. doi: 10.1016/j.tetlet.2012.08.137

Seijas, J. A., Vázquez-Tato, M. P., and Martinez, M. M. (2000). Microwave enhanced synthesis of 4-aminoquinazolines. Tetrahedron Lett. 41, 2215-2217. doi: 10.1016/S0040-4039(00)00090-3

Sharma, A., Luxami, V., and Paul, K. (2013). Synthesis, single crystal and antitumor activities of benzimidazole-quinazoline hybrids. Bioorg. Med. Chem. Lett. 23, 3288-3294. doi: 10.1016/j.bmcl.2013.03.107

Sheu, J. R., Hung, W. C., Wu, C. H., Lee, Y. M., and Yen, M. H. (2000). Antithrombotic effect of rutaecarpine, an alkaloid isolated from Evodia rutaecarpa, on platelet plug formation in in vivo experiments. Br. J. Haematol. 110, 110-115. doi: 10.1046/j.1365-2141.2000.01953.x

Shi, D., Wang, J., Shi, C., Rong, L., Zhuang, Q., and Hu, H. (2004). Synthesis of quinazolines and imidazo[1,2-c]quinazolines with the aid of a low-valent titanium reagent. Synlett 2004, 1098-1100. doi: 10.1055/s-2004-822893

Shiri, M., Heravi, M. M., Faghihi, Z., Zadsirjan, V., Mohammadnejad, M., and Ranjbar, M. (2018). Tandem and transition metal-free synthesis of novel benzoimidazo-quinazoline as highly selective $\mathrm{Hg}^{2+}$ sensors. Res. Chem. Intermed. 44, 2439-2449. doi: 10.1007/s11164-017-3239-2

Sonawane, A. D., Sonawane, R. A., Ninomiya, M., and Koketsu, M. (2020). Synthesis of seleno-heterocycles via electrophilic/radical cyclization of alkyne containing heteroatoms. Adv Synthesis Catalysis. 362, 3485-3515. doi: $10.1002 /$ adsc. 202000490

Sreenivas, D. K., Ramkumar, N., and Nagarajan, R. (2012). Copper-mediated domino synthesis of pyrimido[4,5-b]carbazolones via Ullmann $\mathrm{N}$-arylation and aerobic oxidative C-H amidation. Org. Biomol. Chem. 10, 3417-3423. doi: $10.1039 / \mathrm{c} 2 \mathrm{ob} 07179 \mathrm{~g}$

Storelli, S., Verdijk, P., Verzijl, D., Timmerman, H., van de Stolpe, A. C., Tensen, C. P., et al. (2005). Synthesis and structure-activity relationship of 3-phenyl3H-quinazolin-4-one derivatives as CXCR3 chemokine receptor antagonists. Bioorg. Med. Chem. 15, 2910-2913. doi: 10.1016/j.bmcl.2005.03.070

Strauss, C. R., and Trainor, R. W. (1995). Developments in microwave-assisted organic chemistry. Aust. J. Chem. 48, 1665-1692. doi: 10.1071/CH9951665

Tandon, P. K. (2019). Catalytic applications of copper species in organic transformations: a review. JoCC 1, 21-34. Available online at: http:// engineeringjournals.stmjournals.in/index.php/JoCC/article/view/2336

Tavalaie, Z., Sabzevari, O., Bakavoli, M., and Rahimizadeh, M. (2007). A novel synthesis of 2-(alkylamino) and 2-(arylamino)-4 (3H) quinazolinones by heterotrocyclization of 2 -aminobenzamide with isothiocyanates (or isocyanates) under microwave irradiation. Sci. Iran. 14, 320-322. Available online at: https://www.sid.ir/en/journal/ViewPaper.aspx?ID=92576

Thapa, S., Shrestha, B., Gurung, S. K., and Giri, R. (2015). Copper-catalysed cross-coupling: an untapped potential. Org. Biomol. Chem. 13, 4816-4827. doi: $10.1039 / \mathrm{C} 5 \mathrm{OB} 00200 \mathrm{~A}$

Tiwari, A. R., and Bhanage, B. M. (2017). Chemoselective cleavage of C(CO)-C bond: molecular iodinecatalyzed synthesis of quinazolines through $\mathrm{sp}^{3} \mathrm{C}-\mathrm{H}$ bond functionalization of aryl methyl ketones. Asian J. Org. Chem. 6, 831-836. doi: $10.1002 /$ ajoc.201700217

Toure, B. B., and Hall, D. G. (2009). Natural product synthesis using multicomponent reaction strategies. Chem. Rev. 109, 4439-4486. doi: $10.1021 / \mathrm{cr} 800296 \mathrm{p}$

Tseng, M.-C., Lai, C.-Y., Chu, Y.-W., and Chu, Y.-H. (2009). Tin triflatemediated total synthesis of circumdatin F, sclerotigenin, asperlicin C, and other quinazolino[3,2-a][1,4]benzodiazepines. Catal. Commun.4, 445-447. doi: $10.1039 / \mathrm{B} 813880 \mathrm{~J}$

Tsou, H.-R., Mamuya, N., Johnson, B. D., Reich, M. F., Gruber, B. C., Ye, F., et al. (2001). 6-Substituted-4-(3-bromophenylamino) quinazolines as putative irreversible inhibitors of the epidermal growth factor receptor (EGFR) and human epidermal growth factor receptor (HER-2) tyrosine kinases with enhanced antitumor activity. J. Med. Chem. 44, 2719-2734. doi: 10.1021/jm0005555

Valderrama, J. A., Pessoa Mahana, H., Sarras, G., and Tapia, R. (1999). Access to quinazolines from 2-nitrobenzaldehyde and arylamines. Chemistry. 51, $2193-$ 2201. doi: 10.3987/COM-99-8606

Valizadeh, H., Dinparast, L., Noorshargh, S., and Heravi, M. M. (2016). Microwave assisted synthesis of hydroxychromenes using imidazole-functionalized silica nanoparticles as a catalyst under solvent-free conditions. C R Chim. 19, 395-402. doi: 10.1016/j.crci.2015.11.010

Valizadeh, H., Heravi, M. M., and Amiri, M. (2010a). Conventional and microwave-assisted facile one-pot synthesis of $\mathrm{N}$-substituted pyrrole-2,3,4,5tetracarboxylates under neat conditions. Synth. Commun. 40, 3699-3706. doi: 10.1080/00397910903531680

Valizadeh, H., Heravi, M. M., and Amiri, M. (2010b). Unexpected synthesis of N-methylbenzo[d]isoxazolium hydroxides under microwave irradiation conditions. Mol. Divers. 14, 575-579. doi: 10.1007/s11030-009-9189-x

van Zyl, E. F. (2001). A survey of reported synthesis of methaqualone and some positional and structural isomers. Forensic Sci. Int. 122, 142-149. doi: 10.1016/S0379-0738(01)00484-4

Vasdev, N., Dorff, P. N., Gibbs, A. R., Nandanan, E., Reid, L. M., O’Neil, J. P., et al. (2005). Synthesis of 6-acrylamido-4-(2-[18F] fluoroanilino) quinazoline: a prospective irreversible EGFR binding probe. J. Lablelled Compd. Rad. 48, 109-115. doi: 10.1002/jlcr.903

Von Niementowski, S. (1895). Synthesen von chinazolinverbindungen. J. Prakt. Chem. 51, 564-572. doi: 10.1002/prac. 18950510150

Wakeling, A. E., Guy, S. P., Woodburn, J. R., Ashton, S. E., Curry, B. J., Barker, A. J., et al. (2002). ZD1839 (Iressa): an orally active inhibitor of epidermal growth factor signaling with potential for cancer therapy. Cancer Res. 62, 5749-5754. Available online at: https://cancerres.aacrjournals.org/content/62/20/5749

Wan, Y., Alterman, M., Larhed, M., and Hallberg, A. (2003). Formamide as a combined ammonia synthon and carbon monoxide source in fast palladiumcatalyzed aminocarbonylations of aryl halides. J. Comb. Chem. 5, 82-84. doi: $10.1021 / \mathrm{cc} 0200843$

Wang, D. Z., Yan, L., and Ma, L. (2016). Facile preparation of 4-substituted quinazoline derivatives. J. Vis. Exp. 108:e53662. doi: 10.3791/53662

Wang, G.-J., Shan, J., Pang, P., Yang, M., Chou, C.-J., and Chen, C.-F. (1996). The vasorelaxing action of rutaecarpine: direct paradoxical effects on intracellular calcium concentration of vascular smooth muscle and endothelial cells. $J$. Pharmacol. Exp. Ther. 276, 1016-1021.

Wang, L., Xia, J., Qin, F., Qian, C., and Sun, J. (2003). Yb(OTf) ${ }_{3}$-catalyzed one-pot synthesis of quinazolin-4(3H)-ones from anthranilic acid, amines and ortho esters (or formic acid) in solvent-free conditions. Synthesis 2003, 1241-1247. doi: 10.1055/s-2003-39397

Wenli, S., Jianmin, Z., Jianan, J., and Xiaolei, C. (2011). One-pot preparation of fluorinated $4(3 \mathrm{H})$-quinazolinones under microwave irradiation and solventfree conditions. Chinese J. Org. Chem. 31, 1272-1276. Available online at: http:// sioc-journal.cn/Jwk_yjhx/EN/Y2011/V31/I08/1272

Wolfe, J. F., Rathman, T. L., Sleevi, M. C., Campbell, J. A., and Greenwood, T. D. (1990). Synthesis and anticonvulsant activity of some new 2-substituted 3-aryl-4(3H)-quinazolinones. J. Med. Chem. 33, 161-166. doi: 10.1021/jm001 63a027

Wu, S.-N., Lo, Y.-K., Chen, H., Li, H.-F., and Chiang, H.-T. (2001). Rutaecarpineinduced block of delayed rectifier $\mathrm{K}+$ current in NG108-15 neuronal cells Neuropharmacology 41, 834-843. doi: 10.1016/S0028-3908(01)00114-9

$\mathrm{Xu}, \mathrm{H}$. , and $\mathrm{Fu}, \mathrm{H}$. (2012). Copper-catalyzed one-pot synthesis of imidazo/benzoimidazoquinazolinones by sequential Ullmann-Type coupling and intramolecular C-H amidation. Chem. Eur. J. 18, 1180-1186. doi: 10.1002/chem.201102794

Xu, L., Li, H., Liao, Z., Lou, K., Xie, H., Li, H., et al. (2015). Divergent synthesis of imidazoles and quinazolines via $\mathrm{Pd}(\mathrm{OAc})_{2}$-catalyzed annulation of N-allylamidines. Org. Lett. 17, 3434-3437. doi: 10.1021/acs.orglett.5b 01435 
$\mathrm{Xu}, \mathrm{W}$., and $\mathrm{Fu}, \mathrm{H}$. (2011). Amino acids as the nitrogen-containing motifs in copper-catalyzed domino synthesis of N-heterocycles. J. Org. Chem. 76, 3846-3852. doi: 10.1021/jo2002227

Xu, W., Jin, Y., Liu, H., Jiang, Y., and Hua, F. (2011). Copper-catalyzed domino synthesis of quinazolinones via Ullmann-type coupling and aerobic oxidative C-H amidation. Org. Lett. 13, 1274-1277. doi: 10.1021/ol1030266

Xuan, J., He, X.-K., and Xiao, W.-J. (2020). Visible light-promoted ring-opening functionalization of three-membered carbo-and heterocycles. Chem. Soc. Rev. 49, 2546-2556. doi: 10.1039/C9CS00523D

Yadav, J. S., and Reddy, B. V. S. (2002). Microwave-assisted rapid synthesis of the cytotoxic alkaloid luotonin A. Tetrahedron Lett. 43, 1905-1907. doi: 10.1016/S0040-4039(02)00135-1

Yin, P., Liu, N., Deng, Y.-X., Chen, Y., Deng, Y., and He, L. (2012). Synthesis of 2,4-diaminoquinazolines and tricyclic quinazolines by cascade reductive cyclization of methyl N-cyano-2-nitrobenzimidates. J. Org. Chem. 77, 2649-2658. doi: 10.1021/jo2023697

Yoon, D. S., Han, Y., Stark, T. M., Haber, J. C., Gregg, B. T., and Stankovich, S. B. (2004). Efficient synthesis of 4-aminoquinazoline and thieno[3,2-d]pyrimidin4-ylamine derivatives by microwave irradiation. Org. Lett. 6, 4775-4778. doi: 10.1021/ol047919y

Zhang, X., Ye, D., Sun, H., Guo, D., Wang, J., Huang, H., et al. (2009). Microwave-assisted synthesis of quinazolinone derivatives by efficient and rapid iron-catalyzed cyclization in water. Green Chem. 11, 1881-1888. doi: $10.1039 / \mathrm{b} 916124 \mathrm{~b}$

Zhou, J., Fu, L., Lv, M., Liu, J., Pei, D., and Ding, K. (2008). Copper(I)iodide catalyzed domino process to quinazolin-4(3H)-ones. Synthesis 2008, 3974-3980. doi: 10.1055/s-0028-1083245

Zhu, K., Hao, J.-H., Zhang, C.-P., Zhang, J., Feng, Y., and Qin, H.-L. (2015). Diversified facile synthesis of benzimidazoles, quinazolin-4(3H)ones and 1,4-benzodiazepine-2,5-diones via palladium-catalyzed transfer hydrogenation/condensation cascade of nitro arenes under microwave irradiation. RSC Adv. 5, 11132-11135. doi: 10.1039/C4RA15765F

Conflict of Interest: The authors declare that the research was conducted in the absence of any commercial or financial relationships that could be construed as a potential conflict of interest.

Copyright (๑) 2020 Mohammadkhani and Heravi. This is an open-access article distributed under the terms of the Creative Commons Attribution License (CC BY). The use, distribution or reproduction in other forums is permitted, provided the original author(s) and the copyright owner(s) are credited and that the original publication in this journal is cited, in accordance with accepted academic practice. No use, distribution or reproduction is permitted which does not comply with these terms. 